\title{
Fuelwood Studies in India Myth and Reality
}

Devendra Pandey

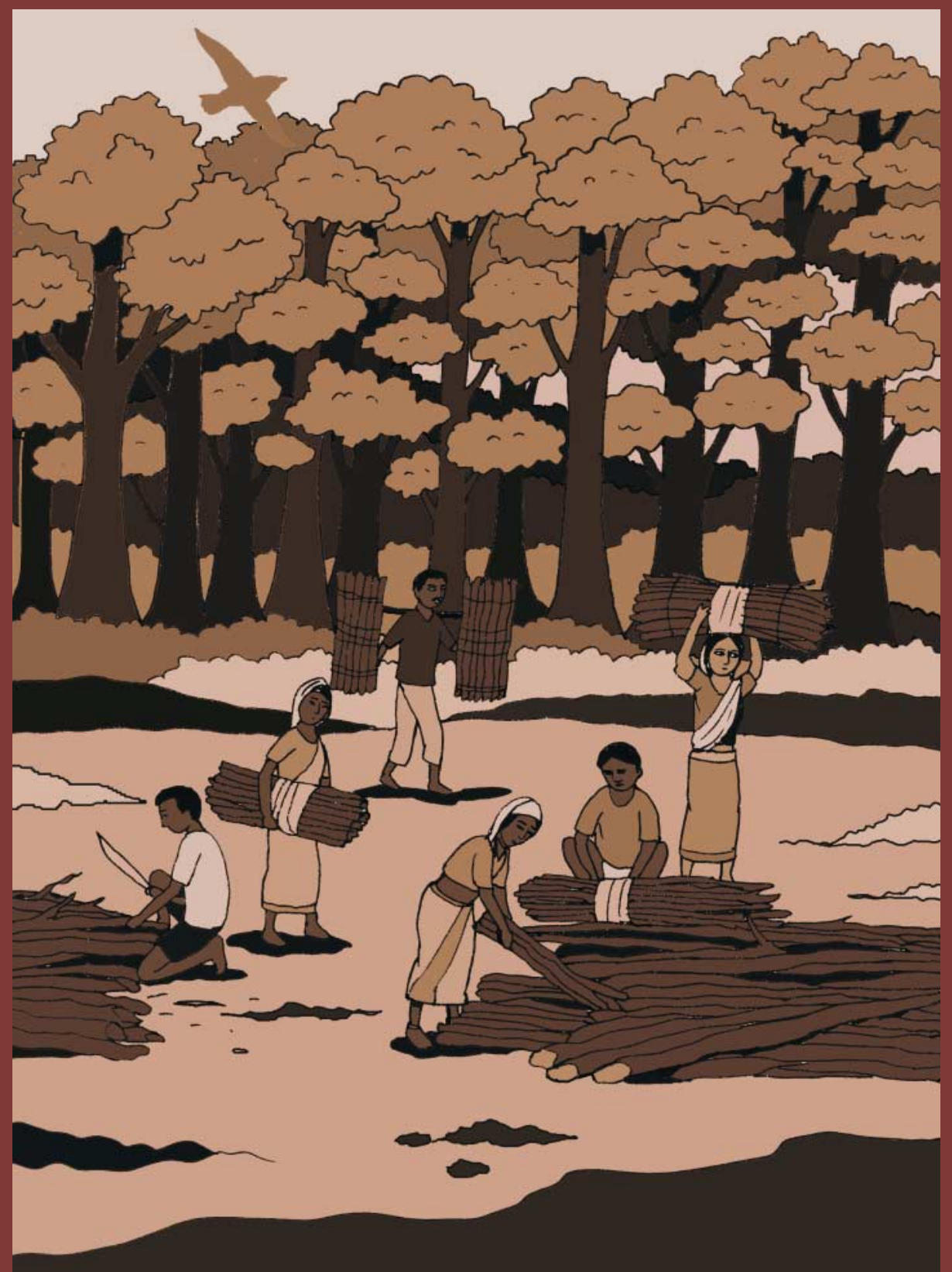




\section{Fuelwood Studies in India Myth and Reality}

Devendra Pandey 
The Center for International Forestry Research (CIFOR) was established in 1993 as part of the Consultative Group on International Agricultural Research (CGIAR) in response to global concerns about the social, environmental and economic consequences of forest loss and degradation. CIFOR research produces knowledge and methods needed to improve the well-being of forest-dependent people and to help tropical countries manage their forests wisely for sustained benefits. This research is done in more than two dozen countries, in partnership with numerous partners. Since it was founded, CIFOR has also played a central role in influencing global and national forestry policies.

() 2002 by Center for International Forestry Research All rights reserved. Published in 2002

\section{ISBN 979-8764-92-7}

Published by

Center for International Forestry Research

Mailing address: P.O. Box 6596 JKPWB, Jakarta 10065, Indonesia

Office address: Jl. CIFOR, Situ Gede, Sindang Barang,

Bogor Barat 16680, Indonesia

Tel.: +62 (251) 622622; Fax: +62 (251) 622100

E-mail: cifor@cgiar.org

Web site: http://www.cifor.cgiar.org 


\section{Table of Contents}

Acronyms vi vi

Definitions vii vili

Acknowledgements viii

Foreword ix

Abstract

1. Introduction 1

$\begin{array}{ll}1.1 \text { Background } & 1\end{array}$

1.2 Objectives of the Study 2

1.3 Plan of the Study 2

2. India's Energy Use Dynamics 5

2.1 Energy Consumption pattern in India $\quad 5$

2.2 Developments in the Commercial Energy Sector 6

2.2.1 Petroleum and Gas 7

$\begin{array}{ll}2.2 .2 \text { Coal and Lignite } & 7\end{array}$

$\begin{array}{lll}2.2 .3 & \text { Electricity } & 7\end{array}$

2.3 Developments in the Non-conventional Energy Sector 8

3. Review of Sampling Designs and Methodologies for

$\begin{array}{ll}\text { Assessing Consumption } & 10\end{array}$

$\begin{array}{ll}3.1 \text { National Studies } & 10\end{array}$

3.2 State Level Studies $\quad 11$

$\begin{array}{ll}3.3 \text { Local Studies } & 12\end{array}$

4. Results of Fuelwood Studies: Review and Analysis 13

4.1 Estimates of the Planning Commission 13

4.2 Assessment of Per Capita Consumption $\quad 14$

4.3 Per Capita Consumption in Relation to Urbanisation 14

4.4 Per Capita Consumption in Relation to Nearness to Forests $\quad 15$

4.5 Per Capita consumption in Relation to Income 16 
4.6 Energy Consumption Pattern in Rural and Urban Areas $\quad 17$

$\begin{array}{ll}4.7 \text { Assessment of Fuelwood Sources and Supply } & 17\end{array}$

5. Trends 20

5.1 New Policies in the Energy Sector 20

$\begin{array}{ll}5.2 \text { Growth of LPG } & 20\end{array}$

$\begin{array}{ll}5.3 \text { Electrification of Villages } & 21\end{array}$

5.4 Growth in Fuelwood Production $\quad 22$

5.5 Energy Transition $\quad 22$

$\begin{array}{ll}5.5 .1 \text { Rural Sector } & 22\end{array}$

$\begin{array}{ll}\text { 5.5.2 Urban Sector } & 23\end{array}$

6. Identification of Fuelwood Hot Spots 24

6.1 Degradation of Forests due to Fuelwood Collection 24

6.2 An Approach to Identifying Hot Spots 25

6.2.1 Identification of Forest Degradation Areas 26

6.2.2 Identification Fuelwood Scarcity Areas 26

$\begin{array}{ll}6.3 \text { Villages in Proximity to Forests } & 27\end{array}$

7. Policy Responses to Fuelwood Issues 28

$\begin{array}{ll}7.1 \text { Social Forestry and Afforestation Programmes } & 28\end{array}$

$\begin{array}{ll}7.2 \text { Fuelwood in Five-year Development Plans } & 29\end{array}$

$\begin{array}{ll}7.3 \text { Joint Forest Management Programmes } & 29\end{array}$

7.4 Technological Initiatives Including the Fuelwood Saving Campaign $\quad 30$

7.5 Integrated Rural Energy Programmes 30

$\begin{array}{ll}\text { 7.6 National Project on Biogas Development } & 31\end{array}$

$\begin{array}{ll}\text { 7.7 National Biomass Resource Assessment Programme } & 31\end{array}$

$\begin{array}{ll}7.8 \text { Allocation of Funds } & 32\end{array}$

8. An Approach to Make Fuelwood Statistics Reliable 33

$\begin{array}{ll}8.1 \text { The Issues } & 33\end{array}$

8.2 Assessing Consumption $\quad 33$

8.3 Assessing Sources and Supply 34

9. Conclusions and Recommendations 36

$\begin{array}{ll}\text { 9.1 Major Findings } & 36\end{array}$

9.1.1 Fuelwood Scenario after Two Decades 36

9.1.2 Energy Consumption Patterns $\quad 36$

9.1.3 Reliability of Fuelwood Consumption and Production Statistics 37

$\begin{array}{ll}\text { 9.1.4 Sources and Supply of Fuelwood } & 37\end{array}$

$\begin{array}{ll}9.2 \text { Recommendations } & 37\end{array}$

9.2.1 Formulation of a Suitable Rural Energy Policy 37

$\begin{array}{ll}\text { 9.2.2 Development of Wastelands } & 38\end{array}$

9.2.3 Promotion of Renewable Energy 38

9.2.4 New Fuelwood Studies $\quad 38$

9.2.5 Agency for Periodic Assessment of Fuelwood
Consumption and Production 
References $\quad 40$

Appendix I. National, State and Local Level Studies 45

I A. National Level Studies 45

I A.1 Energy Consumption in Households and Selected Establishments of India 45

I A.2 Trends in Firewood Consumption in Rural India 49

I A.3 A National Estimate of Fuelwood Consumption 51

I A.4 Energy Used by Indian Households in 1993/94 54

I A.5 Energy Used by Indian Households in 1999/2000 57

I A.6 Consumption and Sources of Fuelwood in India 60

I A.7 Energy Strategies for Rural India 62

I B. State Level Studies 63

I B.1 Wood Balance Study of Andhra Pradesh 63

I B.2 Gujarat Wood Balance Study 1984

I B.3 Wood Balance Study of Haryana 68

I B.4 Wood Balance Study of Rural Himachal Pradesh 70

I B.5 Wood Balance Study of Jammu and Kashmir 72

I B.6 Demand and Supply of Fuelwood in Karnataka 75

I B.7 Wood Balance Study of Kerala 78

I B.8 Wood Balance Study of Orissa 80

I B.9 Fuelwood in Rural Households of Tamilnadu 82

I B.10 Wood Balance Study of West Bengal 84

I C. Local Level Studies 86

I C. 1 Production of Fuelwood in Villages-A Case Study of Two Villages of Haryana 86

I C.2 Fuelwood in Urban Markets $\quad 87$

I C.3 Household Energy Strategy for Urban India 89

I C.4 Fuelwood Collection and Trade in Northwest Bengal 91

I C.5 Energy Consumption in Rural Households of Two Districts of Orissa 93

Appendix II. Coal Replacement Ratios $\quad 94$ 


\title{
Acronyms
}

\author{
DES Department of Economics and Statistics \\ ESMAP Energy Sector Management Assistance Programme (of the World Bank) \\ FSI \\ Forest Survey of India \\ HPU \\ ICFRE \\ IDA \\ IIFM \\ IIMB \\ IWST \\ KFRI \\ LPG \\ MNES \\ MoEF \\ NCAER \\ NSSO \\ OCC \\ Himachal Pradesh University \\ Indian Council of Forestry Research and Education \\ International Development Association (of the World Bank) \\ Indian Institute of Forest Management \\ Indian Institute of Management, Bangalore \\ Institute of Wood Sciences and Technology \\ Kerala Forest Research Institute \\ Liquefied Petroleum Gas \\ Ministry of Non-conventional Energy Sources \\ Ministry of Environment and Forests \\ National Council of Applied Economic Research \\ National Sample Survey Organisation \\ ORG \\ RWEDP \\ TERI \\ TOE \\ Oil Co-ordination Committee \\ Operation Research Group \\ Regional Wood Energy Development Programme \\ Tata Energy Research Institute \\ ton of oil equivalent \\ USAID \\ United States Agency for International Development
}




\section{Definitions}

Household: A group of persons living together and taking food from a common kitchen constitutes a household. It includes persons temporarily staying with the group but excludes temporary visitors.

Biomass: The wood products obtained from portions of trees including branches, twigs, tops and unmerchantable stems, usually for energy production.

Biofuel: The fuel produced from biological sources such as fuelwood, crop residue and dung cake.

Cogeneration: Generation of electricity/energy by an industrial unit using byproducts/waste material, such as bagasse-based cogeneration in a sugar mill.

Fuelwood: Wood in rough form obtained from the trunk and branches of trees to be used for fuel purposes such as cooking, heating or power generation.

Commercial Energy: The form of energy produced and sold on a commercial basis; includes hydrocarbons (kerosene, gas, diesel etc.), coal and electricity.

Non-Commercial Energy: The traditional form of energy locally produced and used for cooking and heating. It generally includes fuelwood, crop residue and dung cake.

Urban Area: It includes all places with municipality, corporation, cantonment or a notified town area, and all other places having a minimum population of 5000 with at least $75 \%$ of the male workforce in non-agriculture pursuits and a density of population of at least 400 per square $\mathrm{km}$. 


\section{Acknowledgements}

The Swedish International Development Cooperation Agency (Sida) provided financial support to the study. The Tata Energy Research Institute (TERI), New Delhi, India assisted through access to numerous studies. The Planning Commission of India, National Sample Survey Organistion (NSSO) and National Council of Applied Economic Research (NCAER) at New Delhi India also provided access to their documentation centre. The support provided by these institutions is gratefully acknowledged. I would thank the Ministry of Environment and Forests, Government of India for sparing me from the regular job to take up this study.

I wish to thank profusely Dr. Reidar Persson, who has been the prime mover and spirit behind this study. I express my gratitude to Mr. Mafa E. Chipeta for providing constant guidance during the course of the study. For constructive comments and review, I thank Dr. K. D. Singh, Dr. Tara Bhattarai, Mr. J.E. M. Arnold, Ms. Gill Shepherd and Dr. N.C. Saxena. Lastly I am thankful to Dr. T. P. Singh for providing logistic support during my visits to TERI.

Devendra Pandey 


\section{Foreword}

Given my long association with forestry planning and policy development in India, I am pleased to see The Center for International Forestry Research associate itself with establishing the latest information on the fuelwood situation in that country.

Fuel is by far the largest use of wood in India, dominating all other uses, as is the case in most developing countries. The estimated annual consumption of fuelwood far exceeds estimates of the sustainable annual output of wood from the country's forests. This has long given rise to serious concerns that harvesting of fuelwood could be depleting the country's forest patrimony. The evolution of India's Social Forestry Programmes in the late 1970s was strongly influenced by these concerns.

Subsequently, arguments have been advanced that in practice much, and possibly most, of the fuelwood used comes from sources outside forests, such as trees on farms and common lands, and so imposes much less of a drain upon the forest resource than had been assumed. However, debate over this issue has been hampered by a lack of reliable information. Direct records of fuelwood production are sparse, and of variable coverage and quality across the country. Very little is known and documented about the productivity of many of the resources from which fuelwood is derived. Information about fuelwood use has to be derived mainly from surveys of related issues, such as energy use, and from studies at state, area or project levels. Differences in methodology, objectives, measures and scale hamper comparison of information emerging from such different sources.

The value of having a better database in this area is evident. More accurate information on the drain on forests due to fuelwood harvesting is necessary in order to identify what environmental problems it could be causing, and to define needs for possible intervention. Having adequate data could be equally important in establishing the impact on the country's continuing potential to supply industrial wood products. As fuelwood is the principal domestic fuel in rural areas, information about patterns of supply, and about shortages, can be critical for monitoring the potential need for forestry support to this key aspect of rural livelihoods. In addition, with the 
selling of fuelwood providing income to large numbers of the poor and very poor, knowledge is needed about trade and markets in fuelwood.

It can be equally important to monitor and understand changes in use and availability. Issues that could need monitoring include: How have rapid changes in the availability of alternative sources of energy in urban markets in India impacted on urban use of fuelwood, and on the fuelwood supply chains feeding those markets? How have reductions in the size and quality of common lands affected the availability of fuelwood to neighbouring rural populations, and how are they adapting to such changes? What has been the impact of the often very large increases in availability of wood supplies from trees on farm as a result of Social Forestry; have these changed fuelwood supply-demand relationships?

In this study Dr Devendra Pandey, a noted authority on forest resources assessment and forest data in India, has identified and brought together fuelwood-related information from a wide range of surveys and studies. Their findings have for the first time been presented and analysed within a common framework, to allow more meaningful comparison between studies at different points in time, and in different parts of the country. Though, as the author stresses, weaknesses and gaps remain in the database, limiting what can emerge at this time, the result is a more comprehensive and informative review of the fuelwood situation in the country than has been available previously. CIFOR hopes that it will prove of value not only to those concerned with fuelwood and forestry in India, but to those in other countries trying to establish stronger databases with which to analyse the importance of fuelwood use and supply in their national situations.

\section{J.E.M. Arnold}

Oxford

November 2002 


\section{Abstract}

This report provides an in-depth review and critical analysis of the fuelwood, wood balance and household energy studies done in India in the last two decades, and of developments in the commercial energy sector. In all, seven national level, ten state level and five local level studies have been reviewed and summarised. Each study reviewed has been systematically presented in a standard format. This included the purpose, agency and period of survey work, the methodology of collecting consumption and production data, estimated per capita as well as total consumption of domestic energy, the contribution of fuelwood in household energy consumption and its sources of supply. At the end of each summary, comments have been offered on the strength and weakness of the study. The summaries of these studies have been then synthesised to identify the trend in the consumption of domestic energy and also the reliability level of fuelwood statistics. The consumption of fuelwood has been analysed in relation to availability of forests/tree resource, urbanisation and income level. The impact of fuelwood collection on depletion of the forest resource has also been examined in specific areas and an approach to identify fuelwood hot spots has been suggested. The report also provides a synoptic view of the various programmes undertaken by the government to meet the fuelwood needs of the country.

The analysis has tried to reveal the myth and reality of the fuelwood studies. It has been found that the fuelwood consumption and production statistics estimated by most of the studies are often not very reliable. Average reliance can be placed on the consumption statistics, because most of the fuelwood studies/household energy surveys have focused on the consumption part but statistics on the supply and source aspect are extremely weak and unreliable. The fuelwood produced from the forests has been either assumed with little justification or underestimated and fuelwood from trees outside forests, etc. has been ignored. The sustainability of fuelwood production and the actual contribution of different sources is still a myth.

The review of the consumption aspect has found that traditional fuel (fuelwood, crop residue and dung cake) still dominates domestic energy use in rural India and accounts for about $90 \%$ of the total. The composition of traditional fuel varies from locality to locality and depends on 
their relative availability. Fuelwood alone accounts for about $60 \%$ of the total fuel in the rural areas. In urban areas, the consumption pattern is changing fast due to increased availability of commercial fuel (LPG, kerosene, and electricity). During 1983-1999, the consumption of traditional fuel declined from $49 \%$ to $24 \%$ and LPG connection to households increased from $10 \%$ to $44 \%$.

To make fuelwood statistics reliable, it has been suggested that key factors influencing consumption of fuelwood such as, urbanisation, nearness to accessible forest/tree resource, income level and climate should be used to stratify the population and repeated physical measurement should be done estimate per capita consumption precisely. For estimating the production of fuelwood new volume growth models of trees relating to their biomass produced during life cycle should be made. And to determine the actual source of supply of fuelwood, investigators have to observe the flow of wood to households and other consumption and distribution centres for a longer period (perhaps for a full year), which would also cover the seasonal variation, instead of depending upon questionnaires. 


\section{Introduction}

\subsection{Background}

Fuelwood has remained the principal component of rural domestic energy in India and in most developing countries. Most of the fuelwood has been reported to be derived from forests with some from trees growing on homesteads, farmlands, and common lands outside forests. Because of the increasing population, the area under agriculture expanded and forests shrunk. In India, the land under cultivation increased from 118 million in 1951 to 142 million ha by 1987 . This expansion also included the diversion of about 4.5 million ha of forests to agriculture. On the other hand, the demand for fuelwood increased in spite of the rapid growth in the commercial energy sector. Fuelwood consumption studies commissioned during the 1970s and 1980s revealed a widening gap between demand and recorded supply from the forests. Fuelwood prices were soaring.

In India, it was recognised that the recorded production of fuelwood was scarcely $10 \%$ of the total requirements in 1970 (Anon. 1976). In addition, a large quantity of fuelwood was collected from the forests by the local people as a matter of right and no records were found anywhere. There was also pilferage from nearby forests to meet a large part of the fuelwood requirement in neighbouring areas and this was treated as unrecorded.

A situation similar to that in India prevailed in many developing countries. The unrecorded removal of fuelwood from forests was considered as an extra drain on the forest resource. The FAO and other international organisations identified fuelwood collection as one of the underlying causes of deforestation in the developing countries. Over-exploitation of fuelwood was responsible for a number of environmental problems. Many plantation projects, popularly known as community/ social forestry, were launched in India and other countries from the late 1970s to bridge the demand and supply gap of fuelwood, small wood and timber etc. External donors supported most of the projects. Many social forestry programmes, however, did not succeed as desired due to improper planning and wrong practices (Pandey 1995). 
Many State Forest Departments initiated state level wood balance studies as an integral part of the Social Forestry Projects during the mid 1980s. The Ministry of Non-conventional Energy Sources and the Planning Commission of the Government of India in the early 1990s also sponsored a few national studies to judge the efficacy of their energy-related programmes. In addition, ESMAP World Bank/RWEDP-FAO also sponsored national and some local level studies. The studies were mostly conducted by autonomous bodies. Based on the studies, two divergent views are in place. Governmental agencies and Forestry Departments still advocate the shortage of fuelwood, which is leading to an excess drain on forests and their degradation. Non-governmental organisations, meanwhile, advocate that much of the fuelwood is now gathered from non-forest lands and fuelwood collection is not a major cause of deforestation except in limited pockets. The FAO, in its outlook study for the Asia Pacific Region, has rejected the 'gap theory' (FAO 1997) formulated in 1970s, which implied that wood fuels originating from forests were consumed on a nonsustainable basis. It has been argued that on the basis of current knowledge, the majority of the fuelwood (over 60\%) originated from non-forest sources and appeared sufficient to fill the gap.

A quick review of the fuelwood studies reveals that most of the studies have focused on the consumption aspect of energy/fuelwood and other biofuels (dung cake and agriculture residue) and not on the supply and source aspect. Knowledge of the tree resource outside forests and its annual productivity is highly inadequate. In many fuelwood consumption studies, only population has been treated as dynamic, while per capita consumption is treated as a static entity.

\subsection{Objectives of the Study}

The main purpose of this study is to make an in-depth review and critical analysis of the fuelwood/ household energy studies done in India in the last two decades to discover the myths of fuelwood studies and prepare a synthesis report of the developments taking place in the household energy sectors (commercial and non-commercial) during this period. The detailed objectives are:

(a) To review the methods followed by different fuelwood/wood balance studies.

(b) To comment on the quality of fuelwood consumption statistics.

(c) To review the process followed to assess sources of fuelwood/biomass supply.

(d) To find trends in domestic energy consumption and determine the responses of the government.

(e) To analyse the extent to which fuelwood collection is responsible for the degradation of forests in India.

\subsection{Plan of the Study}

The first step of the study was to collect fuelwood, wood balance and household energy studies conducted in India during the last two decades at the national, state and district/local levels. Since such studies are often done to meet specific planning requirements, they have remained mostly in unpublished form as grey literature. Collection is possible mainly through personal contacts.

Each study reviewed has been systematically presented in a standard format. This included the purpose, agency and period of survey work, methodology of collecting consumption and production data, estimated per capita as well as total consumption of domestic energy, contribution of fuelwood in household energy consumption and its sources of supply. At the end of each summary, comments have been offered on the strength and weakness of the study. In all, seven national level, 10 state level and five district/local level studies have been reviewed and presented in appendices I.A, I.B and I.C, respectively. The review forms the main basis of the report. 
Lists of the studies reviewed are presented in the Table 1.3.1. to 1.3.3.

Table 1.3.1 National Level Fuelwood/Household Energy Studies

\begin{tabular}{|c|c|c|}
\hline $\begin{array}{l}\text { Name of the } \\
\text { agency/author }\end{array}$ & $\begin{array}{l}\text { Year of study } \\
\text { report }\end{array}$ & Remarks \\
\hline NCAER & 1985 & $\begin{array}{l}\text { Based on primary data from a field survey done } \\
\text { in } 1978-1979 \text { and covers both rural and urban sectors }\end{array}$ \\
\hline NCAER & 1993 & $\begin{array}{l}\text { Based on primary data from a field survey done in } 1992 \\
\text { and covers only rural sector }\end{array}$ \\
\hline FSI/Rai et al. & 1996 & $\begin{array}{l}\text { Based on primary data from field surveys of FSI spread } \\
\text { over 1974-1993 in forested districts; the rest is based } \\
\text { on secondary data }\end{array}$ \\
\hline NSSO & 1997 & Based on primary data from a field survey in 1993-1994 \\
\hline NSSO & 2001 & $\begin{array}{l}\text { Based on primary data from field survey } \\
\text { in July } 1999 \text { to June } 2000\end{array}$ \\
\hline Ravindranath et al. & 1995 & Based on secondary data \\
\hline ESMAP & 2001 & $\begin{array}{l}\text { Based on primary data from a field survey conducted } \\
\text { by ORG in } 1996 \text { and covers only the rural sector }\end{array}$ \\
\hline Planning Commission & 1985 & Based on secondary data \\
\hline
\end{tabular}

Table 1.3.2 State Level Fuelwood/Wood Balance Studies

\begin{tabular}{|c|c|c|c|}
\hline State & $\begin{array}{l}\text { Name of the } \\
\text { agency/author }\end{array}$ & $\begin{array}{l}\text { Year of } \\
\text { study report }\end{array}$ & Remarks \\
\hline Andhra Pradesh & IWST/ICFRE & 2001 & $\begin{array}{l}\text { Based on primary data from a field survey } \\
\text { in } 2000\end{array}$ \\
\hline Gujarat & Forest Dept. & 1985 & $\begin{array}{l}\text { Based on primary data from a field survey } \\
\text { in } 1984\end{array}$ \\
\hline Haryana & NCAER & 1988 & $\begin{array}{l}\text { Based on primary data from a field survey } \\
\text { in } 1985-1986\end{array}$ \\
\hline Himachal & HPU & 1994 & Based on primary data from a field survey \\
\hline Pradesh & $\begin{array}{l}\text { Shimla/ } \\
\text { Singh et al. }\end{array}$ & & of rural areas in $1989-1990$ \\
\hline $\begin{array}{l}\text { Jammu \& } \\
\text { Kashmir }\end{array}$ & DES & 1987 & $\begin{array}{l}\text { Based on primary data from a field survey } \\
\text { in } 1986\end{array}$ \\
\hline Karnataka & IIMB & 1993 & $\begin{array}{l}\text { Based on primary data from a field survey } \\
\text { in } 1986-1987\end{array}$ \\
\hline Kerala & KFRI & 1989 & $\begin{array}{l}\text { Based on primary data from a field survey } \\
\text { in } 1987-1988\end{array}$ \\
\hline Orissa & ORG & 1989 & $\begin{array}{l}\text { Based on primary data from a field survey } \\
\text { in } 1989\end{array}$ \\
\hline Tamilnadu & Statistics Dept & 1985 & $\begin{array}{l}\text { Based on primary data from a field survey } \\
\text { of rural areas in } 1984\end{array}$ \\
\hline West Bengal & Forest Dept & 1987 & $\begin{array}{l}\text { Based on primary data from a field survey } \\
\text { in } 1984-1985\end{array}$ \\
\hline
\end{tabular}


Table 1.3.3 District/local Level Fuelwood/Wood Balance Studies

\begin{tabular}{llcl}
\hline District/locality & $\begin{array}{l}\text { Name of the } \\
\text { agency/author }\end{array}$ & $\begin{array}{c}\text { Year of } \\
\text { study report }\end{array}$ & Remarks \\
\hline Two villages of Haryana & Chaturvedi & 1990 & Field work carried out in 1989 \\
Hyderabad city, AP & Alam et al. & 1984 & Survey conducted in 1981-1982 \\
Hyderabad city, AP & ESMAP & 1999 & Survey conducted in 1994 \\
$\begin{array}{l}\text { Cooch Bihar, } \\
\text { Darjeeling \& Jalpaiguri }\end{array}$ & Bhattachrya et al. & 2000 & Survey conducted in 1998-1999 \\
$\begin{array}{l}\text { districts of West Bengal } \\
\text { Cuttack \& Sambalpur }\end{array}$ & Mahapatra et al. & 1999 & Survey conducted in 1994-1995 \\
districts of Orissa & & & \\
\hline
\end{tabular}

Section 2 of this report offers energy consumption patterns in India over the last 45 years. Since developments in the commercial energy sector have a direct impact on the consumption pattern of traditional/non-commercial energy by households, most of which is fuelwood, a summary of developments along with future prospects of the individual sectors viz. electricity, coal and lignite and petroleum and gas has also been given. Similarly, developments in nonconventional energy sources, e.g. solar, wind and biomass, has also been mentioned. A profile of the income distribution in India has been added to indicate the potential population likely to remain dependent on traditional sources of energy in future.

In Section 3, the methods used by the fuelwood studies under review have been summarised and, based on the methods, the reliability of each study is considered.

Section 4 analyses the results of fuelwood consumption studies. To demonstrate the influence of different factors on per capita consumption, results have been analysed in relation to urbanisation, nearness to forests and income. The change in the energy mix of the domestic sector in rural and urban areas of the country has been discussed to understand the impact of different policies and programmes. .

Section 5 describes the likely trends of energy consumption in the household sector. This is based on the synthesis of the fuelwood studies, the developments taking place in the commercial energy sector, particularly in the petroleum (LPG) and electricity sectors, and the tree plantations outside forest areas.

Section 6 discusses the degradation of forests due to fuelwood collection and also identifies fuelwood'hot spots (fuelwood scarcity as well as forest degradation areas)'. In Section 7, a summary of efforts made by the government to solve the fuelwood problem has been presented. Section 8 describes an approach to make fuelwood statistics reliable.

The last Section of the study brings out the main findings and a set of recommendations. 


\section{India's Energy Use Dynamics}

\subsection{Energy Consumption Pattern in India}

Energy is one of the critical inputs in the economic development of any country as most development activities are associated with a massive requirement of energy. Growth in the commercial energy sector is considered as a positive sign of development. Per capita income is strongly correlated with the per capita consumption of commercial energy in both developing and industrialised countries.

In India, the use of commercial energy increased tenfold during 1953-1997; still, the per capita consumption remains very low. As per British Petroleum statistics (1998), the per capita consumption of energy in India was 0.3 tonnes oil equivalent (toe) in 1997 compared to the world average of 1.5 toe and against 6.7 toe of some of the developed countries. In the commercial energy sector, the major growth has taken place in coal and hydrocarbon areas. The expansion of hydropower, nuclear power and exploration of lignite for power generation has been moderate. Coal continued to be the principal source of primary commercial energy, mainly as indirect energy use through electricity generation. The share of coal, however, has declined from $90 \%$ in 1953 to about $50 \%$ in 1997 because of the increase in the relative share of oil, natural gas and electricity (PC 1999). The import of oil and oil products has increased over the years as the country is not self-sufficient in hydrocarbon resources. More than $65 \%$ of the hydrocarbons consumed during the year 1998/9 was imported. In addition, superior quality coal needed for the steel industry and a limited quantity of electricity is also imported. The share of imports in the total supply of primary commercial energy in the country was about $25 \%$ during $1996 / 7$.

Non-commercial energy, comprising fuelwood, dung cake and crop residue, remained the dominant source in the total primary energy supply until 1980, of which fuelwood was the major component. The percentage of non-commercial energy of total energy in 1953/4 was $71.6 \%$, which declined to $34 \%$ in 1996/7 (PC 1999). The pattern of commercial and non-commercial energy supply in India is given in fig 2.1 . 
Figure 2.1 Energy supply pattern in India over the years (Source: PC 1999)

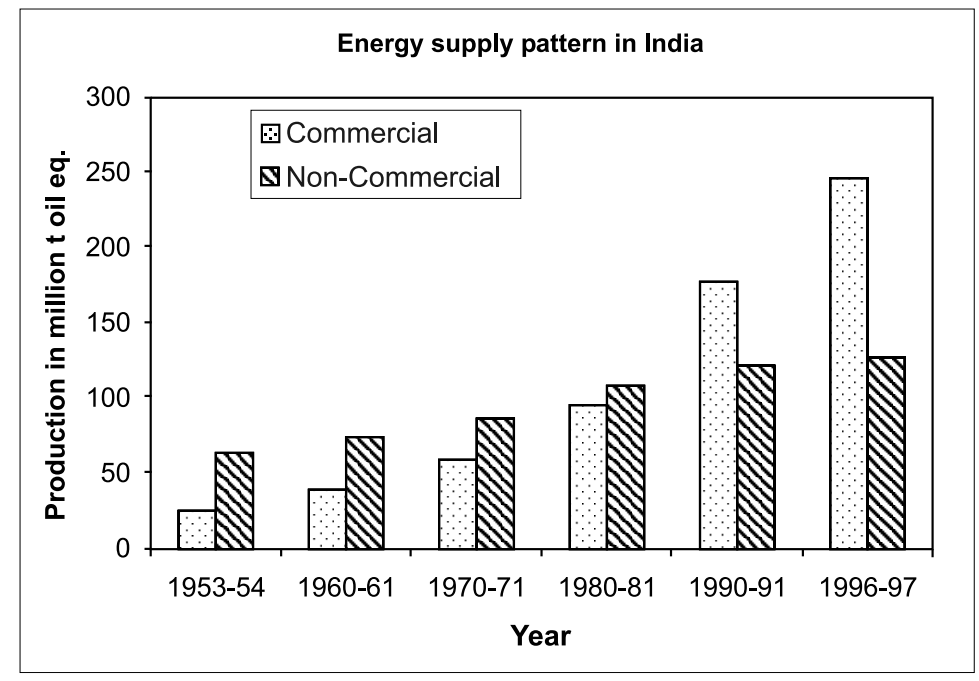

An analysis of the consumption of final commercial energy in various sectors shows that in 1995, industry consumed $42 \%$ of total commercial energy, transport $21 \%$, and households only about $12 \%$. Sectors consuming the rest of the energy were agriculture, commercial establishments, feedstock etc.

Non-commercial energy is largely consumed in the rural areas, with cooking as its dominant end-use activity. The high cost and non-availability of alternate commercial fuel has led to the continued dependence by rural households on traditional fuels. It is to be noted that about $83 \%$ of the population was living in rural India in 1953 but due to growth in urbanisation this percentage has gone down to about $72 \%$ in 2001. In terms of real numbers, the rural population of India has increased from about 300 million in 1953 to 720 million in 2001 due to population growth, thereby increasing the demand for non-commercial energy.

\subsection{Developments in the Commercial Energy Sector}

Developments in the commercial energy sector have a direct impact on the consumption pattern of traditional/non-commercial energy. Developments in the petroleum sector facilitate the availability of LPG and kerosene, the two most important forms of energy preferred as substitutes for fuelwood in households for cooking. In India, electrical energy in the household sector is mainly used for lighting, partly for heating during winter and for cooking only in affluent homes, the number of which is quite small. Development in this sector helps to substitute kerosene, which has been the main source for lighting unelectrified Indian households. Some kerosene is also utilised for cooking and heating. The development in the coal sector has, however, little impact on the use of household energy, because it is not a preferred energy source for households, as is the case for LPG and kerosene. Coal is mainly used for the generation of electricity and meets the requirements of metallurgical, cement, brickmaking and other industries.

To bring qualitative and quantitative improvement in the energy sector in India, an Industrial Policy Resolution was announced in the year 1991. The Policy is to promote private participation in energy sector programmes and is guided by the need for additional investment and competitiveness. The ninth five-year development plan of the country has fixed an annual growth rate of $6.8 \%$ in commercial energy for the period 1997-2002 and to bring down the use of noncommercial energy to $25 \%$ from $34 \%$ (PC 1999). Sector-wise developments are briefly presented in the following paragraphs. 


\subsubsection{Petroleum and Gas}

The petroleum and gas sector has played a crucial role in meeting the energy needs of the country. The contribution became significant after a quantum jump in production since the early 1980s. The annual production of crude oil and natural gas reached 33 million metric tonnes and 18 billion cubic metres respectively in 1990 from 10.5 million $t$ and 2.36 billion in 1980 . The production of crude oil has been stable since then but production of natural gas steadily increased to 27.4 billion cubic metres by $1998 / 9$. Though two-thirds of the potential source of oil and gas have not been explored, the balance of recoverable reserves of crude oil and gas stand at 715 million $\mathrm{t}$ and 675 billion cubic metres as per a 1999 estimate.

The demand for oil and gas has been consistently rising due to increasing population and a consumptive life style, particularly the use of natural gas, due to its clean and environmentfriendly nature. Since domestic production has not kept pace with demand, self-reliance dropped from $56 \%$ in 1990 to $34 \%$ in 1998. Imports of crude oil alone in 1998 reached 39.8 million $t$. In the liberalisation programme, the New Exploration Licensing Policy has thrown open the participation of the private sector, both Indians and foreigners. The import of Liquefied Natural Gas has been put under 'Open General License' and private companies are free to import and market gas directly. The government provides some incentive in the form of a subsidy and has rationalised customs duty on imports to encourage investors. In view of the availability of petroleum reserves in the country and the possibility of imports, the hydrocarbon vision for 2025 estimates the share of hydrocarbons in the future energy supply up to the year 2025 to be $45 \%$, against the existing share of $42 \%$.

\subsubsection{Coal and Lignite}

Coal has remained the main source of commercial energy in India, not only for direct use in industry, but also for indirect use for power generation. Lignite joined later and along with coal, constitutes the major fuel for the generation of electricity. Almost $70 \%$ of India's electricity is produced from coal and lignite. The total production of coal increased to about 300 million $t$ in $1999 / 2000$ from about 100 million $t$ in 1975. The production of lignite in 1999/2000 was 22 million $\mathrm{t}$. The proven reserves for coal and lignite in the country are about 82.4 billion $\mathrm{t}$ and 32.3 billion $t$ respectively as per the January 2000 estimate (TERI 2001). The demand for coal has been increasing at an average rate of $7 \%$ and the total requirement by $2011 / 2$ has been estimated to be 776 million $\mathrm{t}$, about $85 \%$ of which would be met from domestic sources and the rest by imports. Domestic production has to be more than doubled. To achieve this, the private sector is being allowed into commercial coal mining, coal prices have been deregulated and coalproducing companies are given full autonomy. Much of the coal in India is produced through open cast mining but the calorific value of the coal is low, with a high ash content (34\%). Due to the high ash content of the coal, the dependency on imported coal for the steel industry is steadily increasing. The use of coal for household energy is popular in limited areas where coal is abundant, like the states of Bihar, Orissa, West Bengal, and available cheaply.

\subsubsection{Electricity}

Electricity is the lifeline of the major economic activities of the modern age and is the commercial form of energy most in demand. The generation of electricity in the last three decades has increased from 61 billion kilo watt hour (kWh) in 1970/1 to 464 billion kWh in 1997 of which $72 \%$ was thermal, $24 \%$ was hydro electrical, $3 \%$ nuclear and about $1 \%$ wind. The compound growth rate during 1992-1997 was $6.6 \%$. The growth rate targeted for the subsequent plan period (19972002 ) is $9 \%$, to bring the total power generation by the terminal year of the plan to 662 billion kWh. The number of villages electrified has increased from 272000 in 1981 to 505000 in 1999 , thus electrifying about $87 \%$ of villages in the country. The number of energised pump sets used for irrigation in rural areas increased from 4.4 million in 1980 to 12.2 million in 1999. Transmission 
and distribution losses in the power systems throughout the country have, however, remained quite high (22\%) mainly due to theft and pilferage. Some of the pilfered electricity is used for cooking food in rural and urban areas.

Despite significant development in this sector, the demand for electricity continues to outstrip the supply. A policy to encourage private sector participation was initiated in 1991 to mobilise resources for power generation, transmission and distribution. The policy facilitates the raising of capital from domestic and foreign markets to set up power generation capacities or to operate as licensee (distribution) companies, which was hitherto a monopoly of the public sector undertakings. The major consumer categories for electricity are domestic, agricultural, commercial, industrial and railway traction. The tariffs in these categories, however, vary greatly. For domestic and agricultural consumers, the tariff is subsidised and is less than the average cost of production, while in other sectors it is more than the cost of production. The subsidy provided to the agricultural sector between 1992 and 1997 was 79\% (PC 2000).

\subsection{Developments in the Non-conventional Energy Sector}

The energy derived from sources other than the well-known commercial sources (electricity, coal and hydrocarbon) using mainly renewable sources fall in this category. Recourse to renewable sources of energy has become essential with the growing concerns about climate change and the dwindling of fossil fuel reserves. Though experimental use of non-fossil fuel energy sources has been in vogue in India for many decades, the large-scale initiative to develop and use this resource is a relatively recent. Since the creation in 1982 of a Department of Non-conventional Energy Sources and its subsequent upgrading as an independent ministry in the Government of India, the focus has been on promotion and use of renewable sources of energy. The programmes include harnessing solar, wind and bioenergy sources through different devices and systems.

The country's abundant sunshine is being tapped for cooking, water heating, drying of farm produce, water pumping, home and street lighting, and decentralised power generation for meeting requirements in villages, schools, hospitals etc. The government provides financial assistance to offset the initial high cost of these systems. For a certain category of government buildings, it has been made mandatory to provide a solar heating system. The total installed capacity of collector areas for solar water heating systems was about 0.5 million squire meters by the end of 1999 . Solar cooking systems are being repopularised by extending repair and application facilities even in the rural areas of the country. Solar photovoltaic systems are being promoted to supply power in a decentralised way in inaccessible areas. A significant saving of fuelwood used for cooking and heating has been noticed due to the promotion of the solar cooker and heater (MNES 2000).

In the wind power sector, the potential has been estimated to the tune of $45000 \mathrm{MW}$ in the country, but the installed capacity till the year 1999 was only $1080 \mathrm{MW}$. Windmill installations are mainly in the states of Tamilnadu (758 MW), Gujarat (167 MW), Andhra Pradesh (67 MW), Maharastra (33 MW) and Karnataka (27 MW). The largest installation of $400 \mathrm{MW}$ is near Kanyakumari in Tamilnadu (MNES 2000). The Ministry of Non-conventional Energy Sources (MNES) is persuading private entrepreneurs to set up more commercial wind power projects in windy areas. A package of incentives, which includes tax concessions, soft loans, liberalised foreign investment procedures, etc. is provided to promote wind power farms.

The promotion of energy using biomass available in form of natural waste such as agricultural residue, sugarcane bagasse, banana stems, organic effluents, cattle dung, night soil, fuelwood and twigs holds considerable promise. A National Programme on Biomass Power/Cogeneration was launched in 1994/5 to optimise the use of a variety of forestry-based and agro-based residues for power generation by the adoption of state-of-the-art conversion technologies. Though no reliable data is available about the surplus biomass resources in the country, the power potential 
has been estimated at around $19500 \mathrm{MW}$. The installed capacity until 1999 was $222 \mathrm{MW}$, of which $184 \mathrm{MW}$ is through cogeneration. Under the biomass gasifier programme, solid waste is first converted into producer gas through a thermo-chemical process and then used as thermal, mechanical or electrical energy. About 1700 gasifiers have been established in the country since the inception of the programme in the mid 1980s with a total capacity of about 34 MW (MNES 2000).

The focus of the wind power and biomass power programmes has been on decentralised power generation to provide electricity to industrial units and villages, and they have little impact on energy consumption in households for cooking and heating. In fact these programmes are supplementing the commercial energy sector. The other programmes of MNES which have a direct impact on saving household energy for cooking and heating have been described in Section 7.4 to 7.7 .

\section{Box 2.1 Profile of Income Distribution in India}

The Indian economy in the last one and half decades has undergone profound change. The Gross Domestic Product (GDP), which was growing at an average rate of $3.5 \%$ until 1980 , grew to over $6 \%$ after 1990, as economic liberalisation took root. This has led to a simultaneous fivefold increase in per capita income. Income distribution is, however, uneven. During 1993/4 about $36 \%$ of the population was living below the poverty line*, unable to meet the basic needs of life. In rural and urban areas this percentage was $37 \%$ and $32 \%$ respectively. Though the poverty ratio has declined from $55 \%$ in 1973 due to economic development, the absolute number of people below the poverty line has remained more or less unchanged at 320 million due to population growth.

Based on surveys, the National Council of Applied Economic Research, New Delhi estimated in $1993 / 4$ that $53.6 \%$ of households in the country were in the low income group (INR $22550=$ US\$750 per annum), 28\% in the lower middle income group (INR 22 550-45 $000=$ US\$750-1500 per annum) and remaining $18.4 \%$ in middle to higher income groups (INR $30=$ US\$1, the rate prevalent at that time).

India's economy is agriculture-based with more than $70 \%$ of the people living in rural areas. The economic activity of the rural people is greatly governed by the distribution of land. Of the country's total geographic area of 329 million ha, only 143 million ha is cultivated. An additional 23 million ha of cultivable land is available in different forms of agricultural fallow, thus giving a total operational land area of 166 million ha. The distribution of operational holdings per family (on average one family = 5.5 persons) is however, uneven. About 59\% of families in 1990 had only marginal land holdings (less than $1 \mathrm{ha}$ ) with an average land holding of 0.39 ha. The percentage of small land (between 1 to $2 \mathrm{ha}$ ) holders was $19 \%$, with an average holding of $1.43 \mathrm{ha}$. The total operational holding by the marginal and small land class families was $32.4 \%$, whereas the $22 \%$ of holders with land holdings of more than 2 ha had the remaining $67.6 \%$ of the land (MoA 2000).

\footnotetext{
* Poverty line: The expenditure required for a daily calorie intake of 2400 per person in rural areas and 2100 in urban areas. This expenditure was officially estimated at INR 228.9 per capita per month in rural areas and INR 264.1 in urban areas at $1993 / 4$ prices.
} 


\section{Review of Sampling Designs and Methodologies for Assessing Consumption}

The accuracy and validity of fuelwood statistics depends on the way the data have been collected and processed. Though there are several considerations to be made while collecting the data, a few important ones are: the criteria adopted for stratification which influence fuelwood consumption (nearness to accessible forest resource, urbanisation, income level and climate), coverage of a cross section of the population, the sampling design followed, rationality of assumptions, method of data collection (direct measurement or by questionnaire), duration of data collection, skill of measurement, etc. Availability of funds becomes the major factor influencing the design and methodology.

\subsection{National Studies}

Of the seven national fuelwood consumption studies reviewed, only four (NCAER 1985, 1993 and NSSO 1997, 2001) have designed the survey for a national level estimate and collected primary data. These studies have covered the entire country and collected data in a time frame of about one year. After dividing the population into rural and urban sectors, a multistage sampling was followed. NCAER used districts or groups of districts as a first stage unit whereas NSSO used agroeconomic regions. Villages in the rural sector, and urban survey blocks in the case of the urban sector were treated as second stage units. Households were used as the third and final stage unit in all four studies. While selecting the households for the final survey, the studies have taken care to appropriately represent different income groups and population classes in the case of urban centres. The total number of households selected by NCAER (1985 and 1993) was 12650 and 16167 households respectively, and by NSSO in 1997 and 2001, 115354 and 120309 respectively. The coverage of the sample by NSSO to catch different variables is quite comprehensive; the results could therefore be the most reliable. But this organisation assesses fuel expenditure and not the quantity used. The assessment of expenditure on fuelwood consumption is a part of the NSSO regular consumer expenditure surveys done through a nation 
wide network. The NCAER generally conducts studies when sponsored by some agencies. The study in 1978/9 (NCAER 1985) was sponsored by Indian Oil Corporation to study the consumption of kerosene and in 1992/3 by the Ministry of Non-conventional Energy Sources to evaluate the national programme on improved chullah (cooking stove). The selection of samples by NCAER (1985) was objective; the first national level quantitative information on fuelwood consumption, can be considered reliable. In 1992/3 study, the selection of samples was purposive and limited to rural sector and therefore had bias and less widely applicable.

All the above studies have, however, missed the influence of the forest resource (abundance vis-à-vis scarcity) on the consumption of fuelwood and therefore no such consideration has been made in designing the survey or data collection.

Two national studies (Rai and Chakrabarti 1996 and Ravindranath and Hall 1995) are based on limited data and on a number of assumptions that may not be true. FSI used its per capita consumption data of 67 surveys, mainly confined to forested areas of the country conducted over a period of 24 years (1970-1994), and for the rest of the areas NCAER (1985) data was used. The per capita consumption was multiplied by the current population of the states having three strata (forested rural, non-forested rural and urban areas) to derive the total consumption of fuelwood in the households. Consumption by industries and other establishments was assumed. Ravindranath and Hall (1995) meanwhile, has assumed one of the lowest national level consumption figures estimated by others. The reliability level of these studies for national estimation is therefore poor.

The seventh national study (ESMAP 2001) covers only the rural areas of the country. Purposive sampling was followed to select six Indian states representing different climatic and socioeconomic conditions and 18 districts from these states based on diversity. The selection of 180 villages and 5048 households was done by random sampling. Stratification based on presence and absence of forest resource in villages has not been done. The reliability level of this study can be treated as average.

\subsection{State Level Studies}

Of the 10 wood balance studies conducted at state level, six states (Gujarat, Haryana, Jammu and Kashmir, Karnataka, Orissa and West Bengal) have followed a sampling design similar to NCAER (1985), with some modification. Only the modified part is mentioned in the following paragraphs.

In Gujarat, rural areas were divided into villages with forests and those without forests, and urban areas into two broad classes (population of more than 0.1 million and less than 0.1 million). A total of 2000 households were surveyed. The reliability level of the fuel consumption study is rated high.

In Haryana, although rural areas were stratified according to the same criteria as Gujarat, a separate analysis for forested and non-forested villages was not done. For the selection of samples from urban areas, the methodology adopted by NSSO was followed with slight modification, where urban centres with a population of less than 50000 were further classified. A total of 1000 households were surveyed. The reliability level of the study is rated average.

The distance of a village from the forest was taken as a criterion for the classification and selection of sample villages in Jammu and Kashmir. Urban centres were not classified on the basis of population. A total of 4936 households were selected for the survey. The reliability level of the study is rated average.

In Karnataka, rural households were selected by classifying rural areas according to extent of forests and rainfall but fuelwood consumption was not separately analysed to understand the quantitative impact of these two factors. Urban centres were classified according to proximity of forests and population. In total, 3750 households were selected. The reliability level of this study is rated average. 
In Orissa, the abundance and scarcity of forest cover were taken as criteria to select sample villages so that villages of both categories are properly represented. Sample households were selected to represent land-holding classes. In all, 1080 households were selected. The reliability level of this study is rated average.

In West Bengal, the economic classification of the households was based on quality of houses, and in all, 18750 households were selected. The reliability level of consumption aspect is rated high but of the supply aspect it is poor.

The Tamilnadu fuelwood survey followed the NSSO design but it was limited to rural areas only. Ten households were selected from each sample village, representing different livelihood classes (self-employed in non-agriculture, rural labour and others). There was a total of 1000 households in the final survey. The reliability level of per capita consumption is high.

In Andhra Pradesh, blocks from the state as the first stage unit and villages from blocks as the second stage unit were selected randomly. Selected households from the villages represented different land holding classes. The reliability level of the study is poor.

In Himachal Pradesh, the survey was done only for the rural areas and households were classified according to the land holdings. In total, 560 households from 40 sample village clusters were selected. The data on consumption was collected continuously for the whole year following the 'cost accounting method'. The reliability level for per capita consumption of this study is rated high.

The Kerala study used per capita data of a study recently concluded by some other organisation for the rural sector, and for the urban sector, a fresh study of 750 households was conducted. The reliability level of fuelwood consumption is average.

Most of the studies have adopted a questionnaire approach to estimate consumption, and actual measurements have been taken in limited cases to verify the replies. NCAER (1985), however, followed a normative approach using consumption of food-grains as a variable to estimate the quantity of fuelwood used for cooking. The NSSO, on the other hand, converts different forms of fuel used in households into money based on local prices.

\subsection{Local Studies}

The local studies, which are either confined to rural or to urban areas, have divided the population on an income or land holding basis.

The two studies conducted at an interval of 13 years in the city of Hyderabad for studying consumption patterns in urban areas, have used socio-economic variables (literacy, income, caste and demographic features) for stratifying the city. The totals of households selected were 1809 and 2800 , giving a high intensity $(0.5 \%)$ of sampling. In studying energy consumption in rural households in two districts of Orissa, households of the selected villages were classified according to land holdings and in all, 428 households were selected. The reliability level of these three studies (two urban plus one rural) is treated as very high. 


\section{Results of Fuelwood Studies: Review and Analysis}

This chapter presents a systematic review and critical analysis of the results of the fuelwood and wood balance studies done in India, mainly in the last two decades. Some highlights of the earlier studies have also been given. The review, however, should not be treated as complete. The review has focused broadly on the following aspects:

- Results of per capita as well as total consumption in rural and urban sectors

- Fuelwood consumption vis-à-vis availability of forest resources

- Energy consumption patterns in rural and urban areas to reflect share of different energy forms: commercial (LPG, kerosene, coal and electricity) and non-commercial (fuelwood, dung cake and agricultural residue)

- Assessment of fuelwood source and supply

- Contribution of different sources (forests, private farmlands, common wastelands, homesteads etc.) in meeting fuelwood needs

In India, though fuelwood has remained a very important source of energy for the household sector, no institution has been exclusively dedicated to undertake regular study at the national or regional level. One of the basic reasons is, historically, that fuelwood has been gathered free of cost; as a result, consumption and production aspects have not been given adequate attention. Studies done from time to time have been mostly conducted by institutions dealing with socioeconomic issues. Two institutions, namely, the National Council of Applied Economic Research (NCAER), an autonomous body, and the National Sample Survey Organisation (NSSO), a government organisation, have made pioneer efforts to collect primary data on fuel consumption at the national level.

\subsection{Estimates of the Planning Commission}

The Planning Commission of the Government of India has tried to estimate the domestic energy requirements of the country from time to time by constituting committees and working groups. 
The committees included the Energy Survey of India Committee (1965), the Fuel Policy Committee (1974), the Working Group on Energy Policy (1979), the Advisory Board on Energy (1985) etc. A common feature of all the estimates was that they were based on secondary data and per capita consumption. The per capita consumption of domestic energy estimated by the NCAER during the 1953/4 Urban Survey (Calcutta, Bombay and Delhi) and the 1962/3 Rural Survey was slightly modified by the Planning Commission and the same per capita consumption was used in the first three estimates. The per capita consumption of non-commercial energy at the national level was $335 \mathrm{~kg}$ coal replacement in which fuelwood, dung cake and agricultural residue were in the ratio of $65: 15: 20$.

\subsection{Assessment of Per Capita Consumption}

Assessment of the per capita consumption is most vital in fuelwood studies, as it is the sole basis for estimating total fuelwood consumption. Before looking into the results of various studies, it is important to bear a few facts in mind.

A major segment of the rural population gathers fuelwood and other biofuels free of cost and therefore does not maintain an accurate account of consumption. And like many other economic surveys, a precise estimate of the per capita consumption of fuelwood is not possible as it depends to a great extent on the response of the consumer and the perception of the investigator.

The studies quote per capita fuelwood consumption in different units, viz. in cubic metres $\left(\mathrm{m}^{3}\right)$, in tonnes or kilograms, in tonnes or kilograms coal replacement, in tonnes or kilograms oil replacement and in joules or gigajoules. The wood balance studies have often used cubic metre or tonne to measure fuelwood because it is easy to link with other end uses of wood and the volume of the forest resource. Since the density of wood and its calorific value varies according to the tree species and the moisture content, the conversion factors of fuelwood from one unit to another are generally approximate. A similar situation arises with dung cake and agricultural residues. The energy used in the household sector is a mixture of different forms of energy; conversion to one standard unit is essential to make them comparable but at the same time there is a risk of using the wrong conversion factor. Many studies have not quoted the conversion factors used. NSSO (1997) has, however, recorded the consumption of fuel in terms of money. The investigators first ascertain the quantity of fuel consumed and convert it into money using local rates.

Per capita consumption of fuelwood is a dynamic entity and varies in time and space. The factors strongly influencing this variable are income level of the household, availability of a clean and convenient form of commercial energy (LPG, kerosene and electricity), use of fuel efficient cooking/heating equipment, availability of fuelwood from the forest or other wooded resources, relative price of the fuelwood vis-à-vis other energy forms, interfuel substitution and climate.

\subsection{Per Capita Consumption in Relation to Urbanisation}

All the studies in India have reported per capita consumption of the rural and urban sectors separately because of the marked difference in income levels, availability of commercial energy, lifestyle, etc. The per capita fuelwood consumption of urban areas is expected to be lower than in the rural sector because of the use of more efficient fuel in urban areas. The per capita consumption figures obtained from different state level fuelwood/wood balance studies are presented in Table 4.1, along with the national study done by the NCAER (1985) for comparison. In the 1993 study, NCAER did not analyse the fuelwood consumption at state level as it was not part of the terms of reference. Though the national study by NSSO (2001) is the most recent, an analysis has not been made of per capita consumption, thus a comparison cannot be made. 
Table. 4.1 Per capita consumption of fuelwood in kg by NCAER and other wood balance studies

\begin{tabular}{|c|c|c|c|c|c|}
\hline \multirow{2}{*}{$\begin{array}{l}\text { States } \\
(1978 / 9)\end{array}$} & \multicolumn{2}{|c|}{ Rural } & \multicolumn{2}{|r|}{ Urban } & \multirow{2}{*}{$\begin{array}{r}\text { Remarks } \\
\text { Year of } \\
\text { state level } \\
\text { study }\end{array}$} \\
\hline & $\begin{array}{r}\text { NCAER } \\
\text { wood } \\
\text { balance }\end{array}$ & $\begin{array}{r}\text { State level } \\
(1978 / 9) \\
\text { studies }\end{array}$ & $\begin{array}{r}\text { NCAER } \\
\text { wood } \\
\text { balance }\end{array}$ & $\begin{array}{r}\text { State level } \\
\text { studies }\end{array}$ & \\
\hline Andhra Pradesh & 201 & 180 & 115 & 33 & 2000 \\
\hline Gujarat & 147 & $207 / 417^{\#}$ & 79 & 104 & 1984 \\
\hline Haryana & 51 & - & 39 & - & $1985 / 6$ \\
\hline Himachal Pradesh & 478 & 523 & 278 & - & 1990 \\
\hline Jammu \& Kashmir & 237 & 496 & 167 & 180 & 1986 \\
\hline Karnataka & 218 & 551 & 171 & 140 & 1987 \\
\hline Kerala & 149 & 178 & 220 & 151 & $1987 / 8$ \\
\hline Orissa & 167 & 523 & 253 & 285 & 1989 \\
\hline Tamilnadu & 172 & 271 & 166 & - & 1984 \\
\hline West Bengal & 91 & 368 & 13 & 72 & $1984 / 5$ \\
\hline
\end{tabular}

\# The lower figure pertains to non-forested villages and the higher to forested ones. (Source: Appendix 1B of this report)

It can be seen that the per capita consumption estimated by NCAER in 1978/9 does not match the estimates of the wood balance studies of the states, done at a later date. In most cases, the state level studies have estimated higher fuelwood consumption than NCAER. Since the use of commercial energy has been continuously increasing in India, it was expected that the studies conducted at a later date should show a downward trend in fuelwood use, at least in the urban sector. The state of Jammu and Kashmir has a temperate climate similar to Himachal Pradesh but NCAER has grossly underestimated the per capita consumption of the rural areas. The per capita consumption in the rural sector of Himachal Pradesh obtained by the state wood balance study, however, matches well with NCAER results. On the other hand, the Karnataka wood balance study (Ranganathan et al. 1993) seems to have overestimated the per capita consumption of the rural sector, as the state has neither a cold climate nor a rich forest resource. Similarly, the per capita consumption in the rural sector of Orissa obtained from the wood balance study is also very high.

\subsection{Per Capita Consumption in Relation to Nearness to Forests}

It is believed that the availability of fuelwood significantly influences its consumption. The population centres in proximity to the forest resource have higher per capita consumption than those farther away, as an adequate quantity of preferred fuel (wood) is available and mixing/ substitution with inferior fuel (crop residue, dung cake) is not required. The Gujarat study found that the villages with a forest resource have almost twice the per capita consumption of fuelwood than those without forests (Pinto et al. 1985). The rural areas having no forests compensated fuel needs by increasing the share of agricultural residues, dung cake and kerosene. Similarly, the Jammu and Kashmir wood balance study found decreasing consumption of fuelwood with increasing distance of forests from the village. The pattern is given in Figure 4.1.

The study found that beyond $8 \mathrm{~km}$, consumption is almost constant. As the distance from the forest increased, fuelwood was substituted by dung cake and kerosene oil. The per capita consumption of dung cake was $43 \mathrm{~kg}$ in the villages within forest areas and $102 \mathrm{~kg}$ in villages beyond $8 \mathrm{~km}$ from the forests. Similarly, the consumption of kerosene oil increased from 1 litre to 11.5 ( (Anon 1987a). The study also found a strong correlation $(r=0.91)$ between the forest area of the district and per capita consumption of fuelwood. The fuelwood consumption studies done by the Forest Survey of India in forested areas of the country also give high consumption 
Figure 4.1 Per capita consumption of fuelwood in relation to distance from forests (Source: Anon 1987a)

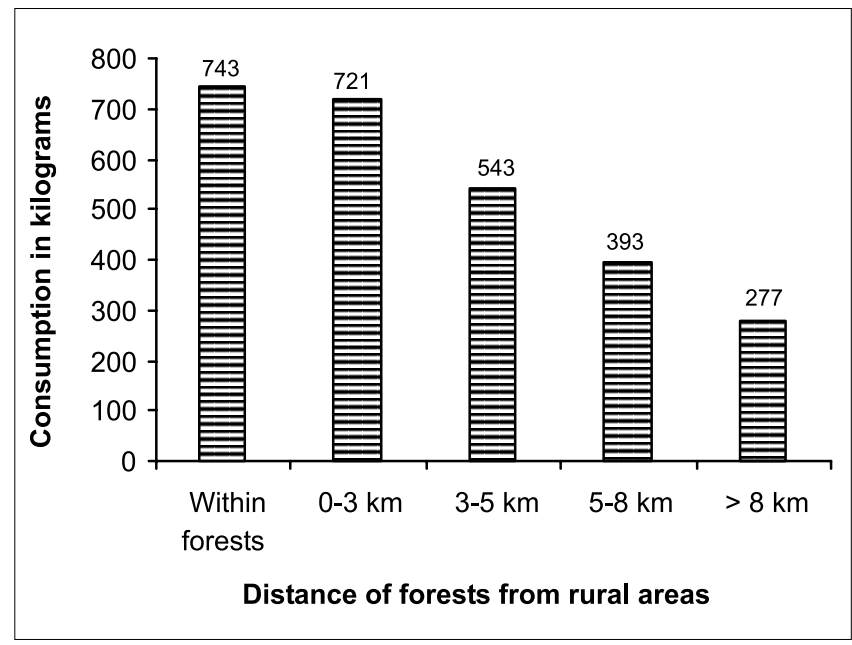

rates, especially in the forest-rich states of Arunachal Pradesh, Madhya Pradesh, Manipur, Meghalaya, Mizoram, Nagaland, Sikkim and Tripura. The per capita fuelwood consumption ranged between $423 \mathrm{~kg}$ to $1320 \mathrm{~kg}$ (Rai and Chakrabarti 1996).

\subsection{Per Capita Consumption in Relation to Income}

The income of households influences fuelwood consumption in two ways. With the rise of income levels, supplementary food items like vegetables, milk, meat, etc. are added to food-grains. The per capita consumption of energy in households goes up and more fuelwood is required to cook the additional food. Secondly, the price of the fuel is less of a constraint. Households prefer to use a clean and convenient form of energy, i.e. LPG, provided it is available. Fuelwood consumption in such cases goes down, even if energy consumption increases. Due to the use of energy-efficient ovens, the total consumption of energy may not increase. Dunkerley et al. (1990) have observed that households tend to use the same amount of energy for cooking regardless of their income, giving an example of two Indian cities.

Almost all fuelwood studies have considered income as an important factor influencing per capita consumption and tried to include it in the sample, but many of them have not analysed it separately to ascertain its influence. NCAER (1985) found that household energy consumption was positively correlated with income. The per capita energy consumption for households with an annual income of below INR 3000 was $192 \mathrm{~kg}$ coal replacement (cr), whereas for those with an income above INR 18000 it was $284 \mathrm{kgcr}$. The rise in rural areas was more modest compared to urban areas. The NSSO (1997) has observed that households tend to switch over to LPG with the rise of monthly per capita expenditure.

In Jammu and Kashmir, fuelwood consumption was found to be a function of landholding size. Marginal farmers with land holdings of up to 0.5 ha consumed $350 \mathrm{~kg}$ per capita whereas those with 2-4 ha holdings consumed $531 \mathrm{~kg}$. Similarly, in Himachal Pradesh, per capita consumption by the landless class was about $292 \mathrm{~kg}$ whereas farmers with large holdings (more than $4 \mathrm{ha}$ ) burnt about $569 \mathrm{~kg}$ of fuelwood per annum. In Karnataka, on the other hand, it has been found that per capita fuelwood consumption decreased with an increase of annual income up to INR 20 000 and then increased again. The decrease was mainly due to the substitution of fuelwood with other fuels like kerosene, LPG, etc. 


\subsection{Energy Consumption Pattern in Rural and Urban Areas}

Knowledge of the energy mix in rural and urban areas has important implications on the policy planning of the energy sector. The impact of different policies/programmes can be judged if the energy mix of the both sectors is periodically assessed.

The two national level institutions in their studies (NCAER 1985 and 1993 and NSSO 1997 and 2001) have analysed the energy mix in the domestic sector. Their studies are not exactly comparable because they pertain to different timeframes. A comparison is made, however, for the sake of knowing the trends. The NCAER in 1978/9 found the contribution of fuelwood and chips (including crop residue to make it comparable with NSSO) in household energy to be $68 \%$ in the rural sector and $36 \%$ in the urban sector. The NSSO, in 1983/4, found these contributions to be much higher: $77 \%$ in the rural sector and $46 \%$ in the urban sector. In a subsequent study in $1992 / 3$, the NCAER found a slight increase in the share of fuelwood and chips in the rural sector to $72 \%$ (Natarajan 1995b). The NSSO in 1993/4 found a marginal change in the share in the rural sector (78\%) but a drastic change in the urban sector. The share of firewood and chips was reduced from $46 \%$ to $30 \%$ due to a relative increase in the share of LPG and kerosene. In the rural sector, the shares of crop residue and dung cake declined from $16 \%$ to $13 \%$ and from $22 \%$ to $17 \%$ respectively over 14 years (1979-93) (Natarajan 1995b). Natarajan (1995b) also found significant change in the composition of fuelwood. The firewood logs and twigs during 1978/9 were in the ratio of 1:2, which had changed to almost $1: 1$ in 1992/3. The energy mix in rural and urban areas as estimated by NSSO (2001) in 1999/2000 is presented in Figures 4.2 (a) and (b). The percentage of crop residue as estimated by Natarajan (1995b) has been assumed to be part of firewood and chips.

Figure 4.2 (a) Composition of energy consumption for cooking in urban India and 4.2 (b) in rural India (Source: NSSO 2001)
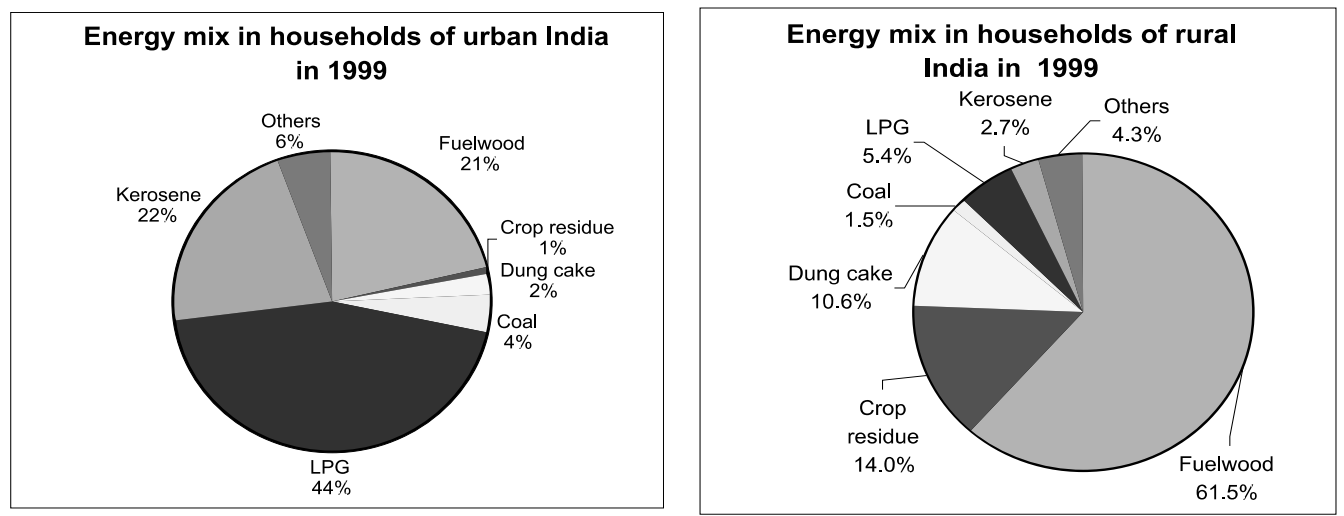

A review of the wood balance studies of the states reveals that the percentage of fuelwood in the energy mix of rural and urban areas varies from state to state and does not follow the national trend. For example, in rural Haryana, the contribution of fuelwood is $30 \%$ (NCAER 1988), whereas in rural Himachal Pradesh it is $89 \%$ (Singh and Sikka 1994). The percentages only partially tally with the national studies.

\subsection{Assessment of Fuelwood Sources and Supply}

Fuelwood is produced from natural forests, plantations, trees outside forests and other wooded lands. Accurate knowledge about the extent of such sources and annual availability of fuelwood from them on a sustained basis is crucial to understanding likely future trends. In the earlier 
fuelwood studies, the forests were considered the main source. Large-scale studies were not conducted to assess the actual availability of fuelwood on the basis of increment in the forests. In fact, traditional volume tables often do not include the fuelwood component (branches, smallwood, etc.) of the trees.

Most of the fuelwood studies under review have focused on consumption and were not able to assess the sources in a proper way. Often, the annual availability has been estimated inaccurately. Among the national studies, the NCAER (1985) and Natarajan (1995b) have estimated the sources on the basis of replies from the households in a single survey. Even if the replies are true, the sustainability of the supply cannot be judged without knowing the increments of different sources. The sources as estimated by NCAER in 1978/9 are presented in Figure 4.3. The NCAER assumed that all the fuelwood sold in the markets had originated from state forests. The total contribution of forests in meeting the fuelwood needs was $53 \%$; villagers' own sources (homesteads and farmlands) contributed only $26 \%$.

Fig 4.3 The sources of fuelwood in India in 1978/9 (Source: NCAER 1985)

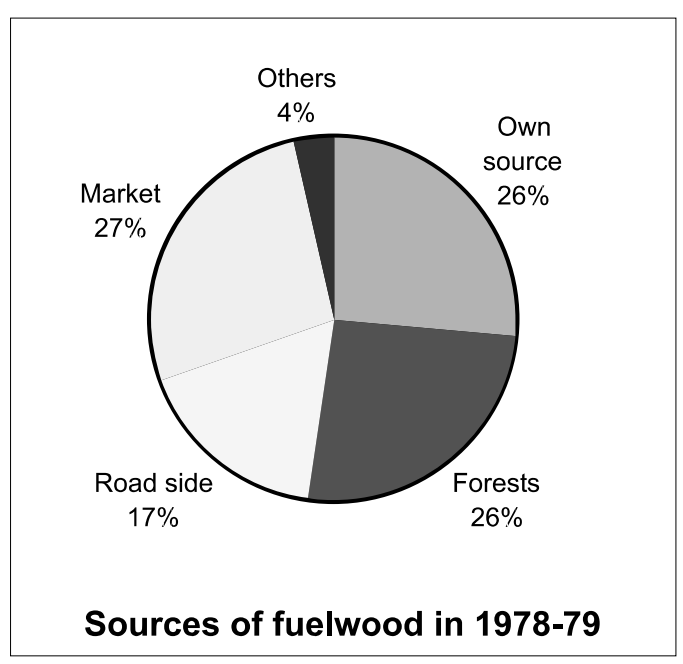

In the subsequent study done in 1992/3 only for rural India, NCAER found that the sources of fuelwood collection had undergone rapid change. Nearly half of the households collected fuelwood from their own farms and only $17 \%$ from forests.

The NSSO (1997 and 2001) studies have not analysed the sources at all. The Forest Survey of India used the traditional approach of estimating fuelwood as a part of the annual increment of the forests. Of the assumed supply of 103 million $t$ from the forest source ( 98 million $t$ was assumed from non-forest areas), only 17 million t were estimated to be available on a sustained basis. This left a gap of 86 million $t$ and as an extra drain on the forest resource. It is to be noted that the annual increment/productivity of India's forests has not been studied in detail, but there are several estimates. The models to be adopted for estimating the productivity of timber and of fuelwood have to be different. Branches and twigs gathered from the forest floor account for a sizeable quantity of fuelwood whereas traditional forest inventories for timber production often measure the standing volume down to $10 \mathrm{~cm}$ diameter, ignoring small dimensions and fallen branches. Ravindranath and Hall (1995) has also tried to estimate the sources for fuelwood based on assumptions. Many of the assumptions are crude, and not true. 
Among the state level studies, Gujarat and Haryana have used the success rate of seedlings planted to estimate fuelwood from farm forestry plantations. The potential contribution to fuelwood by trees outside forests has been grossly underestimated by Gujarat, Haryana, Orissa and West Bengal. The gap between consumption and supply has been assumed to be met partly by importing fuelwood from neighbouring states and partly as an excess drain on the forest resource. The Karnataka study has not considered this source at all and has theoretically estimated the availability of fuelwood from forests using working plan figures. The Andhra Pradesh study (IWST 2001) could not take into account substantial fuelwood supplies from farm forestry (not covered under the government-assisted programme) and agroforestry for want of data.

In Jammu and Kashmir, the growing stock of forests and of trees in private farms and elsewhere was estimated based on principles of traditional inventory, a portion of which was treated as fuelwood. But the actual availability of fuelwood from these sources has not been assessed. Based on field observation and the standing volume of fuelwood within and outside forests, it was estimated that $65 \%$ of the fuelwood came from forests and the rest from individual sources.

In Himachal Pradesh, trees standing in private farms were counted (not measured) and the flow of fuelwood to households was observed for the whole year. The study found that the supply of fuelwood from the forests was inversely proportional to the size of land holdings. Landless masses and marginal farmers collected the major portion of fuelwood from forests. Of the total rural consumption, about $50 \%$ came from forests and the rest mostly from individual sources.

The Kerala study has made a detailed field survey to assess the growing stock of trees outside forests. The annual increment, however, has not been assessed. The entire gap between consumption and recorded supply from forests plus unaccounted removal of fuelwood from forests by the local people, was assumed to be met from trees growing on homesteads and a small portion from estates (plantations of rubber, cardamom, coffee and tea). The supply of fuelwood from non-forest areas was over $90 \%$.

In Tamilnadu, fuelwood sources analysed on the basis of a questionnaire found that about $53 \%$ of the total fuelwood consumed was freely collected and came from horticultural residues, Prosopis species, Acacia species and Casuarina equsetifolia, most of which were growing in nonforest lands. About $20.5 \%$ of fuelwood was sold from the shops, $13.3 \%$ from individually-owned land and only $4.7 \%$ was reported to have originated from forests. 


\section{Trends}

\subsection{New Policies in the Energy Sector}

The Government of India announced a new investment policy for different sectors in 1991 for facilitating the inflow of foreign capital and to encourage entrepreneurs to invest in India. Equity participation in commercial and industrial ventures has been freed from all restrictions and foreign companies can now invest up to $100 \%$ of their equity in different activities including the petroleum, electricity, and coal sectors. The two most recent policies in relation to the growth of LPG, which has direct bearing on the consumption of fuelwood, are mentioned below:

a) India formulated a new exploration licensing policy in 1998 to allow private and joint venture companies to enter into the arena of oil and gas exploration.

b) In the Hydrocarbon Vision-2025, finalised in 2000, it is proposed that $45 \%$ of the total energy needs of the country will be met through hydrocarbons by the year 2025 , compared with the existing contribution of $42 \%$. The mixture of oil and gas will change from the existing $35 \%$ and $7 \%$ to $25 \%$ and $20 \%$ respectively, which will facilitate better energy efficiency, lower pollution and easier availability of LPG for cooking.

\subsection{Growth of LPG}

In recent years, LPG supplies have eased. The LPG market has been opened to private retailers who have been authorised to sell imported LPG. The commission given to retailers has been increased to ensure better consumer service, quality product supply and improved safety measures. The custom duty on the import of LPG has been reduced from $85 \%$ to $25 \%$ and now $16 \%$. Private retailers have been also allowed to produce LPG cylinders, the shortage of which has been a perennial problem in increasing LPG supplies. For easy transportation of gas to distant places, expansion of the pipeline network has been accelerated. About $1250 \mathrm{~km}$ of pipeline has been commissioned in the year 2001. 
A special scheme has been launched to extend LPG connections to the rural sector with associated reduction in the quota of subsidized kerosene, by opening extension counters in rural areas falling within a $15 \mathrm{~km}$ radius of the normal trading area of urban distributors. Some of the state governments are providing grants to poor people to meet the initial cost of buying gas stoves etc. In Himachal Pradesh, a strong financial incentive is provided to use LPG in an effort to slow deforestation.

The growth of the LPG supply has been phenomenal in the last decade, from 18.1 million connections in March 1992 to 54.2 million in December 2000, with an average annual growth of more than 20\% (OCC 2001). As per the plans of the Ministry of Petroleum and Gas, about 10 million new LPG connections are expected to be extended during the year 2001. It has been observed that some LPG connections have been informally diverted to industrial units and for running automobiles. Further, a sizeable percentage of families have double LPG connections (people have done this, mostly in the past, to guard against sporadic shortages and delays in the refilling of gas). It is crudely estimated that of 54.2 million connections, only about 40 million households have effective use for cooking food and water heating. In other words about 220 million Indians at present are using LPG for cooking and heating.

Though the government makes some adjustments through subsidies to partly offset the increase in international prices of LPG, the price of LPG has risen over the years in India from about INR 62 in 1985 to INR 220 in the year 2000 (taking into account the increase in the price index, the real increase may be nominal). When the price of LPG was substantially increased in India during August 2000, it was believed that the lower middle class might switch over to the use of fuelwood and kerosene, as these were more cost-effective than LPG. But it did not happen. The price increase has thus not affected LPG consumers and their number is continuously growing. The growth in LPG connections during 1992/2000 is shown in Figure 5.1.

Figure 5.1 Growth of LPG connections in India (Source: OCC 2001)

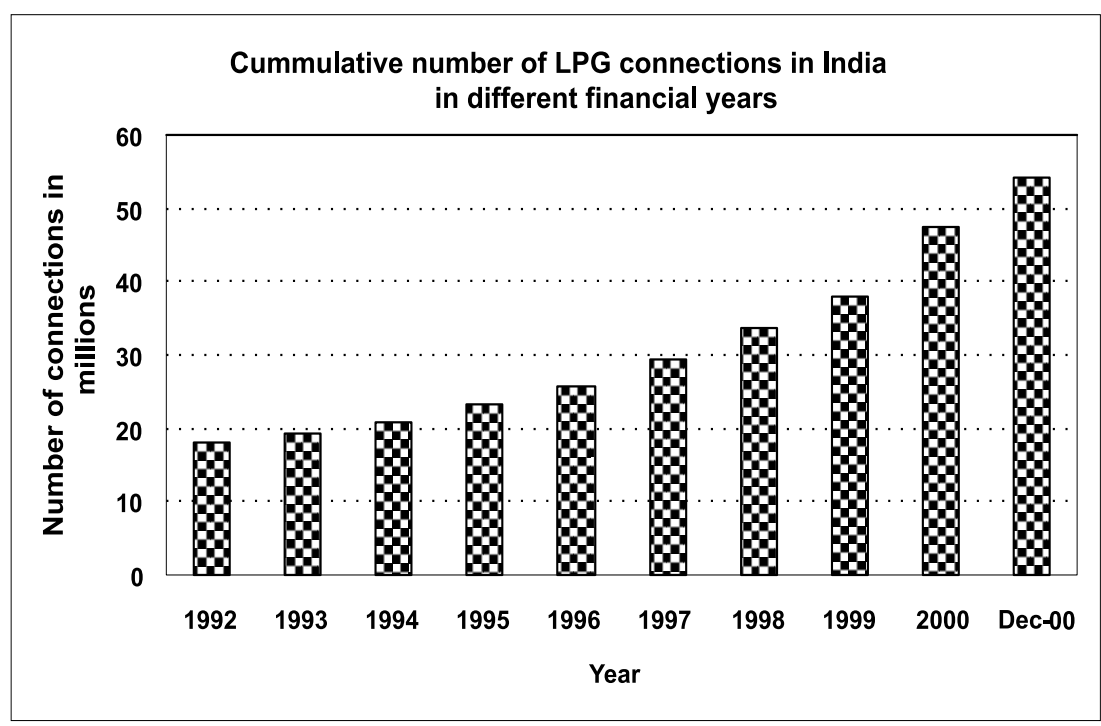

\subsection{Electrification of Villages}

As already stated in Section 1, rapid growth in the electricity sector and the rural electrification programmes have led to high levels of village connections. The percentage of electrified villages has increased significantly. About $87 \%$ of Indian villages are now served by electricity compared 
with $40 \%$ in 1980 . Although the electricity provided in the rural areas is highly subsidised, the connections in households are still about $40 \%$ of the total households (it was $14 \%$ in 1980). This is mainly due to low income, cost of connection and poor quality of houses (ESMAP 2001). One consequence of rural electrification is the development in the use of electrical appliances. At least $12 \%$ of rural households in India owned radios, television sets, ceiling and table fans and irons in 1996 (ESMAP 2001). With the rising rural income, the trend towards more appliances will continue. Almost all households who have electricity connections also use kerosene for lighting, mainly because electricity supplies to villages are erratic and services are poor. In such situations kerosene is necessary to maintain a back-up system. The expansion of electricity connections to rural households in future will depend on economic development and the construction of concrete houses. Temporary houses made of thatch, bamboo and wood are susceptible to fire during electrical sparking.

Electrification in the remaining villages is slow due to their remoteness, as the extension of power lines over a long distance for a small segment of population is uneconomical. As per the government programme, unelectrified villages are to be electrified through a renewable energy approach by establishing local biomass gasifiers, etc. to meet the needs of the villagers.

\subsection{Growth in Fuelwood Production}

Fuelwood has remained the dominant source of household energy in rural India. Since the implementation of the social forestry and large-scale afforestation programmes, the area of production of fuelwood has gradually shifted from forests to non-forest areas. A lot of fuelwood is now being produced from trees planted along roads, canals, farmlands and wasteland. Actual production data at the national level from both the sources are, however, lacking. An assessment of tree resources outside the forests of a few states has revealed that the quantity of fuelwood estimated to be produced from outside forests and wastelands is quite sizeable. For example, a forest-deficient state, Haryana, has surplus fuelwood produced from outside forests (Anon 1996). Similarly, in forest-rich Kerala, most of the fuelwood requirements of the rural population are met from trees grown on the homesteads.

Further, measures taken by the Government to conserve biodiversity and existing forest resources has resulted in an increase of restricted areas where removal of fuelwood is not permitted. The ban on felling trees in many state forests has reduced the production of round wood from forests with a consequent adverse impact on recorded fuelwood production. Since the area under forests is not likely to expand due to competition with agriculture and other land uses, in future most fuelwood will be produced from outside forests, from farm forestry, common wastelands and agroforestry.

\subsection{Energy Transition}

The transition in the energy sector has to be examined in urban and rural areas separately because of the differences in lifestyle, availability of commercial energy and income levels.

\subsubsection{Rural Sector}

Change in rural areas has been slow compared to the urban sector. In the rural sector, even the prosperous households, continue to depend on the traditional fuels for much of their energy requirements supplemented by small amounts of kerosene and electricity mainly for lighting. The share of fuelwood, crop residue and dung cake in total cooking fuels varies considerably, and depends largely on availability, and cost in terms of the time required for collection. For example, fuelwood is largely used when forest/tree resources are easily accessible, dung cake where animal husbandry is an important occupation and crop residues where such residues are available due to the type of the crop and intensive cultivation. 
The easy availability of LPG in the last three to four years has helped prosperous and middleincome rural families located around urban or semi-urban centres to switch over to LPG. At a crude guess, about $20 \%$ of households in the rural sector of Tamilnadu State are now using LPG for cooking (Sarvanan personal communication). In Himachal Pradesh and Punjab, this percentage would be higher. The total number of LPG connections extended to these states until December 2000 was 0.8 million and 2.4 million respectively (OCC 2001). The total populations of Himachal Pradesh and Punjab as per the 1991 census were 5.2 and 20.3 million, respectively. Thus the families using LPG in these states comprised more than $70 \%$ and $50 \%$ of their total population, respectively.

The level of adoption of new and renewable energy devices in rural areas is somewhat disappointing. Despite the significant investment made in the renewable energy programmes, the level of penetration in rural areas is very poor (ESMAP 2001). Besides a lack of training for proper use and maintenance and an effective awareness campaign, the quality of construction, e.g. of improved cooking stoves, has been quite poor. Biogas plants have suffered because of wrong design, use of inferior material in construction and lack of maintenance. The Integrated Rural Energy Programme has also not progressed satisfactorily due to the marginal role played by the state governments.

\subsubsection{Urban Sector}

The change in the urban sector has been quite rapid. Even lower middle class or, to some extent, poor people are switching to the commercial form of energy as soon as they are in a position to afford it. The traditional fuels are gradually disappearing from the urban scene. One of the basic reasons for such a scenario is that a commercial form of energy is best suited to city life. In urban areas, people are in a rush-they have to travel long distances to work, and the cooking time should be as short as possible; there is not enough space to store bulky fuelwood; smokeproducing fuel causes complaints from the neighbours. The trend to switch to the use of commercial energy is common in urban centres of all sizes, but the switching rate differs and depends on the availability of commercial energy and the financial position of the households.

The number of people eating at food outlets is on the increase, particularly in urban areas. NSSO (1997) found that about $6.3 \%$ of households in urban areas have no cooking arrangements, possibly due to the fact that there are more restaurants and eating houses available in urban areas. The percentage of households who prefer to go out to eat are either from the highest income class or the lowest income class. As per the latest report of NSSO (2001), the percentage of non-cooking households decreased slightly during 1999/2000. 


\section{Identification of Fuelwood Hot Spots}

In the context of fuelwood, 'hot spots' include two types of areas, one where the forest/tree resource depletes due to excessive removal of fuelwood, and one where there is fuelwood scarcity and people switch to inferior (less efficient) types of fuel like crop residue, dung cake, leaf litter etc. Different criteria have to be adopted to identify these areas.

\subsection{Degradation of Forests due to Fuelwood Collection}

The collection of fuelwood from forests that exceeds sustainable yield causes degradation. Forest degradation in turn leads to fuelwood scarcity and a variety of adverse consequences, including loss of biodiversity, deterioration of watershed functions, release of carbon dioxide into the atmosphere and soil erosion.

In formulating the fuelwood the gap theory in the 1970s, the forests were considered the main source for the supply of fuelwood, and the potential role of trees standing in non-forest areas was either underestimated or ignored. The recorded supply from forests accounted on the principals of traditional forest inventory was assumed as the sustainable yield by most developing/ tropical countries. Branches and twigs, which often fall below the traditional mensurational limits and form a sizeable portion of fuelwood collected from the forest floor, were also ignored. Fuelwood consumption exceeded the assumed sustainable supply many times and was considered the underlying cause of deforestation.

Not many studies have been done to really understand the dynamics of fuelwood production in totality, and the consumption-production gap. To estimate the potential production of fuelwood from forests, in addition to measuring the total volume of the standing trees, branches and twigs falling on the forest floor, which form an integral part of fuelwood, should also be measured. The estimation level, therefore, comes close to measurement of the biomass of trees. In forestry, there have been limited biomass studies, most of which have been done in relation to ecological/energy cycles. 
A few examples of recent empirical studies done in India and outside involving economic theory on fuelwood collection as a cause of deforestation have been presented in the following paragraphs.

A study of fuelwood collection and trade in three districts (Cooch Bihar, Darjeeling and Jalpaiguri) of Northwest Bengal in India conducted during 1998/9 (see appendix I C.4 for details) estimated that about $10 \%$ of the total rural population, that is, about 730000 people, were engaged in the fuelwood trade due to economic distress. These were mostly landless and marginal farmers who took to the fuelwood trade as an income-generating activity. The total fuelwood collected and traded annually was estimated to be 3.7 million $t$. In addition, fuelwood was collected for self-consumption. The total estimated annual removal was 5.5 million $t$ from about 280000 ha of accessible forests of these districts. The annual removal is high enough for speedy degradation of the forests.

In a study conducted in four villages of Rajasthan in India, it has been found that when there is access to forest stock, people tend to substitute private fuels with forest fuelwood. Even in the case of increasing forest scarcity and higher collection time the collection does not stop (Heltberg et al. 2000).

A study of 26 villages located around forest areas and spread over three states in India (Madhya Pradesh, Orissa and Gujarat) during 1991-93 found that fuelwood and fodder derived from the forests contributed about 35\% of the total income of the rural people (Bahuguna 2000). Though explicit inferences cannot be drawn about the degradation of forests on account of fuelwood collection for self-consumption and trade, implicitly if the population density of these villages is high, forests are bound to degrade.

A preliminary survey of five traditional fuelwood production sites in Nicaragua was carried out by an NGO, PROLENA in 1998 to understand the impact of fuelwood collection on forest. The total area of 8 square kilometers located in five sites was analysed from 1986 to 1996. The study found that deforestation appeared to be more associated with changes in land use from forest to agriculture and cattle ranching. On the other hand forest degradation was directly associated with fuelwood collection for households and industries and charcoal making (De Miranda and Alves-Milho 1999).

\subsection{An Approach to Identify Hot Spots}

Since the fuelwood problem is location specific, identification of the hot spots has to be done at local level. Identification at village level may be the most ideal from the planning point of view, as people in rural areas try to meet household energy requirements from the resources of the village itself or from the neighbouring areas. But the number of the villages in India is so large ( 0.57 million) that implementation of the plan and management of so many units would be a difficult task. The Ministry of Environment and Forests of the Government of India has identified fuelwood-deficient districts in the country, where the Fuelwood and Fodder Project Scheme is implemented under five-year development plans. The size of a civil district in India is, on average, $5000 \mathrm{~km}^{2}$. In such a large area it is possible that some parts may experience a fuel deficit while other parts of the same district may have surplus fuelwood. Identification of hot spots using the district as a unit therefore may not serve the purpose. The Ministry of Non-conventional Energy Sources uses the Community Development Block as an administrative unit for implementing the Integrated Rural Energy Programme. Blocks, on average, cover about 100 villages. The block, therefore, appears to be the appropriate unit for micro-level planning and management to handle the fuelwood problem.

Three basic factors can be used for identifying hot spots in a fuelwood situation:

- Nearness of dense population centres to forests

- Low income level and lack of employment opportunities

- Lack of tree and forest resources within an accessible distance 
Income levels of households and opportunities for employment play the most crucial role in determining hot spots of both categories.

\subsubsection{Identifying Forest Degradation Areas}

Forests around population centres are easily accessible by the local people. People collect fuelwood and other forest products for self-consumption and/or for trade, legally or illegally. The lower the per capita forest area the higher will be the woodfuel extraction per unit area. In addition, if the area is economically undeveloped and people are in economic distress and unemployed, fuelwood collection will be also done for trading purposes. Removal beyond annual productivity leads to degradation. The population density per unit area of accessible forests (excluding remote and restricted areas) combined with the economic condition of the people therefore can be used to determine the possible withdrawal from the forests. If the opportunity cost of labour is higher elsewhere, people may not be attracted to fuelwood collection and trade. In that case collection will be limited to domestic consumption only.

To get clues for identifying hot spots, one can start with macro level information. For example, as per the latest national survey on Household Consumer Expenditure in India, the three states having the lowest monthly per capita expenditure are Bihar, Orissa and Madhya Pradesh (NSSO 2001). In rural areas, average monthly per capita expenditure during 1999 was INR 363 (US\$7.72), INR 394 (US\$8.4) and INR 406 (US\$8.7) for Bihar, Orissa and Madhya Pradesh, respectively, which is an indicator of the poor economic condition of the rural people. Incidentally these states have reasonably good forest cover. The villages located around forests in these states can be taken as the likely location for hot spots.

\subsubsection{Identifying Fuelwood Scarcity Areas}

People experience fuelwood scarcity in areas that are deficient in forest and tree resources. They may switch to alternative fuel such as crop residue, dung cake, leaf litter, etc. to meet their domestic fuel requirements. Prosperous families, however, would opt for commercial forms of energy (LPG or kerosene) if accessible. For example, Punjab State in India is deficient in forest and tree resources, with forest cover at about $3 \%$ of the geographic area, but rich in agricultural and dairy production. In 1993/4 more than 75\% of households in urban areas used commercial energy for cooking (NSSO). In rural areas, only about $14 \%$ of families used commercial energy, 34\% used dung cake and the rest, fuelwood and crop residue. After decontrol of LPG development and trade the supply became easy, the total number of LPG connections given to the state until March 2001 had reached about 2.5 million, which is quite large compared to its size (24.3 million people in 2001). This means that almost half of the households in Punjab State use LPG at present. Thus at macro level, Punjab may not be an example of a fuelwood crisis state even if it is deficient in forest and tree resources. On the other hand, Rajasthan may be an example of a fuelwood deficient state where forest cover is about $4 \%$ and the income level of the households is also relatively low. The rural poverty rate is $37 \%$ and only $34 \%$ of households have electricity connections. The LPG connections extended to the state till March 2001 stood at 2.3 million (against 56.5 million people in 2001), most of which are confined to urban centres.

In India, economic surveys are frequently conducted by governmental as well as nongovernmental organisations, both at micro and macro levels, to judge the impact of various development programmes. Through the analysis of these reports it is possible to identify the areas in the country where the income levels of the households are low, employment opportunities are few and economic developments are poor.

Further, the forest cover in India is assessed at the district level every second year using remote sensing satellite data. By inserting the boundaries of blocks into the maps, the assessment can be brought down to the block level. The population of the blocks available from the census department can then be overlaid and the forest area per capita of the blocks can be estimated. But the tree resources and plantations in small blocks that are available outside forest areas are 
excluded from the assessment, because satellite-based remote sensing techniques can seldom detect such resources. Studies have shown that trees outside forests constitute an important forest resource in many areas. Without the knowledge of this resource, therefore, definite conclusions about the quantity of forest/tree resources in an area cannot be drawn. Thus additional efforts will be required to assess the scattered trees to complete the knowledge of the forest and tree resource.

Besides applying the criteria mentioned, social surveys may be conducted to crosscheck the findings. People may be asked to specify whether they have realised the scarcity of fuelwood, and if so, how are they able to meet their domestic energy needs. Such questions are often included in some of the fuelwood surveys. People inhabiting forest fringes may be asked to specify the change in the condition of the forests over a period of years and the availability of fuelwood from them.

\subsection{Villages in Proximity to Forests}

The Forest Survey of India, Dehradun, recently completed a preliminary exercise of listing the villages in the country which are in close proximity to forests (FSI 2000). In the decennial census conducted in India, the investigators also collect information on land use in villages from the Revenue Department. Village-wise information on land use available from the census department based on the last census (1991) was analysed. It has been found that about $29 \%$ of the villages of the country (170 000 out of 587000 ), comprising 147 million people, are located in the vicinity of forests. The list of these villages is available by district, which can be reduced to the block level by further division. Although the information is incomplete and imprecise, because most of these villages are economically undeveloped, they can be considered to be potential sites for hot spots.

A more detailed study has to be done to know precisely the location of such villages, their distance from the forests, the per capita forest area available, etc. by applying remote sensing and GIS technologies. Digitised village boundaries can be overlaid on the forest cover maps. This of course may not be an easy process because village maps in India are based on cadastral surveys, which do not have geographic coordinates and projection systems. Singh (in preparation) has demonstrated the feasibility of creating village level GIS by supplementing census village maps with control points extracted from the Survey of India maps. Undertaking an exercise at the national level will be a very expensive and time-consuming affair; some sample studies in different agro-ecological zones can therefore be undertaken to understand the dynamics.

To identify the fuel scarcity hot spots, assessment of the trees outside forest resources is essential, as areas identified as deficient in forest resource using remote sensing technology will not be conclusive. 


\section{Policy Responses to Fuelwood Issues}

\subsection{Social Forestry and Afforestation Programmes}

In India, afforestation and tree planting were given high priority when the Government announced a revised ' 20 point programme' in 1980 and a substantial increase in outlay was made for such activities. Simultaneously, the Social Forestry Programmes were also launched, the main goal of which was to increase the production of fuelwood, fodder and small timber in rural areas by planting trees in community wastelands, marginal farmlands, and other vacant lands. There was strong emphasis on local people's participation. This resulted in an increase in annual afforestation from 0.11 million ha prior to 1980 to 0.93 million ha during 1980-85. External aid agencies like the World Bank, United States Agency for International Development (USAID), Swedish International Development Agency (Sida), etc. evinced interest in providing financial assistance. In all, externally aided projects were implemented in 14 states with a total involvement exceeding US\$511 million for tree planting and afforestation of about 2 million ha. Most of the projects ensured popular involvement by setting up Village Social Forestry Committees. The programme of social forestry continued and tree planting was further accelerated, with the annual rate reaching a peak (1.78 million ha) in the Seventh Five-year Plan (1985-1990). New initiatives were taken to develop wastelands. Under a Grants-in-Aid scheme, the government granted funds to the non-governmental organisations for tree planting which function in a 'more' flexible manner than government agencies. Many other autonomous bodies also came forward to support the tree plantation programme. The National Dairy Development Board promoted the creation of Tree Growers' Cooperatives. Each Tree Growers' Cooperative raises its own nursery and develops plantations on private, community and leased government wastelands. Similarly, a Farm Forestry Cooperative was started by the Indian Farmers' Fertilizer Cooperative with funding from banks and the government.

The monitoring mechanism of the government programmes is rather weak and monitoring has been done only through the survival rate, mostly after the first year of planting. Uncertainty, therefore, prevails about the actual area of existing plantations and the quantity they produce. 
An evaluation has shown that, though tree plantations raised by cooperatives are small in extent, they have been highly successful (Singh 1999).

Though the social forestry programme has no doubt made a great impact on the generation of fuelwood resources outside forest areas in the country, because extensive tree planting has been done on farmlands, wastelands, along roads, etc., its extent in terms of volume has not been quantified. The cumulative area of forest plantations established under different programmes in the country until 1999 was 31.2 million ha (FSI 2000) but how much of that has been successful is not known.

\subsection{Fuelwood in Five-year Development Plans}

Realising the increasing demand for fuelwood and its consequences for forests, the Planning Commission of India also started a Rural Fuelwood Plantation scheme during the Sixth Five-year Plan (1980-1985). Its thrust was to produce fuelwood in 157 chronically fuel-deficient districts of the country against about 460 districts existing at that time. The aim was to make this essential commodity available to rural people near their habitats. The total cost of the scheme was INR 499 million, equivalent to US\$45 million (at the prevailing exchange rate of INR $11=$ US\$1). The scheme has continued since then, with modifications, as the Fuelwood and Fodder Scheme. The number of fuelwood-deficient districts covered increased to 229 (out of 590 districts) in the Eighth Five-year Plan (1992-1997) with a budget of INR 1542 million (equivalent to US\$51 million). The number of districts covered under the programme has been increased to 241 in the Ninth Five-year Plan (1997-2002).

The monitoring mechanism for this programme is similar to that of the afforestation programme. Its contribution to the generation of fuelwood resources has not been quantified.

\subsection{Joint Forest Management Programmes}

The 1988 National Forest Policy of India emphasises the creation of a massive people's movement, through the involvement of village communities living close to the forest, in the protection, management and development of forests. It is envisaged that the communities, in return for their participation in the protection and development of forest areas, will be entitled to a share of the usufructs in a manner specified by the concerned State Forest Departments. Usufructs include fuelwood as a major component to which communities get rights. This has led to the development of the Joint Forest Management (JFM) programme.

So far, 25 state governments out of 28 states in India have implemented JFM. The state governments decide their own mechanisms of involving local communities in conformity with the proclaimed policy. The local institutions engaged in the task are known by different names in different states, such as the Forest Protection Committees (FPC), Village Forest Committees (VFC), Van Samrakshan Samiti (VSS), Village Forest Protection Management Committees (VFPMC), etc. The nature of usufruct sharing also varies from state to state. About 36130 Forest Protection Committees are managing a total of 10.25 million ha of forest area. The practice of JFM is generally confined to degraded forests. Micro plans are prepared in conformity with the working plans for areas where JFM is to be practiced.

The mechanism of usufruct sharing varies from state to state. In Madhya Pradesh, the state with largest area under JFM, there are two types of committee, viz. VFC and FPC. The sharing of usufructuary benefits in case of areas under VFC is in the proportion of $70 \%$ to the government, $15 \%$ to the committee formed, $10 \%$ to the individual members and the remaining $5 \%$ is ploughed back for the development of area. In case of FPC the benefits are shared in the proportion of $90 \%, 5 \%, 3 \%$ and $2 \%$ among the above. In Andhra Pradesh and Orissa, the sharing is in the proportion of $50 \%$ each between the government and committee members, while in West Bengal, the sharing is in the proportion of $75 \%$ and $25 \%$. In Bihar, the benefits accrued are divided into three equal 
parts, to be deposited in the Village Development Fund, the Forest Development Fund and the Working Fund, respectively (TERI 1999).

The impact of the JFM programmes in increasing fuelwood production and meeting demands of the local people has been inadequately studied. At macro level, the most recent State of Forest Report (FSI 2000) has identified JFM programmes as one of the reasons for a marginal increase in the forest cover of the country. An analysis of a small area where JFM has been practiced for 12 years, carried out in Orissa State, showed a better regeneration status and better protection of the more valued trees compared to the reference area which was protected only for two years (Ostwald 2000).

\subsection{Technological Initiatives Including the Fuelwood Saving Campaign}

Technological initiatives aim to improve the efficiency of fuelwood-using devices so that the energy content in the wood is optimally used. The traditional cooking stoves commonly used in the rural areas have low thermal efficiency (around 8\%) and consequently consume more fuel, besides emanating a lot of smoke. The smoke causes indoor air pollution, exposing women and young children to health risks. To promote scientifically-developed and user-friendly models of cooking stoves, a National Programme on Improved Chulhas (cooking stoves) was initiated in the country in 1983 as a demonstration programme. Subsequently, under the extension programme, about 31 million improved cooking stoves were promoted until 1999. Different models have been developed and tested to suit varying fuel material, food habits and other requirements but the broad types are (i) the fixed clay/mud type and (ii) the portable metallic type. The programme is implemented by a number of agencies (autonomous bodies, NGOs, self-employed workers), in conjunction with government departments. Nearly 2 million improved stoves are introduced every year.

The National Council of Applied Economic Research, in its study during 1992 of about 15000 stoves acquired in the last three years, found that the efficiency level of the stoves varied greatly, as the quality of construction and maintenance was not uniform. On average, the improved stoves were only $40 \%$ more efficient than the traditional stoves, contrary to the claim of $300 \%$. Only a small number of stoves conformed to the theoretical norms. One-third of the stoves became non-operational in the first year of installation and about $15 \%$ of the stoves did not survive the first three months. The average annual rate of dropouts was estimated to be $20 \%$. The major reason identified for disuse of the cooking stoves was construction and installation defects and improper maintenance (Natrajan 1995a).

\subsection{Integrated Rural Energy Programmes}

Realising that the fuelwood problem is location specific, the Government of India has launched Integrated Rural Energy Programmes (IREP) since 1987. The programmes aim to provide energy to rural people at a minimum cost through a mix of different sources. The planning and implementation of the projects are area-based, at micro level. The area considered for micro level planning is the Community Development Block, an administrative unit covering, on average, 100 villages. IREP cells are formed at state, district and block levels. An energy survey of the blocks is first conducted to assess the supply position of various resources such as land resources, land use pattern, firewood, crop waste etc. Various energy-saving devices are identified, taking into account the suitability and potentiality of the area. An action plan is prepared to bridge the gap between supply and demand. In the planning, conservation of commercial energy sources and promotion of renewable energy sources are emphasised. One of the basic features of this programme is the participation of the local people in planning and of local bodies in the implementation. Large-scale participation of the beneficiaries has created a demand for energy 
devices. Since the area of operation of the programme is small, a close link is maintained between the planners and beneficiaries.

Until 1996/7 about 660 blocks out of more than 2000 blocks in the country were covered, but the actual efficacy of the programme has not been assessed. The role played by the state governments in this programme had been very marginal. The states have experienced institutional and financial constraints (PC 1999).

\subsection{National Project on Biogas Development}

Decomposition of organic materials like cattle dung and human waste in the absence of air produces biogas, the major portion of which is inflammable methane. It is a clean and efficient fuel used for cooking and lighting. On the other hand, the residue is enhanced during the process of digestion and gets used in agriculture. A National Programme on Biogas Development was launched in 1981 for the promotion of family-type biogas plants to provide clean and convenient fuel for cooking and lighting in rural areas. The Ministry of Non-conventional Energy Sources has been following it up since its creation. The traditional design for biogas plants was the floating drum type, but since then many innovations have taken place. The biogas plants installed in the country so far are to meet the requirement of nearly 2.9 million rural households with annual target of over 150000 plants. The installation programme is carried out through state departments, corporate bodies and registered societies. The government provides a subsidy depending upon the category of beneficiary. In addition, there has been a programme to promote large community and institutional biogas plants, where there are assured supplies of cattle dung, mainly to benefit weaker sections of society.

The research and development in biogas is aimed at developing new designs to improve the rate of biogas production, particularly at low and high temperatures, and reduce the cost of construction. Low production of biogas during winter and at higher altitudes has been one of the main problems encountered in biogas technology. Evaluations of the biogas programmes are often done by independent agencies. In an evaluation of the community biogas plants in Tamilnadu, it was revealed that only about $20 \%$ of biogas plants were working because of the damage to drums and pipes and lack of maintenance (IES 1999). Some people are averse to installing biogas plants because of the high cost, day-to-day involvement in running the plants and the bother of maintenance.

\subsection{National Biomass Resource Assessment Programme}

The Ministry of Non-conventional Energy Sources has undertaken a National Biomass Resources Assessment Programme since 1996, under which all kinds of surplus biomass (woody, crop residue, dung cake etc.) available at the block level are being assessed. The objective is to cover the entire country in the next few years and prepare a National Biomass Resource Atlas, and to support biomass-related renewable energy development programmes in the country. Autonomous/ private institutions and NGOs are doing the assessment under the technical supervision of the Apex Institutions. These institutions employ students and put them on the job after orientation training. These investigators visit the site and collect data from different agencies (Revenue, Forests, Statistics and block level functionaries). The four energy-related Apex Institutions identified by the MNES in cooperation with the states are: Tata Energy Research Institute, Delhi; Operation Research Group, Vadodara; Administrative Staff College of India, Hyderabad and Anna University, Chennai. The administrative responsibility for the execution of the programme lies with the Renewable Energy Development Agencies of state governments. By now more than 350 blocks have been covered in the country. 
In theory, the programme can provide the most valuable information for micro level energy planning, identification of fuelwood scarcity areas, etc. However, the data collected on biomass is mostly through secondary sources and field measurements are rarely done. In a few cases, the biomass of the forests is ignored because there is a ban on the felling of trees. The quality of information provided through the assessment is often not very reliable.

\subsection{Allocation of Funds}

Despite several programmes launched to meet domestic energy needs of the country, the overall allocation of funds for the development of the fuelwood sector compared to the commercial energy sector in India is quite insignificant. During the Eighth Five-year Development Plan (19921997), the total allocation for the commercial energy sector was INR 2, 121 billion. On other hand, the total allocation for afforestation programmes, of which the fuelwood component is only a fraction, was about INR 4.6 billion, and for renewable energy programmes for rural areas, it was INR 0.8 billion. Thus the allocation to fuelwood and renewable energy was only about $0.25 \%$ of the commercial energy sector. 


\section{An Approach to Make Fuelwood Statistics Reliable}

\subsection{The Issues}

The collection of primary data and assessment of any resource is an expensive and time-consuming activity. In many cases, the people to be involved in such activities have to be trained. The production, supply, distribution and consumption of fuelwood has mainly remained in the informal sector. Unlike fossil fuels and electricity, there are almost no accounts of sale or bills to derive data on production or sales (Heruela 1996). The form and shape of fuelwood (fire logs, wastewood, branches and twigs) is so variable that precise estimates about consumption and production are almost impossible. The sources of supply are many: forests and non-forest lands (trees growing on common land, bushes, roadsides, users' own farmland and homesteads, market residual wood from wood industries, recovered wood from old construction, etc.). The consumer may obtain fuelwood from one or a combination of sources by collection or purchase and it may be difficult to pinpoint the exact quantity from each source. The user may also tend to lie if the fuelwood has been illegally collected from forests, due to fear of prosecution under forest laws. There is also a lot of flexibility in the demand and supply. People adjust to the resources available by switching over to other inferior biomass or commercial fuel. The amount of fuelwood used in a year and in different periods of the year can vary widely in the same area, depending on the supply.

\subsection{Assessing Consumption}

Different fuelwood consumption studies have followed different approaches depending upon the availability of time, finance and objectives. The key factors influencing consumption level and type of fuelwood are: proximity to forest/tree resource, urbanisation, income level of the household and climate. 
Fuelwood consumption $=$ (urbanisation, nearness to accessible forest/tree resource, climate, income level)

Fuelwood is often gathered and is a non-monetised commodity; people do not maintain accurate accounts of its consumption. The two key points to be focused on in fuelwood surveys, therefore, are stratification and estimation of fuelwood consumption per household. Collection of existing information through available sources is quite useful for stratification. The agencies that can provide most of the information are the Census, Revenue and Forestry departments. The NSSO follows quite a comprehensive approach for stratification of the population in its consumer expenditure survey. Since fuelwood consumption is not the major issue for NSSO, the aspect of nearness to forests is not included. The NSSO stratification approach, with modification of rural areas-villages with forests and villages without forests, as done in Wood Balance Study of Gujarat (Pinto et al. 1985)-would be quite appropriate. Though the questionnaire approach is an accepted and prevalent method for socio-economic surveys and is also followed by most of the fuelwood consumption studies, repeated physical measurements of the fuelwood being consumed in the subsampled households once a month or at least once in each season, should be done to improve the accuracy level of consumption studies. Data should be collected on the different kinds of fuel used. Since the units of measurement of different varieties of fuel differ, they have to be brought to a common denominator for the purpose of aggregation. Analysis of per capita consumption should be firstly done at the disaggregate level so that consumption in different segments of the population and the variability is understood well. This would help in understanding the dynamics of fuel consumption.

\subsection{Assessing Sources and Supply}

At present some information is available about the consumption of fuelwood at national/ subnational/local levels but the knowledge of production and sources is extremely weak and unreliable. Most of the fuelwood studies have focused on the consumption part and the source/ supply aspect has been either ignored or given less attention. The study of supply and sources is more difficult. In most of the earlier studies, forests were treated as the main source, and the production figures of fuelwood available in the records of the forestry administration were taken as the potential supply. Unrecorded removal by the local people was treated as an extra drain on the forest wealth. Some studies have estimated the source based on crude assumptions and have often used traditional forest inventory models (Rai and Chakrabarti 1996 and Ravindranath and Hall.1995). A few fuelwood studies have adopted a questionnaire approach to assess the source by asking questions to consumers about sources of supply of fuelwood (NCAER 1985 and Natrajan 1995b).

It is important to note that fuelwood comprises not only the wood from the tree bole but also branches and twigs and, in fuel scarcity areas, even the leaf. The production of fuelwood is, therefore, closely related to the biomass of the tree produced during the full life cycle of the tree. Fuelwood can be produced by lopping and pollarding or collecting the fallen branches/ twigs of the tree, and it is often not necessary to fell the tree. Traditional inventory models that have been developed to estimate the commercial volume of the trees, therefore, do not apply. New models have to be developed to estimate the utilisable biomass of trees for fuelwood calculation from natural forests and plantations. Though biomass studies have been done for many fuelwood plantation species (Acacias, prosopis, etc.) and also of natural forests in the past, these have been only for experimental purposes (Hussain 1989 and Rai 1981). It may not be desirable to project the results of these studies to estimate the fuelwood production from largescale forest areas. Further, fuelwood collection by head or shoulder loads is not done from the entire/gross forest area but from the areas that are in the vicinity of habitation centres, as 
collection from a longer distance is physically not possible. Fuelwood available in remote and inaccessible forest areas as well as in restricted forests remains unexploited. In India, there are 87 National Parks with a total area of 4.06 million ha where fuelwood collection is not permissible, in addition to other areas (FSI 2000). When estimating the fuelwood resource, it is therefore advisable to exclude such areas.

A lot of fuelwood is produced from trees outside 'forests' in several localities/countries. Trees growing outside forests, particularly in agroforestry systems, are subjected to different conditions of site and competition than those of natural forests and plantations. Morphologically, such trees are different, usually showing extensive branching and crown development. The crown normally constitutes from $30 \%$ to $50 \%$ of the total wood biomass (Jensen 1995). Their rate of growth is also very different from that of compact plantations and forests. Separate volume estimation models should be developed for such trees by following destructive sampling, by incorporating all prevailing agroforestry production systems. Similarly, growth studies should be taken up to develop biomass growth models by laying out permanent sample trees or tree groves on the line of permanent sample plots and measuring them periodically.

Though trees outside forests in rural areas have been contributing significantly in various ways for a long time, knowledge of their extent is highly inadequate in most countries. An assessment of this resource is crucial to the sustainable supply of fuelwood in developing countries. It is to be noted that the methodology for assessment has not yet been standardised. Recently, Singh (2000) has prepared detailed guidelines to provide a basis for nationwide inventory. India and Bangladesh have been assessing following the field inventory approach with village and household as the final sample units, respectively. In Pakistan and Sri Lanka, remote sensing was combined with field measurements (Pandey 2000). In Kenya, a two-phase sampling procedure was followed where aerial photos were used in the first phase and field measurements in the second phase (Holmgren et al.1994). A combination of modern tools, remote sensing and GIS with field inventory seems to be best option. Smallscale satellite imagery (1:50 000) with Landsat Multispectral scanner or IRS IC/ID can be used for land use classification and mapping as well as identification of tree cover classes. This will help in stratifying the population into homogeneous subpopulations. Aerial photos on a larger scale (1: 10000 or 1: 5000) or high resolution satellite data can be used to measure tree parameters, but cost and the timely availability of the data has to be borne in mind. Singh (2000) has suggested the village as the sampling unit for an efficient field inventory. While estimating fuelwood volume and increment, trees playing an environmental role, say, in urban areas (roadsides, parks and gardens) may be treated separately, as these trees provide fuelwood from fallen branches, twigs and leaves when alive and from their trunk etc. at the end of their physical life.

To determine the actual source of supply of fuelwood, investigators have to observe the flow of wood to households and other consumption and distribution centres for a longer period (perhaps for a full year), which would also cover the seasonal variation, instead of depending upon questionnaires. In the wood balance study of Himachal Pradesh in India, trained persons worked continuously for 12 months in the selected nucleus village by following the cost accounting method (Singh and Sikka. 1994).

In short, the approach impinges on the development of new models to estimate the fuelwood biomass of trees from natural forests and plantations and separate volume estimation models for trees growing outside forests. The potential of trees outside forests can be assessed faster and more precisely by integrating new technologies with traditional forest inventories. Inaccessible and restricted areas may be excluded from fuelwood estimation. 


\section{Conclusions and Recommendations}

\subsection{Major Findings}

The major findings of the study based on the review of the fuelwood and wood balance studies conducted during the last two decades in India, and of the developments taking place in the energy sector including the hydrocarbon, electricity, coal, forestry and non-conventional sectors, are summarised in the following paragraphs.

\subsubsection{Fuelwood Scenario after Two Decades}

There have been many changes in the fuel consumption scenario in the country during the last two decades. There has been phenomenal growth in the commercial energy sector leading to easy availability of LPG and kerosene. More than $87 \%$ of the villages of the country have been electrified, an increase of $47 \%$ during the period. A lot of fuelwood is now produced from 'trees outside forests' planted during social forestry and afforestation programmes. The area under Joint Forest Management has been gradually expanded since its launching in 1990, and the production of fuelwood from such areas is likely to be enhanced. Though it is not possible to comment precisely on the supply-demand situation, as the statistics on sources and supply are extremely weak and unreliable, a few state level case studies (Haryana and Kerala) indicate that the gap between supply and demand has been substantially reduced compared to in the past. The forests in the vicinity of the villages, however, continue to degrade due to excessive removal of fuelwood for trade in urban markets in addition to self-consumption, and due to grazing.

\subsubsection{Energy Consumption Patterns}

Energy consumption patterns in rural and urban areas differ a great deal. In rural India, there has been marginal change in the fuel consumption pattern during 1981-1999. Traditional fuel (fuelwood, crop residue and dung cake) still accounts for about $90 \%$ of domestic energy. The 
composition, however, varies considerably between states and localities and depends on relative availability. For example, per capita consumption of fuelwood is quite high in forested areas compared to non-forested areas. Consumption decreases with the distance of villages from forests. Areas having no forest/tree resources meet fuel needs by switching to inferior fuelscrop residue and dung cake-and partly to kerosene. Overall, fuelwood accounts for about $60 \%$ of the total fuel consumption in rural India.

In urban India, fuel consumption patterns are changing rapidly. The share of traditional fuel in urban areas has declined from $49 \%$ in 1983 to $24 \%$ in 1999 due to increased accessibility to commercial energy (LPG, kerosene and electricity). The share must have declined further as about 11 million new LPG connections have been given to households during the year 2000, making it a total of 54 million, most of which are in urban areas.

\subsubsection{Reliability of Fuelwood Consumption and Production Statistics}

The consumption aspect of fuelwood studies reviewed in this report has a varying degree of reliability. The data collection is mostly based on questionnaires with limited physical checking and on one-time visits without adjustment for seasonal variation. High reliability, therefore, cannot be placed except in a few local and state level studies.

Most of the fuelwood consumption studies have stratified the population to pick up samples from a wide cross section of varying agro-ecological conditions, forested levels, urbanisation and economic groups, but the analysis has often been aggregated to rural and urban sectors only. Per capita consumption is not a static quantity but many national estimates are based on per capita consumption estimated in the past, multiplied by current population and, therefore, have low reliability.

\subsubsection{Sources and Supply of Fuelwood}

The statistics on the sources and supply of fuelwood are extremely weak and unreliable. Most of the fuelwood studies have focused on the consumption aspect; the sources and supply aspect has been either neglected or paid scant attention. In a few cases the sources of fuelwood supply have been estimated, where estimates are based on inventory, they are often based on traditional forest inventory models. The questionnaire approach on supply followed by a few studies cannot be treated as reliable as people tend to lie due to fear of prosecution under forest laws. The supply of fuelwood from non-forest areas has been either underestimated or ignored. Reliable studies at national or state level are not available to prove or disapprove the sustainability of the fuelwood supply from forest or non-forest areas.

\subsection{Recommendations}

\subsubsection{Formulation of a Suitable Rural Energy Policy}

The efficient use of fuelwood offers the ideal option for sustainable household energy, particularly for rural India. It is also environment-friendly because the amount of $\mathrm{CO}_{2}$ released by burning fuelwood can be captured through the regrowth of woody vegetation.

But commercial energy (LPG, kerosene and electricity), being the most convenient and clean, is more popular. Trends in the energy consumption of the household sector clearly indicate that in future more people will switch to the commercial form of energy, particularly to LPG, as accessibility and the economic level of the people improves. But availability of LPG will not be infinite, as reserves are limited. It cannot, therefore, meet the requirement of all people/ households of the country on a sustainable basis. Further, about $54 \%$ of India's households belong to the low-income group and this group cannot afford to spend much money on fuel-most of them use traditional fuel free of cost. The other factor affecting the switch to LPG is its price 
relative to traditional fuels. If the price of the commercial fuels is too high, rural people who are in the lower middle-income group may not switch over to LPG or other commercial forms of energy. The prices of LPG and other petroleum products are partly influenced by the international market. The current subsidy provided by the government of India for LPG may not continue for ever.

It is the author's firm belief that at least $50 \%$ to $60 \%$ of India's population, most of which will be in rural areas, will continue to depend on traditional fuel for many decades to come. A suitable rural energy policy therefore needs to be formulated to ensure a sustained supply of traditional fuel without having adverse consequences on forest resources, agricultural productivity and the environment. The energy policy should take into account the emerging trends in the development of renewable sources into modern energy carriers (electricity, gas, heat etc.) by the adoption of new technology available in the commercial markets. The policy should place a clear focus on the development of the solar, wind and biomass energy and on the use of fuel saving devices.

\subsubsection{Development of Wastelands}

Wastelands constitute a large part of the country's land area where productivity is not being fully utilised due to various factors. Parts of this land are suitable for supporting woody vegetation and can be developed to meet the fuelwood and timber needs of the country. The National Forestry Action Programme of India (MoEF 1999) has identified about 60 million ha of such land, more than $50 \%$ of which is in degraded forests and the rest on non-forest land. By protection, assisting in natural regeneration and reforestation, the productivity of degraded forests can be enhanced. The non-forest wastelands are mostly in the form of 'cultivable wastelands' and 'fallow lands' where tree plantations with suitable species can be established to produce fuelwood and timber. Low productive lands are expected to support only bushy vegetation that would be suitable for fuelwood purposes. Additional funds will be required to set up these activities.

In addition, a lot of potential exists for growing multipurpose trees in agroforestry and farm forestry, particularly on farm boundaries, although much depends on the complementarity with agriculture and also the opportunity cost of land and labour (Saxena 1997). Choice of the species has to be the primary consideration for planting such areas and farmers have to have the appropriate incentives. Based on the total cultivated land of the country, the notional area tentatively estimated is about 4 million ha (MoEF 1999).

\subsubsection{Promotion of Renewable Energy}

Renewable energy will play a major role in meeting future energy needs in a sustainable way, in particular in rural India; this sector has, therefore, to be promoted. It will not only help in solving energy problems but also in reducing carbon emissions. Research and development, technological innovations for clean and convenient energy applications, cost reduction, increased conversion efficiency and new designs for adaptation to diverse field conditions are areas that require more attention. The programme of energy technologies, such as improved stoves for saving energy and biogas plants, have to be reoriented to offset the inadequacy of funds.

\subsubsection{New Fuelwood Studies}

In order to make the fuelwood statistics reliable, it is imperative that new fuelwood consumption and production studies based on statistically sound principles are taken up at the national level. A model approach for undertaking such a study has been described in Section 8 .

The size of the sample could be decided according to the time and budget for the study. It is important that both consumption and source aspects are given equal importance to make the study of value. If conducting an intensive study at the national level is difficult due to cost, time and other constraints, a limited number of representative districts or blocks scattered over the country/state can be chosen where studies can be conducted to derive a crude estimate. 


\subsubsection{Agency for Periodic Assessment of Fuelwood Consumption and Production}

As fuelwood is a major component of household energy in India, it is essential that a dedicated agency be mandated to conduct periodic surveys for the collection, collation and updating of fuelwood consumption and production statistics on a regular basis. Besides improving the quality of fuelwood statistics, this agency will also help in assessing the situation of sustainability of fuelwood derived from different sources. Though a number of government organisations (FSI, NSSO, State Forest Departments etc.), non-government organisations (NCAER, ORG, etc.), autonomous bodies and research institutions in India have undertaken fuelwood studies from time to time, these have been either project-based or have remained a side issue for them. For example, the NSSO conducts a household consumer expenditure survey every year and includes fuels for cooking and light as parameters. Expenditure being the main objective, analysis is done in terms of money spent on fuel by households in urban and rural areas with different income levels, and not in terms of quantity. The availability of fuelwood from nearby forest/tree resources and climatic conditions are not taken into account. The fuelwood sources/production aspect is ignored. Thus, there has been a lack of continuity and focus on this subject. It is, therefore, important to assign responsibility to any one of the existing institutions or create a mechanism or a new agency to conduct fuelwood consumption/production studies at regular intervals. 


\section{References}

Alam, Manzoor, Dunkerely, J., Gopi, K.N., William Ramsay and Davis, E. 1985 Fuelwood in Urban Markets: A Case Study of Hyderabad. Concept Publishing Co. New Delhi.

Anon. 1976 Report of the National Commission on Agriculture, Part IX Forestry. Government of India, Ministry of Agriculture and Irrigation, New Delhi. 457p.

Anon. 1985 (unpublished) Household Fuelwood Consumption: A Study in Rural Tamilnadu. Commissioner of Statistics, Department of Statistics, Madras. 44p.

Anon. 1987a (unpublished) Wood Balance Study, Government of Jammu and Kashmir. Directorate of Economics and Statistics, Planning and Development Department (Wood Balance Unit), Social Forestry Project, Srinagar, Jammu and Kashmir.

Anon. 1987b (unpublished) Wood Balance Study, West Bengal. Planning and Statistical Cell, Office of the Chief Conservator of Forests, West Bengal Forest Department, Calcutta. 90p + $75 p$.

Anon. 1996 HARYANA State Forestry Action Programme. 218p.

Bahuguna, V.K. 2000 Forests in the Economy of the Rural Poor: An Estimation of the Dependency Level, Ambio XXIX: 126-129. Royal Swedish Academy of Sciences.

Bhattacharya, P. and Joshi, B. 2000 A Case Study on Forest and Displaced People: Fuelwood Collection and Trade as a First Step Survival Strategy, Indian Institute of Forest Management, Bhopal and RWEDP, FAO Regional Office for Asia and the Pacific, Bangkok.

Chaturvedi, A.N. 1990 Trees and Fuelwood from Non-forest Lands-A Methodology for Assessment. India. Regional Wood Energy Development Programme in Asia, FAO Regional Office, Bangkok.

De Miranda, R.C. and Alves-Milho, S.F. 1999 Deforestation and Forest Degradation by Commercial Harvesting of Firewood and Charcoal in the Pacific Region of Nicaragua. Boiling Point 42: 11-13.

Dunkerley, J., Macauley, M., Naimuddin, M. and Agarwal, P.C. 1990 Consumption of fuelwood and other household cooking fuels in Indian cities. Energy Policy January/February: 92-99.

Energy Sector Management Assistance Programme (ESMAP) 1999 Household Energy Strategy for Urban India: The Case of Hyderabad. Joint UNDP/World Bank Energy Sector Management 
Assistance Programme (ESMAP), Mining and Telecommunication Department, The World Bank, 1818 H Street, NW Washington, DC 20433 USA.

Energy Sector Management Assistance Programme (ESMAP) 2001 Energy Strategies for Rural India:

Evidence from Six States (draft), Joint UNDP/World Bank Energy Sector Management Assistance Programme (ESMAP), Mining and Telecommunication Department, The World Bank, $1818 \mathrm{H}$ Street, NW Washington, DC 20433 USA. xvi + 89p.

Food and Agriculture Organisation (FAO) 1993 Forestry Statistics today and tomorrow. FAO, Rome. Food and Agriculture Organisation (FAO) 1997 Regional Study on Wood Energy Today and Tomorrow, Asia-Pacific Forestry Sector Outlook Study. Working Paper Series No. APFSOS/WP/34, Regional Wood Energy Development Programme in Asia, FAO Regional Office for Asia and the Pacific, Bangkok.

Forest Survey of India (FSI) 1988 State of Forest Report 1987, Forest Survey of India, Ministry of Environment and Forests, Dehradun

Forest Survey of India (FSI) 1995 Extent, Composition, Density, Growing Stock and Annual Increment of India's Forests. Forest Survey of India, Ministry of Environment and Forests, Dehradun.

Forest Survey of India (FSI) 2000 State of Forest Report 1999, Forest Survey of India, Ministry of Environment and Forests, Dehradun.

Heltberg R., Arndt, T. C. and Sekhar, N.U. 2000 Fuelwood Consumption and Forest Degradation: A Household Model for Domestic Energy Substitution in Rural India. Land Economics 70(2): 213-232.

Heruela, C. 1996 Wood Energy Data-an overview. Wood Energy News 11 No.2. Regional Wood Energy Development Programme in Asia (GCP/RAS/154/NET), FAO Regional Office for Asia and the Pacific, Bangkok.

Holmgren, P., Masakha, F.J. and Sojoholm, H. 1994 Not All African Land is Being Degraded: a recent survey of trees on farms in Kenya reveals rapidly increasing forest resources. Ambio 23(7): 390-395.

Hussain 1989 Modelling for determination of biomass of Acacia nilotica, A. albida, A. tortalis and Prosopis ceneraria in arid areas. Pakistan Journal of Forestry 39/ 4. Pakistan Forest Research Institute, Peshawar.

Institute of Energy Studies (IES) 1999 (unpublished) Performance, Evaluation Study on Institutional and Community Biogas Plants of Tamilnadu. Institute of Energy Studies (IES), Anna University Chennai. Sponsored by Tamilnadu Energy Development Agency.

Institute of Wood Sciences and Technology (IWST) 2001 Wood Balance Study of Andhra Pradesh (draft), Institute of Wood sciences and Technology (ICFRE), Bangalore.

Jensen, M. 1995 Woodfuel Productivity of Agroforestry Systems in Asia-A review of current knowledge. Field Document No. 45. Regional Wood Energy Development Programme in Asia (GCP/RAS/154/NET). FAO Regional Office for Asia and the Pacific, Bangkok.

Joshi, V., Sinha, C.S., Karuppasawmy, M., Srivastava, K.K. and Singh, P.B. 1992 Rural Energy Data Base. TERI, New Delhi.

Krishnakutty, C.N. 1990. Demand and Supply of Wood in Kerala and their Future Trends. KFRI Research Report 67. Kerala Forest Research Institute, Peechi, Kerala. 66p.

Macauley, M., Naimuddin, M., Agarwal P.C. and Dunkerley, J. 1989 Fuelwood use in urban areas; a case study of Raipur, India. Energy Journal 10: 157-180.

Mahapatra, A.K. and Michell, C.P. 1999 Biofuel consumption, deforestation, and farm level tree growing in rural India. Biomass and Bioenergy 17: 291-303.

Ministry of Agriculture (MoA) 2000 Agricultural Statistics at a Glance 2000. Agricultural Statistics Division, Directorate of Economics \& Statistics, Department of Agriculture \& Cooperation, Ministry of Agriculture, Government of India, New Delhi.

Ministry of Environment and Forests (MoEF) 1999 National Forestry Action Programme-India Vol. 2. Ministry of Environment and Forests, Government of India, New Delhi. Under Project IND/ 93/021 of the UNDP and FAO. 
Ministry of Non-conventional Energy Sources (MNES) 2000 Annual Report 1999-2000. Ministry of Non-conventional Energy Sources, Government of India, New Delhi.

Natarajan, I. 1995a Improved Chulha Programme-How to Make it Effective. MARGIN JulySeptember: 381-385. National Council of Applied Economic Research (NCAER), New Delhi.

Natarajan, I. 1995b Trends in Firewood Consumption in Rural India. MARGIN 28: 41-47. National Council of Applied Economic Research (NCAER), New Delhi.

National Council of Applied Economic Research (NCAER) 1985 Domestic Fuel Survey with Special Reference to Kerosene Volume I. National Council of Applied Economic Research (NCAER), New Delhi. 296p.

National Council of Applied Economic Research (NCAER) 1988 (unpublished) Haryana Wood Balance Study. Sponsored by the Government of Haryana, Chandigarh. National Council of Applied Economic Research (NCAER), New Delhi. 240p.

National Council of Applied Economic Research (NCAER) 1993 (unpublished) Evaluation Survey of National Programme on Improved Chulha. National Council of Applied Economic Research (NCAER), New Delhi.

National Sample Survey Organisation (NSSO) 1997 Energy Used by Indian Households. Fifth Quinquennial Survey on Consumer Expenditure, July 1993-June 1994. National Sample Survey Organisation (NSSO), Department of Statistics, Government of India, New Delhi.

National Sample Survey Organisation (NSSO) 2001 Energy Used by Indian Households, NSS 55 $5^{\text {th }}$ Round, July 1999-June 2000. Report No. 464 (55/1.0/6). National Sample Survey Organisation (NSSO), Ministry of Statistics and Programme Implementation, Government of India, New Delhi. $26+132 p$.

Oil Coordination Committee (OCC) 2001 Personal Communication from the Oil Coordination Committee (OCC). Ministry of Petroleum and Gas, Government of India, New Delhi.

Operations Research Group (ORG) 1989 (unpublished) Wood balance in Orissa by 2000. Operations Research Group (ORG), Bhubaneshwar. Sponsored by Directorate of Social Forestry Project, Orissa. 127p.

Ostwald, M. 2000 Local Protection of Tropical Dry Natural Forest, Orissa, India. Ph.D. thesis, Department of Earth Sciences, Goteborg University, Sweden.

Pandey 1995 Forest Resources Assessment 1990: Tropical forest plantation resources. FAO Forestry Paper 128. FAO, Rome.

Pandey, D. 2000 Methodologies for Estimating Wood Resources in South Asia. Wood Energy News 15/1. Regional Wood Energy Development Programme in Asia (GCP/RAS/154/NET). FAO Regional Office for Asia and the Pacific, Bangkok.

Planning Commission, Government of India (PC) 1999 Ninth Five-year Plan 1997-2002. Volume II, Thematic Issues and Sectoral Programmes. Government of India Planning Commission (PC), New Delhi.

Planning Commission, Government of India (PC) 2000 Annual report on the working of the State Electricity Boards and Electricity Departments. Power and Energy Division, Planning Commission, Government of India, New Delhi.

Pinto, A.G., Khanna, P. and Pandey, C.N. 1985 (unpublished) Gujarat Wood Balance Study 1984. Gujarat State Forest Department, Vadodara.

Rai, S.N. 1981 Productivity of Tropical Rain Forests of Karnataka. Ph.D. Thesis, Botany Department, Bombay University.

Rai, S.N. and Chakrabarti, S.K. 1996 Demand and Supply of Fuelwood, Timber and Fodder in India. Forest Survey of India, Ministry of Environment and Forests, Dehradun. 36p.

Ranganathan, V., Subba Rao, S. and Prabhu, G.S. 1993 (unpublished) Demand and Supply of Fuelwood in Karnataka. For the Forest Department, Government of Karnataka. Indian Institute of Management (IIM), Bangalore. 187p.

Ravindranath, N.H., Somashekar, B.S. and Gadgil, M. 1992 Carbon emission and sequestration in forests: case studies for India and China. Lawerence Berkley Laboratory, LBL:32759 UC-402. LBL Berkley, USA. 
Ravindranath, N. H. and Hall, D.O. 1995 Biomass, Energy, and Environment: A developing country perspective from India. Oxford University Press. 367p.

Saxena, N.C. 1997 The Woodfuel Scenario and Policy Issues in India. Regional Wood Energy Development Programme in Asia (GCP/RAS/154/NET), FAO Regional Office for Asia and the Pacific, Bangkok.

Seebauer, M. 1992 Review of social forestry programme in India. GWB Gesselschaft Fur Walderhaltung und Waldbewirtschaftung GMBH, Michelstadt, Germany.

Singh, D.V. and Sikka, B.K. 1994 Forest Farming Conservation, Production and Consumption in Rural India, in special Reference to Social Forestry. AERC, H.P. University, Shimla. Mittal Publications. $x i+132 p$.

Singh, K. 1999 An evaluation of some selected social forestry models adopted in India. Working Paper 128. Institute of Rural Management, Anand. 21p.

Singh, K.D. 2000 Guidelines on National Inventory of Villages Forests. ISBN 979-8764-55-2. Center for International Forestry Research (CIFOR), Bogor, Indonesia.

Singh, K.D. A GIS Analysis of causes of chronic poverty among indigenous people in India (in preparation).

Tata Energy Research Institute (TERI) 1999 National Study on Joint Forest Management: Government Orders. Project Report No. 98 SF 64. Tata Energy Research Institute, New Delhi.

Tata Energy Research Institute (TERI) 2001 Teri Energy Data and Directory Year Book 2000/2001. Tata Energy Research Institute (TERI), Darbari Seth Block, Habitat Place, Lodi Road, New Delhi 110003.

Unni, N.V.M. 1995 Biomass Estimation and Changes in the Vegetal Cover in the Fuelwood Catchment of Hyderabad by Indian Resource and Management Technology Ltd. Hyderabad. A report prepared for the Institute of Energy and Environmental Studies, Hyderabad. 


\section{Appendix I. National, State and Local Level Studies}

\section{A. National Level Studies}

\section{A.1 Energy Consumption in Households and Selected Establishments of India}

Source: NCAER. 1985. Domestic Fuel Survey with Special Reference to Kerosene. Volume I. National Council of Applied Economic Research, New Delhi. 296p.

The study was carried out by the National Council of Applied Economic Research (NCAER), New Delhi, an autonomous body, with the sponsorship of the Indian Oil Corporation, Government of India, in the year 1978/9.

As per the terms of reference, the focus of the study was on the consumption of kerosene and LPG in households. But the study covered all the energy sources used in the household sector and establishments in rural and urban areas as the future projection of kerosene and LPG was related to the developments in other energy sectors. For example, kerosene in India has been used for dual purposes-lighting and heating. In rural areas, it is mostly used as an illuminant while urbanites use it for heating/cooking. The consumption of kerosene for lighting was expected to decline with the spread of rural electrification.

\section{Sampling Design and Methodology for Consumption}

The survey was designed to allocate samples in all the states in order to derive consumption estimates at the state level. Rural and urban areas in each state formed broad strata. Two recently concluded studies by the NCAER for rural and urban areas in the northern Indian states were used to decide the sample size of desired accuracy. A multistage sampling approach was followed. For the rural survey, the districts served as the first stage unit, villages the second stage and households the third and final stage units. In all, 300 districts and 600 villages (two 
from each district) were selected. For urban areas, cities and towns were grouped according to population size. All big cities with a population of more than 0.5 million were selected. The number of smaller towns being large, a progressively decreasing fraction of samples was drawn from urban centres with decreasing population size (population classes were 200-500, 100-200, 50-100, 20-50 and up to 20 thousand). In all, 312 cities/towns were selected, which formed the first stage unit. The NSSO divides towns into blocks of almost equal size for the purpose of sampling. These blocks have population of around 600 and formed the second stage unit. The number of blocks selected from each town varied from two to twenty depending on the size of the town, with a total of 1014. Households in the selected villages and blocks, which formed the final sampling units, were listed and arranged into five income groups. Since the number of households increased with decreasing income, the percentage of households selected from each income group increased with increasing income. In all, 12560 households -7875 from rural areas and 4685 from urban areas-were selected.

To estimate the fuel consumed by commercial and industrial establishments, about 8000 units were selected: 3200 from rural and 4800 from urban areas. Care was taken to cover all types of establishments.

The correlation between the fuel consumed for cooking per unit of food grain and the household income level was used to quantify the non-monetised energy consumed by households. The fuel consumption was worked out in terms of coal replacement. The quantity of food grain consumed daily per household was used to estimate the quantity of fuel used for rural and urban areas separately. Norms were established by crosschecking replies to a questionnaire furnished by households against the results of independent field studies/observations. The fuel used for water/space heating was worked out for the areas where it was practiced. In an earlier study, fuel consumption per worker in establishments was found to be fairly stable, hence this relationship was used to estimate consumption of fuel in this sector.

\section{Energy Consumption}

Energy consumption in the domestic sector in India was estimated at 148.7 million tonnes coal replacement ( $\mathrm{cr}$ ), of which 133.2 million $\mathrm{t}$ was in the household sector and the rest in the selected establishments. The national average of per capita consumption in the household sector was $206 \mathrm{kgcr}$. The per capita energy consumption in urban areas was $266 \mathrm{kgcr}$, whereas in rural areas it was $190 \mathrm{kgcr}$. Household energy consumption was positively correlated with income. The per capita energy consumption for households having an annual income of below INR 3000 was $192 \mathrm{kgcr}$, whereas for those with an income above INR 18000 it was $284 \mathrm{kgcr}$. The rise in rural areas was more modest compared to urban areas.

It was found that the households consumed around 95 million $t$ of fuelwood, one-third of which was logs and the rest was twigs. Twigs were mostly consumed in the villages where per capita consumption $(117 \mathrm{~kg})$ of this fuel was four times that of urban areas $(30 \mathrm{~kg})$. Logs, on the other hand, were more popular in cities, where per capita consumption $(83 \mathrm{~kg})$ was more than double that of the villages $(40 \mathrm{~kg})$. Of the total quantity of fuelwood consumed in the country, about 79 million $t$ were in rural areas and 16 million $t$ in urban areas.

The overall contribution of fuelwood, including sawdust and wood waste, was about $46 \%$ of the total energy consumed in the domestic sector, with $51 \%$ in the rural sector and $34 \%$ in the urban sector. The additional contribution of charcoal (derived from wood) was $1.6 \%$. The pattern of energy consumption in India is given in Table IA. 1.

The study has not explained the higher dependence on fuelwood in urban sectors of Kerala and Orissa compared to the rural sectors, which is contrary to the trend. Further, Jammu and Kashmir State has a temperate climate similar to Himachal Pradesh and per capita energy consumption is expected to be similar, but the study found the consumption in Jammu and Kashmir to be almost half that of Himachal Pradesh. 
Table I A. 1 Percentage contribution of various forms of energy used in the household sector in India in 1978/9

\begin{tabular}{lccr}
\hline Forms of energy & Rural areas & Urban areas & Total \\
\hline Coal/coke & 1.8 & 17.7 & 6.2 \\
Kerosene & 7.1 & 21.2 & 11.0 \\
Electricity & 1.8 & 9.3 & 3.9 \\
LPG & 0.1 & 8.5 & 2.4 \\
\hline Sum of com. energy & 10.8 & 56.7 & 23.5 \\
\hline Logs & 17.8 & 27.8 & 20.9 \\
Twigs & 33.7 & 7.0 & 25.8 \\
rop residue & 16.3 & 1.7 & 12.2 \\
Dung cake & 21.1 & 4.1 & 16.3 \\
Charcoal & 0.1 & 2.6 & 0.8 \\
Biogas & 0.1 & 0.0 & 0.1 \\
\hline Sum of non-com. energy & 89.1 & 43.2 & 76.1 \\
\hline Total & 100 & 100 & 100 \\
\hline
\end{tabular}

Note. Totals may not tally due to rounding

Table I A. 2 Per capita consumption of fuelwood in rural and urban areas of different states in $1978 / 9$ in $\mathrm{kg}$, along with percentage of the total

\begin{tabular}{lrr}
\hline States & Rural & \multicolumn{1}{c}{ Urban } \\
\hline Andhra Pradesh & $201(70 \%)$ & $115(50 \%)$ \\
Assam & $193(69 \%)$ & $120(42 \%)$ \\
Bihar & $119(30 \%)$ & $54(16 \%)$ \\
Gujarat & $147(50 \%)$ & $79(23 \%)$ \\
Haryana & $51(19 \%)$ & $39(14 \%)$ \\
Himachal Pradesh & $478(87 \%)$ & $278(58 \%)$ \\
Jammu \& Kashmir & $237(63 \%)$ & $167(39 \%)$ \\
Karnataka & $218(75 \%)$ & $171(55 \%)$ \\
Kerala & $149(59 \%)$ & $220(63 \%)$ \\
Madhya Pradesh & $171(56 \%)$ & $168(52 \%)$ \\
Maharastra & $163(62 \%)$ & $82(23 \%)$ \\
Meghalaya & $282(77 \%)$ & $112(23 \%)$ \\
Orissa & $167(61 \%)$ & $253(69 \%)$ \\
Punjab & $92(27 \%)$ & $46(5 \%)$ \\
Rajasthan & $208(71 \%)$ & $144(39 \%)$ \\
Tamilnadu & $172(64 \%)$ & $166(53 \%)$ \\
Uttar Pradesh & $141(49 \%)$ & $121(42 \%)$ \\
West Bengal & $91(24 \%)$ & $13(4 \%)$ \\
Delhi & $101(28 \%)$ & $19(4 \%)$ \\
\hline Total & $157(51 \%)$ & $113(34 \%)$ \\
\hline
\end{tabular}




\section{Sources and Supply of Fuelwood}

The questionnaire on sources of collection was also analysed. Of the total 31.6 million $t$ of logs consumed, 19.7 million $\mathrm{t}$ were purchased from markets and the remaining 11.9 million $\mathrm{t}$ were collected. The purchased logs were assumed to have originated from the forests, since the recorded figure from forest departments tallied with it. More than $90 \%$ of twigs were collected from different sources. The breakdown of the collection of logs and twigs is provided in Table IA.3.

Table I A. 3 Percentage of fuelwood collected from different sources

\begin{tabular}{lccc}
\hline $\begin{array}{l}\text { Source of fuelwood } \\
\text { collection }\end{array}$ & $\begin{array}{c}\text { Logs (total quantity } \\
\mathbf{3 1 . 6} \text { million } \mathbf{~})\end{array}$ & $\begin{array}{c}\text { Twigs (total quantity } \\
\mathbf{6 3} \text { million t) }\end{array}$ & $\begin{array}{c}\text { Fuelwood (total quantity } \\
\mathbf{9 4 . 6} \text { million } \mathbf{~} \text { ) }\end{array}$ \\
\hline Own source & 17.2 & 31.2 & 26.5 \\
Forests & 15.3 & 31.0 & 25.7 \\
Roadside & 4.2 & 23.6 & 17.1 \\
Others & 1.0 & 5.0 & 3.6 \\
Market & 62.4 & 9.3 & 27.0 \\
\hline Total & 100 & 100 & 100 \\
\hline
\end{tabular}

\section{Comments}

The study has tried to make a realistic assessment of the energy consumption for cooking food on the basis of the food grain consumed in households, besides using a questionnaire. The replies of consumers were crosschecked against sampled field trials. However, on the supply aspect, no detailed investigation has been made to learn if the fuelwood collected was from private farms, common land or elsewhere. It is possible that the consumers, when served with a questionnaire, may hide the information on the cutting of trees from forest areas due to fear of being punished. As it was a single visit survey, it was not possible to observe the flow of fuelwood to the households from actual sources. The entire volume of the marketed fire logs has been assumed to be the part of the recorded production from forests which may not be correct, as in many areas people in economic distress collect fuelwood from common land, roadsides etc. for trading. 


\section{A.2 Trends in Firewood Consumption in Rural India}

Source: NCAER. 1993. Evaluation Survey of National Programme on Improved Chulha (unpublished). National Council of Applied Economic Research, New Delhi.

The National Council of Applied Economic Research undertook the study, with the sponsorship of the Ministry of Non-conventional Energy Sources (MNES), Government of India. The main purpose was to estimate the fuel efficiency of improved cooking stoves in field conditions relative to traditional cooking stoves popularised under different schemes of the MNES. The questionnaire was also designed to collect information on the fuel consumption pattern. The survey was conducted in 1992.

\section{Sampling Design and Methodology for Consumption}

The country was divided into six zones (North, South, East, Northeast, West and Central) for the purpose of data collection, aggregation, analysis and presentation of the results. The size of the sample (16 000 households) was decided in advance, based on the previous results of the survey done by this organisation. The civil districts were selected independently from each state with probability proportional to the total number of improved stoves installed during the last three years (1988-1991) in the districts. From the 173 selected districts, one to three blocks were selected from each, depending upon the availability of improved stoves. A multistage stratified sample design was used to select sample households of improved stove owners. At the first stage, a random sample of villages was drawn from each block after stratifying the villages by year of installation of improved stoves and eight households owning improved stoves were then selected from each village. An additional sample of $10 \%$ of households was selected to be kept on the reserve list so that if the households in the main sample were found not to own improved stoves, they could be replaced. In all, 16167 households were finally selected in the survey from 1622 villages, which included about 3000 households owning traditional cooking stoves. In 118 villages, the fuel efficiency of improved cooking stoves was estimated through actual weighing of the fuel. The data collected from households through the questionnaire was also supplemented with a village schedule filled in after detailed discussion with selected villagers, village level workers and important persons. The focus of the study was to identify problems and solutions to improve the National Programme on Improved Chulhas.

\section{Energy Consumption}

The total consumption of energy for rural households in 1993 was estimated at 153.8 million tonnes of coal replacement (cr). The average annual growth of fuel consumption during 1979-93 was about $4 \%$. The per capita consumption of fuel in the rural household sector increased from $190 \mathrm{kgcr}$ in 1979 to $241 \mathrm{kgcr}$ in 1993.

Wide variation was observed in the share of fuel and average energy consumption per household between different zones. The share of fuelwood used was highest $(92 \%)$ in the Northeast zone (Assam, Arunachal Pradesh, Manipur, Meghalaya, Mizoram, Nagaland and Tripura states) which is endowed with rich forest wealth covering about $64 \%$ of the geographic area of the zone (FSI 2000). The use of kerosene was highest in the North (Haryana, Himachal Pradesh, Jammu and Kashmir, Punjab, Uttar Pradesh and Delhi) and West (Gujarat Maharastra and Goa) zones. The use of dung cake was highest in the North and Central (Madhya Pradesh and Rajasthan) zones.

The study revealed that the use of the fuelwood, mainly in log form, increased sharply, which might be the result of massive afforestation efforts under social/community forestry plantations made during these years. A definite shift in the quality of fuelwood consumed was seen. More logs were being used in the rural areas. On the other hand, the share of crop residue and dung cake has declined during these years as they have been substituted by fuelwood, kerosene and LPG. 
Table I A.4 Energy consumption pattern by household in rural India during 1979 and 1993

\begin{tabular}{lrr}
\hline Form of energy & \multicolumn{2}{c}{ Rural } \\
\cline { 2 - 3 } & 1979 & 1993 \\
\hline Fuelwood & 54.6 & 19.0 \\
(i) logs & 35.6 & 61.6 \\
(ii) twigs & 32.5 & 29.1 \\
Crop residue & 17.4 & 13.4 \\
Dung cake & 22.5 & 17.0 \\
Soft coke/coal & 1.9 & 0.4 \\
Kerosene & 2.6 & 4.4 \\
Others & 1.0 & 3.2 \\
\hline Total & 100 & 100 \\
\hline
\end{tabular}

'Others' in the table include LPG, biogas and charcoal.

\section{Sources and Supply of Fuelwood}

The analysis of the questionnaire on sources of fuelwood revealed that the share of collected firewood logs in 1993 by households increased to $84 \%$ compared to $33 \%$ in 1979. Nearly half of the households collected wood from their own sources, which farmers were growing on their own farms and homesteads. About $16 \%$ of the households were reported to have purchased firewood logs from the market. The share of different sources of collection of fuelwood underwent a change during 1979-1993, as shown in Table I A.5 (Natrajan 1995b).

Table I A.5 Major sources of collection of fuelwood in rural India

\begin{tabular}{lcc}
\hline Sources & 1979 & 1993 \\
\hline Own Farm & 35.2 & 48.5 \\
Roadside & 23.9 & 29.8 \\
Forests & 35.4 & 17.0 \\
Others & 5.5 & 4.7 \\
\hline Total & 100 & 100 \\
\hline
\end{tabular}

'Others' include collection from the neighbours' trees or from the land where they worked.

Collection from forests was highest, about 30\%, in the Northeast and East (Bihar, Orissa, West Bengal, Sikkim and Andaman and Nicobar Islands) zones.

\section{Comments}

Though the samples were widely spread across the country, representing different agro-climatic zones, the sample households purposely selected were mainly those who owned improved stoves. The procedure, when viewed from all types of energy use, is biased and therefore less reliable. The study, however, presents a trend in rural energy consumption in 1993 and also reveals the transition from inferior fuel to solid wood in the last 14 years. The estimation of sources of fuelwood made only on the basis of the questionnaire has limited reliability. In the Northeast zone, where forest cover is very rich and most of the villages have government forests, it is expected that almost $100 \%$ of rural fuelwood needs are met from forests, but the study has estimated only $30 \%$. 


\section{A.3 A National Estimate of Fuelwood Consumption}

Source: Rai, S.N. and Chakrabarti, S.K. 1996. Demand and Supply of Fuelwood, Timber and Fodder in India. Forest Survey of India, Ministry of Environment and Forests, Dehradun. 36p.

The study was undertaken on the initiative of the Planning Commission of India, which constituted a committee in 1996 to look at the demand and supply situation of fuelwood, timber and fodder required for the preparation of the country's 9th Five-year Plan (1997-2002). The study was carried out as deskwork, by reviewing the fuelwood/wood consumption studies done by the Forest Survey of India (FSI) and other organisations in the past.

\section{Sampling Design and Methodology for Consumption}

The study placed most reliance on the wood consumption studies done from time to time by the FSI. It should be noted that wood consumption studies, which include fuelwood, are secondary activities of this organisation and done at low intensity. In the methodology, the district is stratified firstly into two parts: rural and urban. The rural areas are then stratified into villages within $5 \mathrm{~km}$ of forests and villages beyond $5 \mathrm{~km}$ from forests. The households of the selected villages from both strata are classified into low-income and high-income groups and then 10 households are selected from each village. Similarly, urban centres are classified according to population into small (less than 50 000) and large (more than 50000 ) centres, and households from the selected centres are stratified according to income groups. Households are then selected from urban centres and surveyed. Compilation of the wood consumption studies is done at the level of districts or groups of districts.

In the present study, 67 of the wood consumption studies (district or group of districts) done between 1970 and 1994 in 19 states were used. The majority of studies were done in the early 1980 s and only a few in the 1990s, and were mostly for the forested districts of the country.

The study assumed that the entire rural population of the forested districts (having more than $50 \%$ forest cover) depended on forests for fuelwood. In districts with less than $50 \%$ forest cover, dependence was only half. The state population in the base year (1996) was multiplied by the per capita consumption to estimate the total consumption. For states where FSI data was not available (almost all states for non-forest rural areas and 13 states for urban areas), the per capita estimates of the NCAER (1985) were used.

\section{Energy Consumption}

The per capita fuelwood consumption of the forested area of the country obtained by the Forest Survey of India studies done from time to time and aggregated at the state level is given in Table I A.6.

The annual consumption of fuelwood by the rural population residing in the vicinity of the forests was estimated at 78 million $\mathrm{t}$, and by those residing in the non-forested area, 74 million t. The averages per capita were $424 \mathrm{~kg}$ (incorrectly estimated at $539 \mathrm{~kg}$ in the report) and $144 \mathrm{~kg}$ respectively.

To estimate the total consumption in urban areas, a few assumptions were made. It was assumed that in big cities with a population of more than 1 million, only $10 \%$ of the population uses fuelwood, and in those between 0.5 and 1 million, $20 \%$ of the population and so on. Separate assumptions were made for those who live in the hilly regions of the country. The total fuelwood demand of the urban areas of the country was roughly estimated to be 10 million $t$, giving an average per capita of $140 \mathrm{~kg}$.

Annual consumption by tile/brick kilns, the tobacco drying industry and other cottage industries was assumed at 25 million $\mathrm{t}$; by tea shops, restaurants etc., 10 million $\mathrm{t}$; and for the cremation 
Table I A.6 Per capita consumption of fuelwood in the forested districts of the country (in kg)

\begin{tabular}{lrr}
\hline State & Rural & Urban \\
\hline Andhra Pradesh & 190 & - \\
Arunachal Pradesh & 423 & 386 \\
Assam & 338 & 435 \\
Bihar & 369 & 112 \\
Himachal Pradesh hills/plains & $689 / 550$ & 440 \\
Jammu \& Kashmir & 949 & - \\
Karnataka & 406 & 314 \\
Madhya Padesh & 576 & 259 \\
Maharastra & 318 & - \\
Manipur & 1320 & 396 \\
Meghalaya & 712 & - \\
Mizoram & 1159 & 660 \\
Nagaland & 1299 & 1008 \\
Rajasthan & 391 & - \\
Sikkim & 1182 & 926 \\
Tripura & 814 & 522 \\
Uttar Pradesh hills/plains & $652 / 592$ & - \\
West Bengal & 563 & 122 \\
\hline
\end{tabular}

of dead bodies and other religious activities, 4 million $t$. The total consumption of fuelwood in the country during 1996 was estimated at 201 million t.

\section{Sources and Supply of Fuelwood}

A few assumptions were made to estimate the supply of fuelwood. It was assumed that all fuelwood consumed by the forested rural households was supplied by the forests and that consumed by non-forested rural households was supplied by non-forest areas. The estimated consumption of 78 million $t$ and 74 million $t$ gave a ratio of 51:49 from forest and non-forest areas, respectively. This ratio was assumed to hold good on the total demand of 201 million $t$. The supply from forests was thus estimated at 103 million $\mathrm{t}$ and the remaining 98 million $\mathrm{t}$ from farm forestry and other wooded land outside forests. Using a tentative estimate of the annual increment ( 87.6 million $\mathrm{m}^{3}$ ) of India's forests and assuming $30 \%$ to be the fuelwood component, it was estimated that only 17 million $t$ of fuelwood could be removed annually from India's forests on a sustained basis. The study concluded that the removal of an additional 86 million $t$ of fuelwood was an excess drain on India's forests.

\section{Comments}

To arrive at the per capita consumption figures at state level, surveys done by FSI at district and catchment levels in different timeframes have been aggregated. Per capita consumption therefore does not pertain to any reference year; neither survey was designed to calculate state level consumption. Further, the study has used the per capita consumption data mostly estimated during the late 1970s and early 1980s, thus the data is more than 15 years older than the study period (1996). The energy consumption pattern in the households during this period, particularly in the urban areas, changed a lot due to the substitution of commercial energy.

There is a little justification for several assumptions that were made in order to estimate the consumption. The entire rural population of a forested district would not necessarily depend on 
forests. Rather, it would depend on the proximity of a village/rural centre to the forests. The assumptions made on the percentage of fuelwood dependent on the urban population are crude.

The supply aspect of fuelwood is also based on many assumptions. The tentative annual increment of India's forests and the fuelwood component out of it are based on traditional inventory methods, which do not include trees below $10 \mathrm{~cm}$ in diameter, twigs or fallen branches. The quantity of sustainable supply of fuelwood from India's forests worked out by this study is, therefore, an underestimate. This quantity, however, matches well with the recorded supply quoted in other national estimates (Planning Commission)/studies. 


\section{A.4 Energy Used by Indian Households in 1993/4}

Source: NSSO 1997. Energy Used by Indian Households, Fifth Quinquennial Survey on Consumer Expenditure, July 1993-June 1994. National Sample Survey Organisation (NSSO), Department of Statistics, Government of India, New Delhi.

The National Sample Survey Organisation (NSSO), a government institution with about 6000 regular staff spread over the country, regularly conducts all-India household surveys on consumer expenditure and employment. The detailed study on consumer expenditure is done through quinquennial surveys. The report presented below is based on the $5^{\text {th }}$ Quinquennial Survey done during 1993/4.

\section{Sampling Design and Methodology for Consumption}

A stratified two-stage sampling is designed to conduct the national survey. The first stage units are villages in the rural sector and urban frame survey blocks for the urban sector. The second stage units are households. Each state/union territory is first divided into agro-economic regions by grouping contiguous districts. In the 1993/4 survey, the total number of regions formed in the entire country was 78 . The allocation of first stage sample size in the rural or urban sector to any state/union territory is dependent on the size of the population, with a double weighting to the urban sector. Urban blocks in towns with a population of more than 400000 are placed in different strata depending on whether they belong to the affluent area of the town or not, so as to allocate a larger proportion of the sample to affluent sections of society to improve the precision of consumer expenditure figures. Sample villages were selected by probability proportional to size circular systematic sampling (with population as the size variable). One of the basic criteria for selecting the households from selected villages/urban blocks was to allocate a larger proportion of the sample to the affluent section of the population wherever possible as this class has a very wide consumer expenditure range. In total, 115354 households spread over 6951 sample villages and 4650 urban blocks were surveyed in 1993/4.

It should be noted that in the consumer expenditure survey, the expenditure incurred by a household on domestic consumption is recorded, which includes fuels for cooking and light, and not the quantity. The expenditure includes the monetary value of all items whether purchased, homegrown, collected free of charge etc. The survey, therefore, does not provide information on the quantity of the energy consumed/per capita consumption of fuelwood etc., rather, expenditure on different types of fuels in the households and their percentage contribution. Unlike other household energy surveys, crop residue has not been assigned a separate category but combined under the heading 'firewood and chips'.

\section{Energy Consumption}

The survey found that firewood and chips were the most important and prevalent primary source of energy for cooking in rural India, with around $78 \%$ of rural households dependent upon it. This percentage has not changed in the last 10 years. In the urban sector, dependence on firewood and chips has declined sharply from $46 \%$ in 1983/4 to 30\% in 1993/4 because of interfuel substitution, mainly by LPG and kerosene. Though dung cake remained the next most important source of fuel in the rural sector $(11.5 \%)$, its percentage has declined by $3 \%$. In urban areas, the consumption of coke/coal has also declined sharply from $16.6 \%$ to $5.7 \%$ but the consumption of kerosene has increased. There is overall, radical change in energy use, mainly in the urban sector, over the 10 years due to increased availability of LPG and kerosene. The changes in the rural sector are only marginal. The dependence on various forms of energy in the household sector based on two quinquennial surveys of the NSSO is shown in Table I A.7. 
Table I A. 7 Energy consumption pattern by households in India during 1983/4 and 1993/4

\begin{tabular}{lccccr}
\hline Form of energy & \multicolumn{2}{c}{ Rural } & & \multicolumn{2}{c}{ Urban } \\
\cline { 2 - 3 } \cline { 5 - 6 } & $\mathbf{1 9 8 3 / 4}$ & $\mathbf{1 9 9 3 / 4}$ & & $\mathbf{1 9 8 3 / 4}$ & $\mathbf{1 9 9 3 / 4}$ \\
\hline Firewood and chips & 77.0 & 78.2 & & 46 & 29.9 \\
Dung cake & 14.5 & 11.5 & & 2.8 & 2.4 \\
Biogas & - & 0.3 & & - & 0.1 \\
Coke/coal & 1.9 & 1.4 & & 16.6 & 5.7 \\
LPG & 0.8 & 1.9 & & 10.3 & 29.9 \\
Kerosene & 0.8 & 2.0 & & 16.7 & 23.2 \\
No cooking & $?$ & 0.7 & & $?$ & 6.3 \\
Others & $?$ & 3.8 & & $?$ & 2.6 \\
\hline Total & $95 / 100$ & 100 & & $92.4 / 100$ & 100 \\
\hline
\end{tabular}

It has been observed that, as the monthly per capita expenditure level rises, the households tend to switch over to LPG use. On the other hand, households with lower expenditure levels continue using firewood and chips in both sectors at the national level.

The 'no cooking arrangement' situation was more prevalent in urban households in general, possibly due to the greater availability of restaurants and eating-houses. It was observed that a comparatively higher percentage of households from the highest and the lowest expenditure classes eat out compared to the middle classes, for economic reasons.

The percentage contribution of 'firewood and chips' to household fuel expenses in different states in India in 1993/4 is given in Table I A.8.

LPG was the major source of energy in urban households in Goa (43\%), Gujarat (40\%), Haryana (39\%), Himachal Pradesh (45\%), Jammu \& Kashmir (56\%), Maharastra (39\%) and Punjab (41\%) whereas the forest-rich states of the northeast (Arunachal Pradesh, Assam, Manipur, Mizoram, Nagaland, Tripura) depended on firewood as a major source. The urban households of Bihar (39\%) and West Bengal (30\%) had major dependence on coal because its extraction is high in these states and it is more conveniently available. The states where a larger percentage of urban households depended on kerosene, compared with the national average, were Goa (37\%), Maharastra (38\%), Meghalaya (30\%), Punjab (36\%) and Sikkim (54\%).

\section{Comments}

The coverage of the survey is very wide and comprehensive, thus the trend of household energy expenses it reveals is quite reliable. Crop residue is an important energy source for rural India and makes a very significant contribution to the total domestic energy, as revealed by other studies, but because it is combined with fuelwood, its contribution and trend have been lost. Prices of the firewood and chips vary in time and space; it may not be possible to estimate their actual share in terms of total energy consumption/quantity, but only of expenditure. No assessment has been made of the supply/source aspect of firewood and chips. 
56 - Devendra Pandey

Table I A.8 Percentage contribution of firewood and chips to household fuel expenses in 1993/4

\begin{tabular}{|c|c|c|}
\hline State/UT & Rural & Urban \\
\hline Arunachal Pradesh & 97.0 & 48.7 \\
\hline Andhra Pradesh & 93.7 & 44.1 \\
\hline Assam & 97.2 & 44.1 \\
\hline Bihar & 63.4 & 21.8 \\
\hline Goa & 65.3 & 17.9 \\
\hline Gujarat & 78.7 & 16.1 \\
\hline Haryana & 68.3 & 23.8 \\
\hline Himachal Pradesh & 88.6 & 13.7 \\
\hline Jammu \& Kashmir & 80.6 & 8.8 \\
\hline Karnataka & 93.9 & 36.2 \\
\hline Kerala & 92.1 & 70.1 \\
\hline Madhya Pradesh & 91.1 & 41.4 \\
\hline Maharastra & 76.7 & 13.8 \\
\hline Manipur & 94.3 & 64.6 \\
\hline Meghalaya & 96.2 & 24.9 \\
\hline Mizoram & 97.9 & 53.2 \\
\hline Nagaland & 98.7 & 68.6 \\
\hline Orissa & 88.9 & 42.3 \\
\hline Punjab & 50.7 & 14.5 \\
\hline Rajasthan & 90.0 & 39.0 \\
\hline Sikkim & 72.6 & 2.7 \\
\hline Tamilnadu & 91.3 & 42.9 \\
\hline Tripura & 98.7 & 74.1 \\
\hline Uttar Pradesh & 62.7 & 39.1 \\
\hline West Bengal & 61.3 & 8.4 \\
\hline Andaman \& Nicobar Is & 74.1 & 18.9 \\
\hline Chandigarh\# & 9.6 & 5.0 \\
\hline Dadra \& Nagar Haveli & 92.5 & 27.8 \\
\hline Daman and Diu & 54.3 & 4.3 \\
\hline Delhi \# & 1.3 & 2.1 \\
\hline Lakshadweep & 91.1 & 83.2 \\
\hline Pondicherry & 93.8 & 51.4 \\
\hline Total & 78.2 & 29.9 \\
\hline
\end{tabular}

\# These territories have mostly urban dwellers. 


\section{A.5 Energy Used by Indian Households in 1999/2000}

Source: NSSO 2001. Energy Used by Indian Households, NSS 55 th Round, July 1999-June 2000. National Sample Survey Organisation (NSSO), Ministry of Statistics and Programme Implementation, Government of India, New Delhi. Report No. 464 (55/1.0/6) August 2001. 26 + A132p.

The National Sample Survey Organisation (NSSO), collected primary data on sources of energy for cooking and lighting as auxiliary information for households throughout the country while conducting the sixth quinquennial ( $55^{\text {th }}$ Round) survey on Household Consumer Expenditure during July 1999-June 2000. The report of this survey is presented in the following paragraphs.

\section{Sampling Design and Methodology for Consumption}

The sampling design and methodology was similar to that adopted during fifth quinquennial survey in 1993/4 through a nationwide network of centres. An additional feature was the classification of households by employment type and social groups, besides household expenditure levels. In total, 120309 households spread over 6046 sample villages and 4116 urban blocks were surveyed in 1999/2000.

As in the previous surveys, NSSO analysed the expenditure incurred by households on domestic fuels for cooking, and not the quantity. The survey, therefore, does not provide information on the quantity of energy consumed or per capita consumption of fuelwood etc. Crop residue was combined under the heading 'firewood and chips'.

\section{Energy Consumption}

The survey found that the firewood and chips continued to be the most important source of energy for cooking in rural India. The dependence had, however, declined by about 3\% during the period $1993-1999$ to $75 \%$. This decline is mainly due to the increasing availability of LPG, the use of which increased from $1.95 \%$ to $5.4 \%$ during the period. There was a marginal decline in the use of dung cake to $10.6 \%$ compared to $11.5 \%$ in $1993 / 4$. The use of kerosene increased slightly to $2.7 \%$ from $2 \%$.

In the urban sector, the trend of rapid decline of firewood and chips use continued and came down to $22 \%$ in 1999 from $30 \%$ in 1993/4. On the other hand, the contribution of LPG to household energy increased from $30 \%$ to $44 \%$ during the period. The changes in the remaining forms of energy used were marginal.

Like earlier studies, this survey also found that rural people belonging to lower income groups used more firewood and chips and dung cake, and those of the higher income groups used more LPG and kerosene in rural areas and LPG in urban areas. The percentage contribution of various forms of energy used in the household sector for cooking in India in 1999/2000 are shown in Table I A. 9.

Statewise, the contribution of fuelwood to household energy is provided in Table I A.10. It can be seen that the pattern of firewood and chips consumption for cooking was almost similar in the rural areas of all the major states except Haryana, Punjab and Uttar Pradesh, where the use of dung cake was relatively common (more than 30\%). The use of dung cake in Bihar was $24 \%$, and in Orissa and West Bengal, about $5 \%$ each. In rural Goa, where the use of firewood and chips was relatively low, LPG substituted it to the extent of $39 \%$. Other major states where the use of LPG in rural households is quite high are Himachal Pradesh $(20.6 \%)$, Haryana $(18.4 \%)$, Punjab (14.2\%), Kerala (11.6\%), Gujarat (10.3\%) and Maharastra (9\%). Coke/coal was significantly consumed mainly in the rural areas of two states: West Bengal (6.6\%) and Bihar (5.1\%). 
Table I A. 9 Percentage contribution of various forms of energy used in the household sector for cooking in India in 1999/2000

\begin{tabular}{lcc}
\hline Form of energy & Rural & Urban \\
\hline Firewood and chips & 75.5 & 22.3 \\
Dung cake & 10.6 & 2.1 \\
Biogas & 0.3 & 0.1 \\
Coke/coal & 1.5 & 4.1 \\
LPG & 5.4 & 44.2 \\
Kerosene & 2.7 & 21.7 \\
No cooking & 1.1 & 4.3 \\
Others & 2.8 & 1.2 \\
\hline Total & 100 & 100 \\
\hline
\end{tabular}

Table I A.10 Percentage contribution of firewood and chips to household fuel expenses during 1999/2000

\begin{tabular}{lrr}
\hline State/UT & Rural & Urban \\
\hline Arunachal Pradesh & 85.7 & 21.9 \\
Andhra Pradesh & 87.1 & 27.1 \\
Assam & 93.4 & 34.1 \\
Bihar & 63.4 & 25.7 \\
Goa & 43.7 & 9.8 \\
Gujarat & 77.6 & 10.7 \\
Haryana & 49.4 & 19.3 \\
Himachal Pradesh & 72.5 & 6.4 \\
Jammu \& Kashmir & 78.5 & 15.9 \\
Karnataka & 86.9 & 23.2 \\
Kerala & 84.7 & 54.1 \\
Madhya Pradesh & 92.7 & 34.6 \\
Maharastra & 70.2 & 9.7 \\
Manipur & 85.9 & 37.7 \\
Meghalaya & 96.5 & 23.5 \\
Mizoram & 89.3 & 20.0 \\
Nagaland & 92.6 & 38.8 \\
Orissa & 89.4 & 43.2 \\
Punjab & 34.9 & 11.3 \\
Rajasthan & 31.2 \\
Sikkim & 93.0 & 6.6 \\
Tamilnadu & 69.9 & 23.3 \\
Tripura & 85.9 & 41.4 \\
Uttar Pradesh & 94.4 & 30.5 \\
Andast Bengal & 57.3 & 12.1 \\
Chandigarh\# & 78.5 & 0.0 \\
Dadra \& Nagar Haveli & 3.0 \\
Daman and Diu & 11.5 & 3.0 \\
Delhi \# & 72.4 & 0.0 \\
Lakshadweep & 28.4 & 0.0 \\
Pondicherry & 0.0 \\
\hline Total & 72.7 & 50.0 \\
\hline & 74.3 & 21.3 \\
\hline
\end{tabular}


The use of LPG was dominant in the urban areas of most of the states except in Orissa (16.9\%), Bihar $(27.9 \%)$ and Kerala (31\%). LPG and kerosene constituted more than $70 \%$ of urban household energy in the states of Maharastra, Gujarat, Haryana, Punjab, Tamilnadu, Goa, Sikkim and Karnataka besides centrally administered territories where fuelwood consumption is nil/negligible.

\section{Comments}

Though the survey provides reliable, and the most recent, data on the trend in the use of energy by households at the national level, it does not provide information on the fuelwood quantity consumed. The consumption of fuelwood for other activities in the domestic sector such as restaurants, brick kilns, potteries, hostels, body cremation etc. have not been accounted for. The supply and source of fuelwood has also not been assessed. 


\section{A.6 Consumption and Sources of Fuelwood in India}

Source: Ravindranath, N. H. and Hall, D.O. 1995. Biomass, Energy, and Environment: A developing country perspective from India. Oxford University Press. 367p.

The authors have estimated the consumption and sources of fuelwood in India using mostly secondary data. The primary data source is only of a few villages.

\section{Sampling Design and Methodology for Consumption}

For estimating the consumption of fuelwood for cooking in rural India, the lowest figure (181 million t) quoted by Joshi et al. (1992) from the rural energy database was accepted because this estimate was close to the estimates of FSI (1988), NCAER (1985) and FAO (1993).

Fuelwood use in the urban domestic sector was estimated at 30 million $t$, assuming the Karnataka level of consumption as reported by Ranganathan et al. (1993) to be valid in all the urban areas of the country.

The requirement for rural brick kilns was estimated at 6 million $t$ by assuming the country's total brick requirements and multiplying it by $0.25 \mathrm{~kg}$ fuelwood burnt per brick. Similarly, fuelwood consumption in establishments (restaurants, bakeries, hostels, rituals etc.) in urban areas was estimated by assuming the Raipur rate (Macauley et al. 1989) of fuelwood use to be valid for all towns with a population of less than 1 million, and Hyderabad-type use (Alam et al. 1985) for a population of more than 1 million. This gave a national estimate of 10 million $t$ of fuelwood used in urban establishments.

The total consumption of fuelwood in the country was estimated to be 227 million $t$.

\section{Sources and Supply of Fuelwood}

For estimating the fuelwood supply from forests, the standing biomass in the forests was first estimated using available data from biomass studies in different forest types and areas of forest cover by major forest types. In some cases extrapolation was done. The total biomass of India's forests (about 64 million ha) was estimated to be 8057 million t or $126 \mathrm{t}$ per ha. The annual increment for some forest types, estimated on the basis of research studies, was extrapolated and the total annual increment for India's forests was estimated at 138 million $t$, of which branches and twigs accounted for 42 million t, i.e. $31 \%$ of the total biomass as reported by Seebauer (1992). The first author, along with others, made these estimates earlier in a separate study (Ravindranath et al. 1992). It was also assumed that the annual increment in the form of branches and twigs (42 million $\mathrm{t}$ ), was removed by rural and tribal households who were allowed to carry headloads for self consumption or sale in nearby markets. The recorded annual supply of fuelwood by the Forest Departments from their depots in the form of cut logs and branches, as quoted by FSI (1988) at 19 million t, was assumed valid. In addition, 31\% was assumed as logging waste comprising branchwood and twigs to be available as fuelwood while producing timber. Assuming 21 million t of timber were produced during the 1990s from the forests, 9.5 million $\mathrm{t}$ of logging waste were available to be collected freely or on payment by the local communities. Thus the total contribution of forests to meeting fuelwood demand was estimated to be 70.5 million $\mathrm{t}$.

Tree plantations raised in the country since 1980 are mostly outside forests. These plantations make a substantial contribution to fuelwood. Of the total 17 million ha plantations established during 1975-92, about 50\% were assumed in the farm forestry sector. It was assumed that these plantations produced $4.5 \mathrm{t} / \mathrm{ha} /$ year of woody biomass. The remaining plantations on degraded forestlands and on village commons produced $2.6 \mathrm{t} / \mathrm{ha} /$ year. Of the total productivity of 57.8 million $\mathrm{t}, 17.8$ million $\mathrm{t}$ was assumed as industrial timber and the remaining 40 million $\mathrm{t}$ as fuelwood. 
The contribution of trees growing on farms and homesteads to meet fuelwood requirements was estimated on the basis of limited data. Data from only five villages-one in south India, two in north India and two in northwest India-were available. Using the average number of trees per farm for different regions, the total number of farms in the country and biomass per tree, the total standing biomass at the national level was estimated. By assuming an annual increment of $2.84 \%$ in the standing biomass, the annual supply of fuelwood estimated from farms was 46 million $\mathrm{t}$. Similar assumptions gave 16 million $\mathrm{t}$ of fuelwood from homesteads.

Assumptions were also made about the availability of woody biomass from village commons and degraded forestlands, which comprise an estimated area of about 52.8 million ha. In the absence of any data on the vegetation status of such lands, an annual increment of $0.5 \mathrm{t} / \mathrm{ha} /$ year was assumed, making the total fuelwood contribution 26 million t. Similarly, additional woody biomass of about $0.25 \mathrm{t} / \mathrm{ha}$ /year was assumed as productivity from the shrubs of the 52.8 million ha of degraded non-forest and 25.7 million ha of open (degraded) forests, with a total fuelwood contribution of 19.6 million t per year.

Thus the estimated fuelwood supply from all sources makes a total of 218.5 million t annually.

\section{Comments}

The estimate of fuelwood consumption has been assumed on the basis of other estimates. On the source and supply aspect, some of the assumptions made are too hypothetical. It is not possible to collect branches and twigs ( 42 million $\mathrm{t}$ ) from all over the forests, as a lot of forest areas are inaccessible and far from habitation. Further, fuelwood is generally supplied from dead/fallen trees/lops and tops of the trees cut for the production of timber, and not by clearfelling of forests. The estimate of recorded supply therefore includes a major part of the wastewood produced while harvesting 21 million t of timber.

The assumption of about $2.84 \%$ annual productivity from the standing biomass of trees on farms is a gross underestimate. Inventories have revealed that at least $50 \%$ of tree species on farmlands have a rotation period of less than 10 years. Based on the growth rate of the species, an average estimate in a village level case study (Chaturvedi 1990) was about 7\% of the standing growing stock.

There is some duplication in estimating the annual production from forest areas. The annual yield of fuelwood has been estimated from the total forest cover (64 million ha), which includes 27.5 million ha of open forests. The area of open forests has been included again in degraded land for estimating fuelwood productivity. Similarly, trees on farmlands form part of the farm forestry plantations, whereas productivity has been estimated from each of them separately. 


\section{A.7 Energy Strategies for Rural India}

Source: ESMAP 2001. Energy Strategies for Rural India: Evidence from six states (draft). Joint UNDP/World Bank Energy Sector Management Assistance Programme (ESMAP), Mining and Telecommunication Department, The World Bank, 1818 H Street, NW Washington, DC 20433 USA. xvi + 89p.

The study was undertaken by the Operation Research Group, Vadodara, in 1996 at the request of the World Bank/ESMAP. The purpose of the study was to understand developmental changes in rural India in general and changes in rural energy in particular. The 132 sample villages covered in an earlier survey in 1983 were included in the present study to examine the changes taking place over the 13-year period.

\section{Sampling Design and Methodology for Consumption}

The six states were chosen to provide a wide range of climatic, topographical and socio-economic conditions. They consisted of Andhra Pradesh, Himachal Pradesh, Maharastra, Punjab, Rajasthan and West Bengal. In each state, districts were selected in such a way that they represent this diversity. The districts served as the first stage unit, villages the second stage and households the final stage unit. In all, 5048 households were selected from 180 villages distributed over 18 districts. In order to draw a random selection of households within selected villages, the team conducted a short census of all households present in the villages. The questionnaire approach was followed to collect the consumption data. However, actual measurement of dung cake and fuelwood was also done in about $25 \%$ of households to verify the answers.

\section{Energy Consumption}

The survey found that average per capita consumption of energy in the rural household sector was $324 \mathrm{k}$ oil equivalent. Traditional fuels constituted more than $90 \%$ of rural energy, fuelwood being the dominant one. The shares of fuelwood, crop residue and dung in total cooking fuel largely depended on their availability. The percentage of different types of energy used as per the study is shown in Table I A.11.

Table I A.11 Share of different types of energy in rural India in 1996

\begin{tabular}{lc}
\hline Fuel type & Percentage \\
\hline Fuelwood & 56 \\
Crop residue & 18 \\
Dung cake & 19 \\
Charcoal & 1 \\
LPG & 1 \\
Kerosene & 3 \\
Others & 2 \\
\hline
\end{tabular}

The study found a significant shift in energy use over the 13 years (1983-96) in villages that were revisited. In Andhra Pradesh, Punjab and West Bengal, the percentage of the households using fuelwood had declined. The switch appeared to be driven by local shortage, commercialisation of fuelwood, or greater availability of other fuels. The growth of commercial energy in the rural sector was, however, not very significant. Only in Himachal Pradesh was the use of LPG and electricity seen to be gaining popularity.

\section{Comments}

The study did not look into the sources and supply of fuelwood. 


\section{B. State Level Studies}

\section{B.1 Wood Balance Study of Andhra Pradesh}

Source: IWST 2001. Wood Balance Study of Andhra Pradesh (draft). Institute of Wood Sciences and Technology (ICFRE), Bangalore.

The study was conducted by the Institute of Wood Sciences and Technology (IWST), Bangalore, an institute of the Indian Council of Forest Research and Education (ICFRE), during the year 2000 and was sponsored by Andhra Pradesh Forest Department. The main objectives were to estimate the present and future consumption and possible sources of production of fuelwood, timber, pulpwood, poles and bamboo and to assess the impact of joint forest management in the promotion of alternative sources of energy and utilisation of energy-saving devices.

\section{Sampling Design and Methodology for Consumption}

The study used both primary and secondary data for estimating the consumption of wood in Andhra Pradesh. For collecting the primary data from rural areas, 5\% of the mandals (blocks)totalling 56 spread over all the 23 districts of the state-were selected. From each selected mandal $20 \%$ of the villages were randomly selected and from each selected village, three to five households belonging to each of the groups of large, small and marginal farmers, together with landless agricultural labourers and artisans, were selected. Similarly, samples of households from urban centres were also selected and the average figure of per unit consumption was estimated. The requirements of artisans and other establishments were also computed by drawing samples. A questionnaire approach was followed to collect the primary data.

\section{Energy Consumption}

The study estimated per capita consumption of fuelwood at $180 \mathrm{~kg}$ for rural areas and $33 \mathrm{~kg}$ for urban areas. In 1978/9, the National Council of Applied Economic Research (NCAER), New Delhi had estimated per capita consumption to be $179 \mathrm{~kg}$ for rural areas, and $115 \mathrm{~kg}$ by urbanites in Andhra Pradesh. Though the data from the present study is not comparable with NCAER data due to procedural differences, the change in the pattern of energy use by households in urban Andhra Pradesh in the last 21 years from $115 \mathrm{~kg}$ to $33 \mathrm{~kg}$ per capita fuelwood is quite revealing. This is mainly due to the substitution of commercial energy. This study has projected that in future, the use of fuelwood in the domestic sector may fall again at the rate of $1 \%$ in urban areas and $0.5 \%$ in rural areas. The contribution of fuelwood to meeting the fuel demand of rural areas was $90 \%$, and of urban areas it was $47 \%$. The total requirement for fuelwood estimated for the year 2000 in the household sector was 9.42 million $\mathrm{t}$, and in the non-domestic sector, 3.95 million $\mathrm{t}$.

\section{Supply and Sources of Fuelwood}

The major sources of supply of fuelwood were forests and the farm forestry sector covered under government-assisted planting. The total supply of fuelwood was estimated to be in the order of $208000 \mathrm{t}$. It should be noted here that the fuelwood supplies from farm forestry not included in the government-assisted planting programme but done by farmers themselves and from agroforestry have not been taken into account for want of data on areas under these. Fuelwood supplies from these areas, however, are quite substantial. Fuelwood markets were virtually nonexistent in areas close to the forests and the households generally extracted fuelwood from the forests at the cost of their labour. The low cost and unsustainable harvesting methods led to overexploitation and seriously affected the regeneration of the forests. 


\section{Comments}

The study has focused only on the wood consumption aspect, and other forms of commercial and non-commercial energy used in the household sector have not been taken into account. The overall fuel use scenario in the domestic sector is, therefore, hazy. In the absence of reliable data, fuelwood produced from agroforestry and farm forestry that is not covered by governmentassisted planting has not been taken into account in estimating the supply. In fact, these two sectors have been assumed to meet a large part of the fuelwood requirement of the state. 


\section{B.2 Gujarat Wood Balance Study 1984}

Source: Pinto, A.G., Khanna, P. and Pandey, C.N. (1985) Gujarat Wood Balance Study 1984 (unpublished). Forest Department, Gujarat State, Vadodara.

The study was carried out in 1984 by the Gujarat Forest Department to estimate the current consumption and supply of wood, mainly in the form of fuelwood, poles and timber, from difference sources and to make future projections in view of the large-scale ongoing afforestation activities since 1980 under the Community Forestry Project.

\section{Sampling Design and Methodology for Consumption}

For estimating the consumption of fuelwood in households, the state was firstly divided into rural and urban population centres.

In the rural sector, sample villages to be selected and surveyed were proportionately distributed in all the districts of the state according to their rural population. Each district was then divided into villages having forests and villages having no forests. It is pertinent to mention here that forests constitute about $10 \%$ of the geographic area of Gujarat. Over the entire state, 10 villages having forests and 66 villages having no forests were randomly selected. From each selected village, 20 households were surveyed which proportionately represented various economic classes. The consumption of fuelwood in each household was obtained by the investigators through a questionnaire. In limited cases, the investigators also physically verified the answers given by the head of the family.

In the urban sector, the population was stratified into urban centres with a population of more than 0.1 million (large) and less than 0.1 million (small). It was assumed that commercial fuels were more in vogue in bigger urban centres, influencing per capita consumption of noncommercial fuels. In all, 13 large and 13 small urban centres were randomly selected. 20 households were selected from each urban centre and surveyed in the same way as in the rural sector.

Consumption of fuelwood for the cremation of dead bodies was estimated using the average $(0.4 \mathrm{t})$ fuelwood required to cremate a body and the death rate of the relevant segment of the population.

For estimating the consumption of fuelwood in other places like hotels, hotels, restaurants and sweetmeat shops, separate surveys were conducted. Lists of these institutions were obtained from the census report. About $20 \%$ of hostels and $1 \%$ of other units were surveyed. A special survey was conducted to estimate the consumption of fuelwood in some specified industries such as bakeries, textile dyeing units, potteries, oil mills and brick kilns. About $10 \%$ to $20 \%$ of centres of each of the fuelwood-using units were surveyed.

\section{Energy Consumption}

Per capita consumption of fuelwood obtained in different situations has been given in Table I B.1. The per capita consumption of fuelwood in urban areas was $104 \mathrm{~kg}$.

Table I B.1 Per capita consumption of fuelwood in different types of area in Gujarat in 1984

Type of area

Urban centres with a population of more than 0.1 million

Urban centres with a population of less than 0.1 million

Rural areas having no forests

Rural areas having forests
Per capita fuelwood consumption in $\mathrm{kg}$ 
The study also estimated the consumption of other forms of energy in the household sector. The percentage contributions of various forms of fuels after converting them into the Coal Replacement Equivalent are given Table I B.2.

Table I B.2 Percentage contribution of various forms of fuel in the household sector

\begin{tabular}{lccccr}
\hline Fuel & $\begin{array}{c}\text { Rural area } \\
\text { having } \\
\text { no forests }\end{array}$ & $\begin{array}{c}\text { Rural area } \\
\text { having } \\
\text { forests }\end{array}$ & $\begin{array}{c}\text { Urban centres } \\
\text { with popn. of less } \\
\text { than 0.1 million }\end{array}$ & $\begin{array}{c}\text { Urban centres } \\
\text { with popn. of more } \\
\text { than 0.1 million }\end{array}$ & Total \\
\hline Fuelwood & 45.7 & 79.1 & 20.5 & 12.4 & 36.5 \\
Agriwaste & 23.4 & 6.1 & 4.6 & 2.6 & 14.2 \\
Dung cake & 16.6 & 6.9 & 4.0 & 3.7 & 10.7 \\
Charcoal & - & - & - & - & - \\
Coke & - & - & 19.3 & 17.5 & 7.4 \\
Kerosene & 12.3 & 7.0 & 23.7 & 22.7 & 16.2 \\
LPG & 0.6 & 0.9 & 27.0 & -70.7 & 14.1 \\
Biogas & 1.3 & - & 0.9 & & 0.8 \\
\hline
\end{tabular}

Use of non-commercial energy in the household sector in the state was about 61\%, more than half of which was fuelwood. In the rural areas, about $50 \%$ of the total energy in the household was from fuelwood and charcoal, whereas in urban areas it was about $16 \%$.

Consumption of fuelwood and charcoal for other purposes such as cremation of dead bodies, hostels, hotels, etc. was about $5 \%$ of the total consumption $(7.4$ million $\mathrm{t})$.

\section{Sources and Supply of Fuelwood}

The sources identified for the supply of fuelwood were forests, community forestry plantations, farm forestry plantations, trees on wastelands, agricultural land, etc., and imports.

The recorded harvesting of fuelwood from forests was taken as $150000 \mathrm{t}$, based on the average for 5 years. It was obtained from official documents of the forest department. The yield from farm forestry plantations was estimated to be $113000 \mathrm{t}$. On the farm forestry plantations, the number of surviving trees was first estimated, then the estimated fuelwood available per tree for different species was multiplied to get the total quantity. The imported fuelwood from official records was only $3741 \mathrm{t}$.

Fuelwood from trees growing outside forest areas (wastelands, agricultural land, etc.) was roughly estimated using a limited number of aerial photographs on 120 000/130 000 scales for the period 1978/76. The average number of trees counted from the photos came to 2.86 per ha. By excluding the forest and plantation areas and the area of Rann of Kachchh, which is devoid of any vegetation, the area of Gujarat state was multiplied by this average number. The total number of trees growing outside forests was estimated to be 45.5 million. The average harvesting age and volume per tree were assumed as 40 years and $2 \mathrm{~m}^{3}$, respectively. The total quantity of fuelwood from such trees was estimated at 1.7 million $t$. It was assumed that only $20 \%$ of the tree volume was timber and remaining $80 \%$ was fuelwood.

The estimated supply of fuelwood from known sources was thus 1.97 million $t$, as against the estimated consumption of 7.4 million $t$. 


\section{Comments}

The variability of the per capita consumption of fuelwood in rural areas both with and without forests and in urban areas with populations of more than and less than 0.1 million found by the study is quite revealing. On the supply side, the recorded production of fuelwood seems to be underestimated considering the extent of forest cover (1.3 million ha) obtained in the state. The number of trees growing outside forest areas has also been grossly underestimated. It is not possible to get a visual count of trees growing in isolation or in sporadic patterns on aerial photographs of 1:120 000 scale. A state with similar agro-ecological conditions has about 13 trees per ha (Pandey 2000). The assumption of the average rotation period of 40 years for trees outside forests is too great and does not conform to the common practice. Except for trees planted exclusively for timber production, most of the tree species in rural settings have short rotation, varying between 10 and 20 years. Besides trees, bushy vegetation of Prosopis spp. contributes a sizeable quantity of fuelwood for households, which has not been included in the source. 


\section{B. 3 Wood Balance Study of Haryana}

Source: NCAER 1988. Haryana Wood Balance Study. Sponsored by the Government of Haryana, Chandigarh (unpublished). National Council of Applied Economic Research (NCAER), New Delhi. $240 p$.

The study was conducted by the National Council of Applied Economic Research (NCAER), New Delhi, an autonomous body, at the request of the Government of Haryana in the reference year $1985 / 6$.

\section{Sampling Design and Methodology for Consumption}

A multistage stratified random sampling was designed to select the rural and urban households. In rural areas, the villages were first classified into two broad groups: (i) villages having forests and (b) villages having no forests. From the first group, 10 villages were selected with a probability proportional to population, and 90 villages were selected from the second group after classifying the villages further into six classes based on the extent of irrigated areas. The premise for classification of the second group was that variations in the use of fuelwood might be due to the availability of other non-commercial fuels. It should be noted that Haryana is rich in agriculture but deficient in forest resources, and forest cover is about $2 \%$ of its geographic area. All the households in the selected villages were listed and then classified into three income groups: high, medium and low, and two occupational groups: cultivators and others. A sample of 600 households was selected from the classified list of households in such a manner that each village and income group and occupation is properly represented.

In the urban household survey, all the towns of the state were classified into seven categories by population size and towns were then selected from each category in proportion to their numbers in the category. The National Sample Survey Organisation (NSSO) blocks formed the second stage unit of the sample and one to four blocks were randomly chosen from the towns, depending upon the population of the towns. The households in the selected blocks were classified into three income groups: high, medium and low, and in all, 400 sample households were drawn in proportion to population representing all the income groups.

The interviewers also collected fuelwood consumption data from other establishments, viz. restaurants, shops, business houses, hospitals, schools etc. separately, while conducting the survey in rural and urban areas. Brick kilns and other industries identified as potential users of fuelwood were randomly selected and consumption was estimated based on the questionnaire. Information on the use of wood for the cremation of dead bodies was collected from the village level officials of the 100 selected villages and from municipal officials in the case of urban centres.

\section{Energy Consumption}

The study estimated the total demand of fuelwood in $1985 / 6$ to be 1.36 million $t$ and consumption by the household sector was the greatest (87\%). The shares of other sectors were: restaurants $4.5 \%$, industries including brick kilns $5.5 \%$, road construction $1.2 \%$ and cremation of the dead 1.9\%. The contribution of fuelwood (solid and twigs) to overall fuel consumption in the household sector in Haryana State was only $25.3 \%$ of the total household energy. Of the fuelwood used, twigs accounted for $65 \%$. Free collection of fuelwood in rural areas was quite high (59\%), whereas in urban areas it was nominal (6\%). Fuelwood consumed in non-household sectors was entirely market-oriented. The percentage contributions of various forms of fuels in households (after converting them into the Coal Replacement Equivalent) are given in Table 1B.3. 
Table I B. 3 Percentage contribution of various forms of fuel in the household sector in Haryana

\begin{tabular}{lccr}
\hline Form of fuel & Rural areas & Urban areas & Total \\
\hline Fuelwood & & & \\
(i) Solid & 9.1 & 8.1 & 8.8 \\
(ii) Twigs & 21.1 & 5.2 & 16.5 \\
\hline Dung cake & 35.0 & 9.3 & 28.2 \\
Crop residue & 30.6 & 2.6 & 22.6 \\
Kerosene & 2.5 & 27.7 & 9.7 \\
LPG & 0.2 & 38.2 & 11.1 \\
Hard/soft coke, etc. & 0.7 & 8.9 & 3.0 \\
\hline Total & 100 & 100 & 100 \\
\hline
\end{tabular}

It can be seen that dung cake contributed most to household energy consumption in Haryana; this is mainly because this state had a high livestock population. In the rural household sector, over $95 \%$ of the total energy consumed was non-commercial, whereas in urban households, these fuels made up only $22 \%$.

\section{Sources and Supply of Fuelwood}

For estimating the supply of wood from government land, the records of the Haryana Forest Department were consulted. In the case of farm forestry and community lands, the number of seedlings planted in a year, the surviving plants estimated at the harvest age and harvesting age were used to estimate the output of plantations in terms of fuelwood and timber. The data on non-government land was collected during the household survey, field visits by the study team and from the records of the Forest Department. Estimates for supply were made based on empirical models or a set of equations. Only in the case of imports was actual data obtained from a sample of traders and octroi points (tax collection points on roads at the entry of cities/ towns) . No reliable estimate of the supply of brushwood from tree growth on farmland etc. could be obtained. The estimate pointed to farm forestry as the major supplier of wood $(0.905$ million $\mathrm{m}^{3}$ ). The estimated supply from the government forests and plantations was 0.48 million $\mathrm{m}^{3}$ and from community lands, 0.1 million $\mathrm{m}^{3}$. Of the total demand of 2.46 million $\mathrm{m}^{3}$ for wood (fuelwood and timber) in the state, the balance of 0.946 million $\mathrm{m}^{3}$ was assumed to be met by importing wood, mainly fuelwood from neighbouring states. 


\section{B.4 Wood Balance Study of Rural Himachal Pradesh}

Source: Singh, D.V. and Sikka, B.K. 1994. Forest Farming Conservation, Production and Consumption in Rural India, In Special Reference to Social Forestry. AERC, H.P. University, Shimla. Mittal Publications. xi+132p.

The study was undertaken by the Agro-Economic Research Centre, H.P. University, Shimla, at the initiative of the Department of Forest Farming and Conservation, Himachal Pradesh, and financed by USAID and IDA World Bank under the National Social Forestry Project. The fieldwork was completed between October 1989 and September 1990.

Himachal Pradesh is a hilly state. The climate in most parts is cold, and fuelwood is required not only for cooking but also for keeping dwellings warm. All the villages of the state were electrified at the time of study and electricity is widely used for lighting purposes. The average size of land holdings in the state is 1.3 ha and about $60 \%$ of the population has less than 1 ha in holdings.

The main objective of the study was to quantify the dependence of rural masses on forest resources, particularly for domestic purposes, over a year. This included estimation of the number and type of trees maintained on private farms and the production of fuelwood and timber from such sources, consumption of fuelwood, timber, fodder, etc. and their sources-privately-owned sources, common sources or forest resources owned by the government. The study also covered the socio-economic aspects of the rural masses.

\section{Sampling Design and Methodology for Consumption}

To cover seasonal variations, day-to-day information was gathered by trained persons who worked continuously for 12 months following the Cost Accounting Method. Keeping in view the heterogeneity of resources and climate, the entire state was first divided into four zones on the basis of tehsil (subdivision of a district) level information, and a three-stage stratified random sampling was followed. Tehsil was used as a first stage unit, a cluster of three villages as the second stage unit and households in the cluster as the third and final stage unit. The allocation of tehsils in each zone was in proportion to the quantum of parameters. In each selected tehsil, village clusters were selected with replacement and probability proportional to the quantum of parameters. For this, the nucleus village was first selected and a cluster was formed by adding two adjacent villages. Households were classified according to land holdings: 0-1, 1-2, 2-4 and above 4 ha, and an equal number of households were randomly selected from each class. In all, 14 households were selected from each village cluster and a total of 560 households from 40 sample village clusters. Field assistants were permanently posted in each village cluster to collect the data for 12 months.

\section{Energy Consumption}

Average per capita consumption of fuelwood was $523 \mathrm{~kg}$ annually. The consumption varied in different land holdings. Per capita consumption by the landless class was about $292 \mathrm{~kg}$ whereas farmers with large holdings (more than $4 \mathrm{ha}$ ) burnt about $569 \mathrm{~kg}$ of fuelwood per annum. Per capita consumption was also higher $(715 \mathrm{~kg})$ in Zone I where climatic conditions were severe and the electricity supply was relatively inadequate. The study found that out of the total energy consumed in a household, fuelwood alone accounted for $86.8 \%$ (all the energy items were converted to the coal replacement ratio for working out the percentage). The consumption of other forms of energy used in the rural sector is presented in Table I B.4. 
Table I B.4 Percentage contribution of various forms of fuel in rural Himachal Pradesh

\begin{tabular}{lc}
\hline Forms of energy & Percentage \\
\hline Fuelwood & 86.8 \\
Wood waste & 2.8 \\
Dung cake & 1.2 \\
Crop residue & 0.1 \\
Electricity & 4.6 \\
Kerosene & 4.5 \\
Charcoal & 0.1 \\
\hline Total & 100 \\
\hline
\end{tabular}

\section{Sources and Supply of Fuelwood}

The study estimated that, on average, 134 trees of different types were maintained by each household on farmland, or approximately 100 trees per ha, of which about $45 \%$ were for fodder and fruit and rest for fuelwood and timber. On the supply front, it has been found that the supply of fuelwood from forests was inversely related to the size of land holdings. The landless masses collected $74 \%$ of their fuelwood requirements from forests. The supply of fuelwood by source is given in Table I B.5.

Table I B. 5 Sources of fuelwood in percent received by farmers with different landholdings

\begin{tabular}{lccc}
\hline Source of fuelwood & $\begin{array}{c}\text { Small and marginal } \\
\text { farmers (0.01-2 ha) }\end{array}$ & $\begin{array}{c}\text { Medium farmers } \\
\text { (2 ha }-\mathbf{4} \text { ha })\end{array}$ & $\begin{array}{c}\text { Large farmers } \\
\text { (more than 4ha) }\end{array}$ \\
\hline Own source & 30 & 59 & 66 \\
Common land & 5 & 1 & 1 \\
Forests & 65 & 40 & 33 \\
\hline Total & 100 & 100 & 100 \\
\hline
\end{tabular}

The total population of small and marginal farmers was about $82 \%$. Thus the overall dependence on forests of the rural population for fuelwood was quite high. Of the total estimated fuelwood consumption by the rural sector in Himachal Pradesh ( 2.5 million $\mathrm{t}$ ), about $50 \%$ came from the forests.

\section{Comments}

By closely observing the consumption and supply of fuels in households continuously for 12 months, the study has covered seasonal variations and made a realistic estimate of the consumption and supply aspect of fuelwood for rural households. However, fuelwood consumption by establishments and for religious/social activities has not been reflected.

The data on fuelwood consumption in urban areas is missing, as the objective of the study was to quantify the dependence of rural people on forest resources. The study has also not considered the sustainability of different fuelwood sources (own/common land and forests) by studying the possible annual increment from them. 


\section{B.5 Wood Balance Study of Jammu and Kashmir}

Source: Anon. 1987. Wood Balance Study, Government of Jammu and Kashmir (unpublished). Directorate of Economics and Statistics, Planning and Development Department (Wood Balance Unit), Social Forestry Project, Srinagar, Jammu and Kashmir.

The study was taken up by the Directorate of Economics and Statistics in collaboration with Social Forestry Organisation of the state and completed in 1986. The study covered both the resource and consumption of fuelwood, timber and fodder to be used in the second phase of the Social Forestry Project. Both rural and urban sectors were covered.

\section{Sampling Design and Methodology for Consumption}

A two-stage stratified sampling was used, in which villages in the rural sector and National Sample Survey blocks in the urban sector formed the first stage unit. Households in each sector became the final stage unit. The state was firstly divided into three different agro-climatic zones and a sample of 494 villages/urban blocks were randomly selected from these zones. There were 386 villages and 108 urban blocks. Distance from forests was taken as one criterion when selecting villages. Of the total villages selected, $68 \%$ were in the concessional zones (0-3 $\mathrm{km}, 3-5 \mathrm{~km}$ and $5-8 \mathrm{~km}$ ) and the rest, beyond $8 \mathrm{~km}$. No further classification of urban centres on basis of population was done. In total, 4936 households were selected from the selected villages and urban centres. The data was collected through questionnaire.

\section{Energy Consumption}

The overall per capita consumption of fuelwood was $430 \mathrm{~kg}$ per annum. It was highest in Zone I $(788 \mathrm{~kg})$, which has largest share of forest resources, and also in the coldest districts of Zone II. The per capita consumption of fuelwood in Jammu and Kashmir State in 1985 in the rural and urban sector was $496 \mathrm{~kg}$ and $180 \mathrm{~kg}$ respectively. The percentage contributions of various forms of fuels after converting them into the Coal Replacement Equivalent are given Table I B.6.

Table I B.6 Percentage contribution of various forms of fuel in the household sector in Jammu and Kashmir

\begin{tabular}{lcc}
\hline Form of fuel & Rural areas & Urban areas \\
\hline Fuelwood & 85 & 62.7 \\
Dung cake & 11.7 & 3.3 \\
Kerosene & 3.0 & 26.7 \\
LPG & - & 4.7 \\
Hard/soft coke & 0.3 & 2.6 \\
\hline Total & 100 & 100 \\
\hline
\end{tabular}

It can be seen that the kerosene and LPG have compensated for the low consumption of fuelwood in urban areas. The use of these two energy sources was found to be fast gaining popularity and it was estimated that they would substitute fuelwood to a great extent in the near future.

The study also found changes in the consumption pattern of fuelwood in the rural sector depending on the distance from forests. The people living close to the forests consumed more fuelwood compared to those living farther away. Details are provided in Table I B.7. 
Table I B.7 Per capita consumption of fuelwood in the rural sector according to distance from forests

\begin{tabular}{lcccccr}
\hline Form of energy & $\begin{array}{c}\text { Within } \\
\text { forests }\end{array}$ & $\begin{array}{c}\text { Within } \\
\mathbf{0 - 3} \mathbf{~ k m}\end{array}$ & $\begin{array}{c}\text { Within } \\
\mathbf{3 - 5} \mathbf{~ k m}\end{array}$ & $\begin{array}{c}\text { Within } \\
\mathbf{5 - 8} \mathbf{~ k m}\end{array}$ & $\begin{array}{c}\text { Within } \\
\text { Above } \mathbf{8} \mathbf{~ k m}\end{array}$ & Total \\
\hline Fuelwood $(\mathrm{kg})$ & 743 & 721 & 543 & 393 & 277 & 496 \\
Dung cake $(\mathrm{kg})$ & 43 & 68 & 90 & 111 & 161 & 102 \\
Kerosene $(\mathrm{lt})$ & 1 & 1.8 & 3.6 & 6.9 & 11.5 & 5.8 \\
\hline
\end{tabular}

Further, a high degree of positive correlation (cor. coeff 0.91) was found between the forest area of the district and per capita consumption of fuelwood.

The consumption of fuelwood was found to be a function of landholding size. Marginal farmers with land holdings of up to 0.5 ha consumed $350 \mathrm{~kg}$ per capita, whereas those with holdings of 24 ha consumed $531 \mathrm{~kg}$.

The estimated amount of fuelwood consumed in the year 1985 was 2.85 million $t$ for domestic purposes and 0.1 million t by bakeries and other shops and for religious and social needs.

\section{Sources and Supply of Fuelwood}

The supply of the fuelwood was estimated from forests, private farms and institutional plantations. Firstly, the total growing stock of the forests was estimated by laying out sample plots. Based on field observation/measurements, a percentage of the growing stock was assumed to be the fuelwood in the forest. Further, to estimate the total number of trees on private farms, a sample of 498 villages was selected and the trees standing in 10 households of each selected village were recorded by different girth classes. The institutional plantations, which included roadsides, canal banks, panchayat plantations etc. were measured by laying out 300 sample plots of 100 metre-long strips and species and diameter class data was collected. The volumes of fuelwood and timber were estimated in the same way as the forest resources.

The estimates of standing volume of fuelwood and timber arrived at from the different sources are presented in Table I B.8.

Actual annual availability of fuelwood from these sources, however, has not been estimated but the figures in the table indicate that the major portion of fuelwood would be derived from the forests. Based on the field observation and free collection of fuelwood permitted by the forest department, a tentative estimate has been made about the sources of supply of fuelwood. It has been estimated that $65 \%$ of the fuelwood came from forests and rest from private sources.

Table I B. 8 Sources of the total stock of fuelwood and timber in Jammu and Kashmir

\begin{tabular}{lcr}
\hline Sources & $\begin{array}{c}\text { Total standing stock of } \\
\text { fuelwood in million } \mathrm{t} \\
\text { with \% of the total }\end{array}$ & $\begin{array}{c}\text { Total standing stock of timber in } \\
\text { million } \mathbf{m}^{3} \text { with \% of the total }\end{array}$ \\
\hline Forests & $153.26(93.7)$ & $131.42(91.4)$ \\
Private farms & $9.93(6.1)$ & $12.21(8.5)$ \\
Institutional plantations & $0.24(0.2)$ & $0.09(0.1)$ \\
\hline Total & $163.43(100)$ & $143.72(100)$ \\
\hline
\end{tabular}


74 - Devendra Pandey

\section{Comments}

The functional relationship of the consumption of fuelwood to the distance of the habitation centre/village from forests is most revealing in this study. The percentage of households covered in the study was quite large $(0.33 \%)$ compared to other wood consumption surveys. The per capita consumption estimated, therefore, appears quite reliable. The study is, however, weak on the sources of supply and their sustainability. 


\section{B.6 Demand and Supply of Fuelwood in Karnataka}

Source: Ranganathan, V., Subba Rao, S. and Prabhu, G.S. 1993. Demand and Supply of Fuelwood in Karnataka (unpublished). For the Forest Department, Government of Karnataka. Indian Institute of Management (IIM), Bangalore. 187p.

The Indian Institute of Management (IIM), Bangalore, undertook the study in 1986/7 at the request of Karnataka Forest Department, mainly to address the supply and demand balance of fuelwood in Karnataka State and also to examine the question of whether fuelwood demand can lead to deforestation. The study also made a demand forecast for future.

\section{Sampling Design and Methodology for Consumption}

For estimating the consumption, the study was divided into two components: the rural survey and the urban survey. For the rural survey, the state was first divided into two broad strata, the hills and the plains. Fifteen blocks from the hills and 27 blocks from the plains were chosen. Further stratification was done on the basis of forest area, rainfall and rural population. Of the chosen blocks, 300 villages were selected for the rural household survey, ensuring that all the characteristics are properly represented, and 3000 households from the selected villages. To arrive at a realistic estimate of per capita consumption, reported consumption by the respondents was crosschecked against reported procurements like how many head loads of fuelwood they gathered/brought in a month, etc. Actual weighing of headloads was also done in a few cases.

For urban survey, 750 households spread over 17 towns were selected. These towns were classified according to proximity to forests and population. In addition, industrial and commercial establishments consuming fuelwood and wood dealers were also surveyed in these towns.

\section{Energy Consumption}

The per capita consumption of fuelwood in the different types of area in the household sector is shown in Table I B.9.

Table I B. 9 Per capita consumption of fuelwood in different types of area in Karnataka during 1987

\begin{tabular}{lc}
\hline Type of area & Per capita FW consumption in kg \\
\hline Rural & 551 \\
Rural hills & 744 \\
Rural plains & 474 \\
Urban & 140 \\
State average & 430 \\
\hline
\end{tabular}

The study made a detailed investigation into the mode of procurement of the fuelwood and found that $83 \%$ of the households procured fuelwood only by gathering, $11 \%$ by gathering and buying and rest by buying only. The people gathered mainly twigs, lops and tops and small branches which could be carried as headloads. The study also quotes matching findings of another study done during 1976-78 in six villages of the Tumkur district of Karnataka State, by ASTRA (Center for Application of Science and Technology in Rural Areas) of the Indian Institute of Science, Bangalore. It was also found that per capita fuelwood consumption decreased with an increase of annual income of up to INR 20 000, and then increased again. The decrease was mainly due to the substitution of fuelwood by other fuels like kerosene, LPG etc. 
Table I B. 10 Percentage contribution of various forms of fuel in the household sector in Karnataka

\begin{tabular}{lccr}
\hline Form of fuel & Rural areas & Urban areas & Total \\
\hline Fuelwood & 80.2 & 49.0 & 70.3 \\
(i) logs & 5.2 & 42.0 & 16.5 \\
(ii) twigs, lops and tops & 75.0 & 7.0 & 53.9 \\
& & & \\
\hline Dung cake & 1.3 & 1.4 & 1.3 \\
Kerosene & 12.1 & 25 & 16.0 \\
LPG & 5.5 & 24 & 11.2 \\
Crop residue & 0.4 & - & 0.32 \\
Charcoal & 0.22 & 0.6 & 0.33 \\
\hline Total & 100 & 100 & 100 \\
\hline
\end{tabular}

The total fuelwood consumed in the form of logs in Karnataka was 3.99 million t, of which about $30 \%$ was for the cremation of dead bodies. Twigs, lops and tops constituted about 15.4 million $\mathrm{t}$, a major portion of which came by gathering only.

\section{Sources and Supply of Fuelwood}

To estimate the production/supply aspect of fuelwood, the study used available data from the forest department and also analysed the results of research studies on the productivity of forests. But due to the knowledge gap on the supply side, no firm conclusion has been drawn. The recorded production of fuelwood from government forests and private lands were obtained from forest divisions. Only 17 out of 34 forest divisions, accounting for $58 \%$ of the forest area of the state, responded. Production from government forests and private land plus import minus export was treated as supply. The percentage of forest area in a district or division was used to estimate the supply in other divisions/districts. The total supply of fuelwood estimated from recorded sources was 0.284 million $t$, of which 0.150 million $t$ was from the forest area. The recorded supply was, therefore, only $1.42 \%$ of the estimated consumption (19.4 million $t)$. Based on the research studies of net primary productivity (NPP) and mean annual increment (MAI), the study tentatively estimated 29 million and 14 million $t$ of annual production of wood from Karnataka's forests. The FSI (1995) has estimated the total growing stock of Karnataka forests to be 272.4 million $\mathrm{m}^{3}$, where volume has been measured down to $10 \mathrm{~cm}$ diameter of the stem. The annual availability of fuelwood will depend upon the rotation. For an average rotation of 50 years, the total wood annually produced will be $(272.4 / 50)=5.5$ million $\mathrm{m}^{3}$, about $50 \%$ of which could be fuelwood. The last theoretical exercise of the annual increment made by the study is based on the Working Plan data. Some assumptions were made as to how many trees would be harvested after a particular year, and then, using district forest cover data, the increment was estimated. The annual availability of fuelwood was estimated at 3.7 million $t$.

\section{Comments}

The per capita consumption of fuelwood at the state level estimated is too high compared to other states with similar climatic and socio-economic conditions and forest resources. The study does not give any reason for this variation. 
While discussing the sources of fuelwood, the study has not focused on the trees growing outside forests, which have great potential for meeting the major fuelwood needs of rural Karnataka. In a pilot survey conducted by the Forest Survey of India in 1994, the number of trees growing in rural Karnataka was 16 per ha. Though growing stock per unit area has not been assessed, the relationship between the number of trees and the growing stock of Haryana state can be extended to make a tentative estimate. In Haryana, 13 trees per ha constituted $2.44 \mathrm{~m}^{3}$ volume; 16 trees in Karnataka would comprise about $3 \mathrm{~m}^{3}$ volume. The standing volume of wood in the non-forest area of Karnataka, which is about 16 million ha, would be around 50 million $\mathrm{m}^{3}$. 


\section{B.7 Wood Balance Study of Kerala}

Source: Krishnakutty, C.N. 1990. Demand and Supply of Wood in Kerala and their Future Trend. KFRI Research Report 67, Kerala Forest Research Institute, Peechi, Kerala. 66p.

The study was carried out by the Kerala Forest Research Institute (KFRI), Peechi, at the request of the Kerala Forest Department, as part of the activities sponsored by the World Bank-aided Social Forestry Project. The study started in October 1987 and was completed in September 1989.

Besides the demand and supply study of wood in Kerala State, an assessment of the growing stock of trees on homesteads and their distribution into different species groups and diameter classes were the main objectives.

\section{Sampling Design and Methodology for Consumption}

Estimates of fuelwood consumption in households of the rural sector in the state were based on the per capita consumption estimated by the State Planning Board, which conducted a survey in 50 villages spread over in eight districts in 1986. To estimate the per capita consumption by urban households, a fresh survey was conducted by selecting 150 households from each of the four municipalities and a town. Based on the per capita consumption and estimated urban population in 1987/8, the fuelwood consumption in the urban areas was estimated. The data on fuelwood consumption by industries such as tile/brick making, tea processing, chemical industries, metal industries etc. was based on the Annual Survey of Industries done by the Department of Economics and Statistics. A limited survey was also done by KFRI to crosscheck the data. The total consumption of fuelwood and charcoal by teashops, restaurants and other institutions was estimated using the number of such units and the average quantity they consumed. For average consumption, a random sample of 62 establishments from rural areas and 56 from urban areas was selected and surveyed.

\section{Energy Consumption}

The per capita annual consumption of fuelwood by households in Kerala was $178 \mathrm{~kg}$ in rural and $151 \mathrm{~kg}$ in urban areas, which was low compared to consumption in other states. Fuelwood was supplemented by non-wood biomass, mainly coconut palm byproducts and crop residues, besides other commercial forms of energy. The total consumption of fuelwood in the household sector in Kerala was estimated at 4.94 million t, $84 \%$ of which was in rural areas and the balance in urban areas. In addition, fuelwood consumption by industries was about 1.3 million $t$, of which tile/ brick kilns accounted for over $61 \%$. The consumption of charcoal by these industries was estimated at 0.052 million $\mathrm{t}$. The consumption of fuelwood and charcoal by shops, restaurants etc. was estimated at 1.89 million $t$ and 0.69 million $t$ respectively.

For non-wood biomass energy, the major contribution was from coconut palm byproducts. A breakdown of the energy mix in the household sector in Kerala is provided in Table I B.11.

Table I B.11 Percentage contribution of various forms of energy in the household sector in Kerala in $1987 / 8$

\begin{tabular}{lcc}
\hline Form of fuel & Rural areas & Urban areas \\
Fuelwood & 35.3 & 28.5 \\
Residue of coconut palm/crop & 59.4 & 25.3 \\
Kerosene & 3.7 & 26.7 \\
LPG & 0.9 & 17.2 \\
Electricity & 0.7 & 2.3 \\
\hline Total & 100 & 100 \\
\hline
\end{tabular}




\section{Sources and Supply of Fuelwood}

To estimate the supply and sources, the focus was on forests, estates (plantations of rubber, cardamom, coffee, tea) and homesteads. The supply from forests was obtained from the official records of the department. An allowance of up to $20 \%$ was given for unrecorded production, especially for meeting the full requirement of populations living adjacent to the forests. Some assumptions were made about the production of wood from estates. In the case of rubber plantations, which cover 0.5 million ha, an annual yield of 9 to $17 \mathrm{~m}^{3}$ per ha was presumed, and from other estates, 2 to $4 \mathrm{~m}^{3}$.

To estimate the volume of the growing stock of trees on homesteads, a detailed survey was designed at the state level. Trees on homesteads included those standing in house compounds and farmlands. A stratified three-stage sampling was designed for the selection of final sampling units. The state was stratified on the basis of area under agricultural use and population density. Revenue villages in each stratum were treated as first stage units of sampling. In all, 30 villages were selected. Groups of households called 'desom' (hamlets) were taken as second stage units. From the selected desom, households were classified on the basis of dry land holdings and randomly selected as third-stage units. All trees on the selected homesteads were then measured. Growing stocks of wood in estates were estimated using collateral information. The estimated total number of trees growing on the homesteads was 442 million, giving an average number of 113 trees per ha. The total volume of growing stock was 104 million $\mathrm{m}^{3}$ which included bark and branchwood above $10 \mathrm{~cm}$ diameter. The main species contributing to the total volume of wood were coconut $(33 \%)$, jack $(15 \%)$, cashew $(12 \%)$ and mango $(11 \%)$. Fuel from coconut, including both wood and non-wood materials (pruned and fallen) constituted about $70 \%$ of the total fuelwood supply.

The direct assessment of wood production from homesteads did not work because people feared divulging information on the felling of trees. Wood production was, therefore, taken as the difference between consumption of wood and the sum of the wood production from forests, estates and imports. The supply of fuelwood in Kerala from different sources is summarised in Table I B.12.

Table I B.12 Sources of supply of fuelwood in Kerala

\begin{tabular}{lc}
\hline Source & Quantity in million $\mathrm{m}^{3}$ and percentage \\
\hline Homesteads & $10.42(85.8)$ \\
Estates & $0.68(5.6)$ \\
Forests & $0.89(7.3)$ \\
Imports & $0.16(1.3)$ \\
\hline Total & $12.15(100)$ \\
\hline
\end{tabular}

The supply of fuelwood from non-forest areas was over $90 \%$ of the total.

\section{Comments}

The assessment of the growing stock of the trees outside forests in a systematic way is a pioneer effort by this study. The estimation of annual production from such resources, however, needs to be examined in depth. If the distribution of the total growing stock (104 million $\mathrm{m}^{3}$ ) is assumed to be normal, an annual yield 10.4 million $\mathrm{m}^{3}$ is possible only when the average rotation of the tree species growing on the homesteads is about 10 years. In this case, the species (coconut, jack, cashew and mango) comprising major portions of the homesteads generally have a rotation age of more than 10 years. The estimated annual yield of fuelwood from homesteads is, therefore, on high side. Moreover, part of the wood produced (stem timber in higher girth classes) would have commercial use and therefore would not be used as fuelwood. The volume of such timber has been estimated to range between $10 \%$ and $12 \%$. 


\section{B. 8 Wood Balance Study of Orissa}

Source: ORG 1989. Wood balance in Orissa by 2000 (unpublished). Operations Research Group (ORG), Bhubaneshwar, sponsored by the Directorate of Social Forestry Projects, Orissa. 127p.

The study was conducted by the Operations Research Group, Bhubaneshwar, an autonomous body, under the sponsorship of the Directorate of Social Forestry Project, Orissa Forest Department, in 1989. The purpose of the study was to estimate the current consumption and availability of fuelwood and timber in different sectors of Orissa State and make projections for the year 2000, keeping in mind the consumption trend and the plantation, afforestation and regeneration programmes pursued in the state. The study was also part of the Swedish International Development Agency (SIDA)-funded phase II Social Forestry Project.

\section{Sampling Design and Methodology for Consumption}

Secondary data was used to draw up the sampling plan. Separate plans were drawn up for urban and rural areas.

For the rural survey, the state was divided into six zones based on agro-climatic, forest cover and demographic patterns, and one district was selected from each zone. All the blocks in the selected districts were first listed. On the basis of per capita forest, three broad categories were made and one block was selected from each category. Care was taken to ensure that at least half of the sampled blocks were covered by social forestry programmes. It should be noted that forest cover in Orissa is more than $30 \%$ of the geographic area. The villages of the sampled blocks were listed and divided into four groups based the extent of forest cover (high or low) and population density (high or low). One village was selected from each group, making four villages from each block or 12 villages from each district. The households in the selected villages were categorised according to land holdings and 15 households were selected from each village so that each land holding class (0-2 ha, 2-4 ha and above 4 ha) were proportionately represented. The number of final stage units in the survey was 1080 rural households out of about 4 million households in the rural areas of the state.

All the urban centres of the state were divided into three categories by population: 100000 and above, between 50000 and 100000 , and less than 50000 . One town each from the first two categories and two from the third category were selected. Urban blocks in the towns constituted by the National Sample Survey were used as a sample frame for the selection of households. The categorisation of households was on the basis of income (high, medium and low) and in all, 350 urban households were selected, ensuring proper representation of all income groups.

The survey was also conducted in the non-domestic sector, which included artisanal (blacksmiths, pottery, laundry), brick making, and community activities, cremation and other commercial establishments. Separate procedures were followed in each case to collect data on consumption.

\section{Energy Consumption}

The study estimated per capita consumption for different activities in the domestic sectorcooking, space heating, water heating, paddy boiling and cattle feed preparation. The average per capita consumption of fuelwood for all the activities was estimated to be $523 \mathrm{~kg}$ or $366 \mathrm{kgcr}$ for rural areas and $285 \mathrm{~kg}$ or $199 \mathrm{kgcr}$ for urban areas. The urbanites obviously met their balance requirements through commercial energy (coal, kerosene, LPG and electricity). In rural areas fuelwood consumption by landless people was about $25 \%$ less than that of large farmers. On the other hand, the low-income group in the urban sector used $50 \%$ more fuelwood than the middleincome group. The higher and middle-income groups had better accessibility to and affordability 
for commercial energy. Cooking alone accounted for three-fourths of the total fuelwood consumed in the domestic sector.

The annual consumption of fuelwood estimated in the domestic sector for 1989 was 15 million $\mathrm{t}$, about $40 \%$ of which comprised branches and twigs. Estimated consumption of fuelwood in the non-domestic sector was about 1.4 million $t$. The projected fuelwood requirement for the year 2000 was 20.7 million $t$, which was based on mainly the population growth of the state during this period.

\section{Sources and Supply of Fuelwood}

Sources of supply of fuelwood were largely based on assumptions and partly on secondary data, which included outturn of forest produce, forest area, area under plantations by different agencies, etc. Two approaches were taken to estimate the availability of fuelwood. In the first approach, the records of actual outturn of fuelwood available from the forest department from 1970 to 1990-about 0.6 million $t$ until 1984, then a sharp decline to 0.11 million t by 1990 -were projected. To this was added the estimated annual harvest of fuelwood from farmers' own land found during the survey $(0.46$ million $\mathrm{t}$ ) and from institutional plantations (about 0.5 million $\mathrm{t}$ ). The rest (the major portion-about 16 million $\mathrm{t}$ ) was treated as unrecorded collection from external sources. In the second approach, the actual outturn from the forest department was replaced by the potential increment from the existing area of natural forests and the rest of the estimates remained the same. The potential increment assumed was $0.25 \mathrm{~m}^{3}$ per ha per year. The natural forest area of the state being 4.3 million ha, the incremental outturn gave about 1.07 million $\mathrm{m}^{3}$, of which about $50 \%$ was fuelwood.

It was found that nearly $90 \%$ of rural households collect fuelwood to meet their domestic needs, mostly on head/shoulder loads. Large and medium farmers used bullock carts and animals. In the urban areas, about $54 \%$ of households purchased fuelwood from the market. It was also found that about $88 \%$ of households collected fuelwood from external sources-surrounding forests, plantations and village forests-and only a small portion from their own farmlands and homesteads.

\section{Comments}

Availability of forest resource is a major factor influencing the consumption of fuelwood in households. Though the survey considered this aspect while collecting data, a separate analysis for rich and poorly forested areas has not been made. The study has also not investigated the consumption of other forms of energy (crop residue, dung cake, kerosene, LPG etc.) in domestic and non-domestic sectors. On the sources and supply aspect, no elaboration has been made about the actual sources of the collected fuelwood and the potential availability. 


\section{B.9 Fuelwood in Rural Households of Tamilnadu}

Source: Anon. 1985. Household Fuelwood Consumption: A Study in Rural Tamilnadu (unpublished). Commissioner of Statistics, Department of Statistics, Madras. 44p.

The Department of Statistics, Tamilnadu, undertook the study at the request of the Social Forestry wing of the Tamilnadu Forest Department. It was done in the brief period of one month, October 1984. The limited objective of the study was to estimate total consumption as well as patterns by fuelwood type in the rural household sector of Tamilnadu through different sources, and to find if there was a scarcity of fuelwood in this sector.

\section{Sampling Design and Methodology for Consumption}

The methodology adopted by the National Sample Survey Organisation in the consumer expenditure survey was adopted to collect data on fuelwood consumption. The state was first divided into four agro-economic regions by grouping contiguous districts which were more or less similar with respect to population density and cropping pattern. Districts constituted the basic stratum and villages as first stage sampling units. The sample villages were selected with probability proportional to size with replacement. One hundred sample villages were selected for detailed survey. The households listed in a sample village were divided into three means of livelihood classes, viz. 'self-employed in non-agriculture', 'rural labour' and 'others'. The 'others' class was arranged into five broad classes according to land holdings. From this frame, a sample of 10 households was selected from each village. Thus 1000 households were selected for the final survey.

\section{Energy Consumption}

The per capita consumption of biofuel (non-commercial energy) estimated by the study varied from $148 \mathrm{~kg}$ to $422 \mathrm{~kg}$ between different districts with an average of $271 \mathrm{~kg}$. The highest per capita consumption was $422 \mathrm{~kg}$ and $416 \mathrm{~kg}$ in two tribal districts, North Arcot and South Arcot, respectively. In the average per capita consumption, fuelwood contributed $187 \mathrm{~kg}$. The total annual consumption of biofuel estimated for rural households was 9.25 million $t$, of which fuelwood, including horticultural residues, was 6.38 million t. The total consumption of kerosene was collected through records but consumption of electricity, charcoal, and gas was excluded from the study.

Table I B.13 Percentage contribution of various forms of biofuel in rural Tamilnadu

\begin{tabular}{lc}
\hline Type of biofuel & Percentage \\
\hline Agricultural residue & 20.2 \\
Fuelwood & 69.0 \\
$\quad$ Horticultural residue & 16.2 \\
Forest and other trees & 52.8 \\
Dung cake & 10.8 \\
\hline Total & 100.0 \\
\hline
\end{tabular}

Nearly $74 \%$ of the total consumption of biofuel was in the income group INR 100-500. The landless people of rural Tamilnadu mostly used forest trees for fuel. 


\section{Sources and Supply of Fuelwood}

The analysis of the questionnaire on sources of fuelwood revealed that the share of freely collected accounted for $53.5 \%$ of the total consumption of fuelwood ( 6.38 million $t)$. The contribution of fuelwood by source is presented in Table I B.14.

Table I B.14 Percent supply of fuelwood in from different sources

\begin{tabular}{lc}
\hline Source & Percentage \\
\hline Own land & 13.3 \\
Shops & 20.6 \\
Government forest & 4.7 \\
Free collection & 53.5 \\
Others & 7.9 \\
\hline Total & 100 \\
\hline
\end{tabular}

Of the total horticultural residues $(1.5$ million $\mathrm{t})$ consumed as fuelwood, about $36 \%$ came from palmyrah palm, $27 \%$ from coconut, $11 \%$ from tamarind and rest from mango and others. Besides being used by owners and sold in shops, a good percentage $(47 \%)$ of the horticultural residue was freely collected.

Of the fuelwood derived from forests and other trees (4.88 million $\mathrm{t})$, the largest proportion (1.8 million $\mathrm{t}$ ) came from Prosopis species, about $65 \%$ of which was freely collected, $19 \%$ was sold from shops and the rest was either used from privately-owned land or from other sources. Other important species contributing to fuelwood were Acacia species (1.366 million $\mathrm{t}$ ) and Casuarina (0.18 million $\mathrm{t})$.

\section{Comments}

The study, confined to the rural sector, does not present the complete picture of energy use. The consumption of fuelwood other than in the household sector, or commercial forms of energy (kerosene, coal, biogas, LPG etc.), was not investigated. The impact on fuelwood consumption of proximity to the forest resource was also not presented. The analysis of sources based on the questionnaire is quite revealing but it is not possible to comment on the sustainability of resources. Though a lot comes from trees outside forests (agricultural residue, privately-owned land, free collection), no reflection in the study is made regarding the incremental aspect of these resources. 


\section{B.10 Wood Balance Study of West Bengal}

Source: Anon. 1987b. Wood Balance Study, West Bengal (unpublished). Planning and Statistical Cell, Office of the Chief Conservator of Forests, West Bengal Forest Department, Calcutta. 90p+75p.

The study was carried out by the West Bengal Forest Department in 1984/5 to assess the present demand for wood, especially fuelwood, and to study the existing supply and sources. The study also made future projections. Besides fuelwood, consumption of other forms of energy in the household and institutional sectors was also studied through field sampling. The Social Forestry Project in West Bengal, which boosted tree plantations outside forest areas, was launched in 1981.

\section{Sampling Design and Methodology for Consumption}

For conducting the rural survey, the state was stratified into four homogeneous units on the basis of extent of forest resources and demographic characteristics, and $2 \%$ of the villages were randomly selected with a probability proportional to their size. All the households in the 758 selected villages were listed and classified into three categories depending upon quality of house (concrete house, semi-concrete or earthen house). About 10\% of households were selected according to proportional allocation from each category.

For the urban survey, towns in the state were classified into four groups according to population, and $5 \%$ of the towns were selected, each with a probability proportional to population. Subsequently, $5 \%$ of the urban blocks of these towns, as adopted by NSSO, were selected. For the selection of households from the selected 767 blocks, a classification similar to the rural survey was followed and $20 \%$ of households were selected from each urban block. In all, 6075 households in the rural sector and 12683 households in the urban sector were covered in the survey. Institutions like schools, hostels, panchayats, hospitals, religious centres, etc. in the villages and urban blocks were also surveyed to assess the consumption of wood and other forms of energy.

\section{Energy Consumption}

Per capita consumption of fuelwood in rural and urban sectors was $368 \mathrm{~kg}$ and $72 \mathrm{~kg}$ respectively. Per capita consumption in the state was $288 \mathrm{~kg}$ with the highest $(1305 \mathrm{~kg})$ in the rural areas of the Darjeeling hills and the lowest $(17 \mathrm{~kg})$ in Calcutta city. It was found that proximity to forest areas bears a positive correlation to the per capita fuelwood consumption pattern. Of the total fuelwood consumed, 93\% was in rural areas and the balance in urban areas. The lower consumption of fuelwood in urban areas was due to the preference for and better availability of alternate fuels like LPG and kerosene. The total fuelwood consumed in the state was 16.85 million $\mathrm{m}^{3}$ ( 11.38 million $\mathrm{t}$ ), of which $94 \%$ was in the household sector, $5.2 \%$ by institutions and $0.7 \%$ for the cremation of dead bodies.

Considering the consumption of other forms of energy, it was found that fuelwood dominated the rural sector, but soft coke and coal briquette dominated the urban areas. It should be noted that West Bengal is one of the major producers of coal in India and there are instances of unauthorised removal of coal from the coalmines of the adjoining coal-rich states (Bihar and Orissa). The consumption of non-commercial energy in the rural sector was over $70 \%$ but in the urban sector it was only about $12 \%$. The contribution of various forms of energy in households, including consumption in institutions and for the cremation of dead bodies, is shown Table I B.15. 
Table I B.15 Percentage contribution of various forms of energy in West Bengal in 1984/5

\begin{tabular}{lccc}
\hline Form of fuel & Rural areas & Urban areas & Total \\
\hline Fuelwood & 56.33 & 9.33 & 42 \\
Dung cake & 4.73 & 2.57 & 4 \\
Crop residue & 11.52 & 0.48 & 8 \\
Kerosene & 0.92 & 9.81 & 3.6 \\
LPG & - & 6.11 & 1.9 \\
Coal briquette/soft coke & 26.15 & 71.7 & 40.1 \\
\hline Total & 100 & 100 & 100 \\
\hline
\end{tabular}

\section{Sources and Supply of Fuelwood}

The sources identified for the supply of fuelwood were forests and trees growing in private ownership. The production figure for fuelwood and charcoal from forests, which was 0.52 million $\mathrm{t}$, was taken from the records of the Forest Department. Trees growing under private ownership were estimated. The number of trees estimated was 88.75 million, of which $60 \%$ were fuelwoodyielding trees, $20 \%$ fruit-bearing and the rest, timber and other miscellaneous species. It was estimated that trees on the private land would yield 2.24 million $\mathrm{m}^{3}$ of fuelwood annually. Wastewood from wood-based industries (sawmills etc.) was also considered as an auxiliary source of fuelwood and the estimated quantity was 0.20 million $\mathrm{m}^{3}$. The total annual supply of fuelwood estimated from these known sources was 2.96 million $\mathrm{m}^{3}$, compared with the estimated consumption of 16.8 million $\mathrm{m}^{3}$, thus showing a staggering deficit of 13.9 million $\mathrm{m}^{3}$. To meet the demand, the fuelwood was imported from the neighbouring states but a detailed estimate has not been made.

It was also revealed that $37 \%$ of the fuelwood was collected from non-forest areas, $11 \%$ from forests and $52 \%$ from traders. Fuelwood collected from forests also consisted of twigs and branches, which were collected by headload and sold in the market. The study has conjectured that to meet the heavy demand, illicit collection of fuelwood from forests and illegal selling in the market cannot be ruled out.

\section{Comments}

The methodology for estimating the total number of trees has not been mentioned in the report. It is not clear if all the trees of the 758 selected villages were counted and measured or only those standing in the selected households. It is also not clear as to what type of volume tables were used to estimate the growing stock of trees of the private lands-i.e., whether they indicated volume measured down to $10 \mathrm{~cm}$ diameter or below or above. The total number of trees estimated appears to be too low. In a pilot study done in West Bengal State to estimate the number and volume of trees growing in non-forest area in 1993/4, the Forest Survey of India found 196 million trees in the state, which is more than twice the number estimated by this study. The trees measured by the FSI were down to $5 \mathrm{~cm}$ diameter. 


\section{C. Local Level Studies}

\section{C.1 Production of Fuelwood in Villages-A Case Study of Two Villages of Haryana}

Source: Chaturvedi, A.N. 1990. Trees and Fuelwood from Non-forest Lands-A Methodology for Assessment. India, Regional Wood Energy Development Programme in Asia, FAO Regional Office, Bangkok.

The study was sponsored by the Regional Wood Energy Development Programme in Asia, FAO Regional Office, Bangkok, to develop a methodology for assessing wood resources in non-forest rural areas and availability of fuelwood from such resources on a sustained basis.

Two villages, namely Berka Alimuddin and Dhanawas, were selected in the Gurgaon district of Haryana State for the study. The number of households in Berka Alimuddin was 175, and in Dhanawas, 91, and they were mostly from the low-income group. Both villages had a dry type climate with average annual rainfall of $700 \mathrm{~mm}$, and were without any forest cover in the vicinity. The households, therefore, depended for fuelwood from trees on private lands. Dung cake and crop residue formed the main source of household energy. In Berka Alimuddin, the consumption of dung cake was $21 \%$, of crop residue $38 \%$ and the rest was fuelwood-21\% twigs and $19 \%$ logs. The consumption of kerosene was almost negligible. In Dhanawas, dung cake constituted $56 \%$, crop residue $28 \%$ and fuelwood $14 \%$ (12\% twigs and $2 \%$ logs).

\section{Sources and Supply of Fuelwood}

To estimate the wood resource, the area of the villages was divided into three strata: (i) homesteads (ii) commercial tree farms and (iii) trees on farmlands. In strata (i) and (ii) all trees in the villages were enumerated, whereas in stratum (iii) samples were drawn using land holding details from the Revenue Department. Measurement of the trees was down to a girth limit of $15 \mathrm{~cm}$. Trees of less than $15 \mathrm{~cm}$ girth were neither counted nor measured. Published volume equations (developed for traditional forest inventory) were used to estimate the volume of trees. Trees growing in the village environment are solitary, in groups of a few, single line etc. so the existing yield tables of pure and compact block plantations are not applicable. But in the absence of any other data, these tables were used as a guide and assumptions were made for estimating the annual yield for fuelwood depending upon the growth rate and coppicing behaviour of the species. For example, $15 \%$ of the growing stock of Eucalyptus hybrid was assumed safe to harvest annually for fuelwood. Similar assumptions for Prosopis juliflora and Acacia nilotica were $20 \%$ and $10 \%$ respectively. For most of the other species a $2 \%$ annual yield was assumed. The total growing stock in Berka Alimuddin village was $343 \mathrm{~m}^{3}$ or $0.7 \mathrm{~m}^{3}$ per ha, of which $53 \%$ was in farmers' fields, $23 \%$ on homesteads and the rest on commercial tree farms. In Dhanawas, the growing stock was $282 \mathrm{~m}^{3}$ or $1.2 \mathrm{~m}^{3}$ per ha, of which $68 \%$ was in farmers' fields and $32 \%$ on homesteads. The estimated annual yield of fuelwood from these two villages was $43 \mathrm{~m}^{3}$ per year or $0.05 \mathrm{~m}^{3 /}$ ha/year, which constituted about $7 \%$ of the total growing stock.

\section{Comments}

The study has used the volume equations of traditional forest inventories, which cannot be applied to trees growing in non-forest areas because of differences in intertree competition and sites. These differences affect the allometric relationship. Unfortunately, the development of volume equations as well as growth data for such trees has been very scanty. In the absence of growth data, the annual availability of fuelwood has been assumed. 


\section{C.2 Fuelwood in Urban Markets}

Source: Alam, Manzoor, Dunkerely,J.,Gopi, K.N., William Ramsay and Davis, E. 1985. Fuelwood in Urban Markets: A Case Study of Hyderabad. Concept Publishing Co. New Delhi.

The study was undertaken by the Osmania University with the financial support of the Rockefeller Foundation, and Resources for the Future, Inc. in 1981/2. The main objectives were to estimate the quantity of fuelwood and charcoal arriving in the city of Hyderabad and to analyse the trade as well as energy consumption patterns among households and commercial establishments.

\section{Sampling Design and Methodology for Consumption}

To estimate the consumption of fuel in households, the city was divided into four strata based on socio-economic variables (literacy, income, caste, and demographic features). In all, 1809 households, representing about $0.5 \%$ of the total, were randomly selected from these strata on a population-weighted basis and surveyed using a questionnaire. In a supplementary survey, 326 slum/squatter households were also included. Among the commercial establishments, which included restaurants, bakeries, sweetmeat shops etc, 299 were selected and surveyed, representing $18 \%$ of the total. A consumption estimate was also made for social and religious institutions. The consumption estimates were crosschecked against the quantity of fuelwood and charcoal received through different channels in the city by observing it for one year.

\section{Energy Consumption}

The average annual consumption of fuelwood was $420 \mathrm{~kg}$ per household or $67 \mathrm{~kg}$ per capita. In the case of slum households, the consumption was slightly higher, at $641 \mathrm{~kg}$ per households or $100 \mathrm{~kg}$ per capita. The total quantity of fuelwood consumed in household sector in the city was $154031 \mathrm{t}$, whereas commercial establishments consumed $13700 \mathrm{t}$ and religious institutions 10 $000 \mathrm{t}$. This gave a per capita consumption for the city of $88 \mathrm{~kg}$. Further, the total quantity of charcoal consumed in a year was $17730 \mathrm{t}$, of which about $60 \%$ was consumed by commercial establishments. The energy mix in the household and commercial sectors is presented in Table I C.1. The consumption of fuelwood per household decreased with increasing income and was substituted by LPG.

Table I C. 1 Energy mix in the household and establishment sectors in the city of Hyderabad in 1981

\begin{tabular}{lc}
\hline Energy form & Percentage contribution \\
\hline Fuelwood & 41 \\
Charcoal & 5 \\
Kerosene & 31 \\
LPG & 24 \\
\hline Total & 100 \\
\hline
\end{tabular}

\section{Sources and Supply of Fuelwood}

To estimate the quantity of fuelwood and charcoal brought in/traded in Hyderabad, four independent sources were tapped. Trucks and bullock carts entering the city by road were surveyed with a questionnaire at the entry points. A round-the-clock count survey was made on 21 selected days, spread over all seasons in the year. The quantity of fuelwood and charcoal transported by rail was obtained from the railway authorities. All the commission agents who 
help in auctioning the fuelwood/charcoal brought by truck and bullock cartloads were surveyed with the questionnaire to ascertain the quantum of such items. The third checking point was interviews of wholesale traders to find the quantity of fuelwood and charcoal, sources of supply and customers. The last checking point was a survey of all the retail traders of fuelwood and charcoal in the city.

The quantity of fuelwood and charcoal arrived at through these check points was used in weighing the consumption figures estimated by the survey.

Based on the questionnaire, the study found that the source of fuelwood was from areas relatively close to Hyderabad city compared to that of charcoal, which was transported from a longer distance. About $95 \%$ of fuelwood was transported by trucks and $5 \%$ by bullock carts, which had declined $20 \%$ from the early 1970 s. This suggested that the distance of fuelwood production centres (areas) gradually increased from the city and the bullock cart transport was no longer feasible. The use of bullock carts was also phased out gradually. The average distance of fuelwood transport ranged from below $50 \mathrm{~km}$ to $130 \mathrm{~km}$, with a weighted average of $88 \mathrm{~km}$. The fuelwood trade in Hyderabad was found to be based on market principles. Private farms appeared to supply the bulk of the fuelwood and charcoal. The supply from the government forests was tentatively estimated at about $6 \%$ of the total. The database on the supply of fuelwood from forest department was quite weak.

\section{Comments}

On fuelwood/charcoal consumption and marketing in urban areas, the study is quite comprehensive, as all possible measures have been taken to crosscheck the data. Therefore, the results of this study can be treated as highly reliable. On the sources and supply aspect, a detailed investigation into the origin has not been done. The contribution from the forests is based on the statistics of recorded production of fuelwood and charcoal of the forest department. Recorded production is often an underestimate because branches and twigs, which are collected free of cost, are not included. The conclusion on sources is therefore less reliable. 


\section{C. 3 Household Energy Strategy for Urban India}

Source: ESMAP. 1999. Household Energy Strategy for Urban India: The Case of Hyderabad. Joint UNDP/World Bank Energy Sector Management Assistance Programme (ESMAP), Mining and Telecommunication Department, The World Bank, 1818 H Street, NW Washington, DC 20433 USA.

The study was undertaken by the Institute of Energy and Environmental Studies in Hyderabad with the support of the World Bank from March through June 1994. The rationale for conducting the study was to evaluate the impact of energy sector policies in urban areas, particularly on interfuel substitution/energy transition and the consequent impact on deforestation rate.

\section{Sampling Design and Methodology for Consumption}

The fieldwork consisted of a survey of 2800 households in the city of Hyderabad, which were chosen by applying a two-stage stratified sampling procedure along the lines of the 1981 survey. Two thousand households were selected from the city area and 800 from the suburbs. In addition, 400 slum households were surveyed to identify key energy problems of the urban poor. The study also included a survey of fuelwood depots, and interviews of commercial establishment owners, kerosene and LPG distributors. Focus group interviews were conducted to provide greater depth of information on energy issues than could be gathered through formal survey alone. An assessment of the vegetation cover and biomass available around Hyderabad was also done using satellite data.

\section{Energy Consumption}

Interfuel substitution was found to take place very rapidly in urban Hyderabad as people switched from fuelwood to kerosene, from kerosene to LPG and from fuelwood to LPG during the period 1981-94. The substitution resulted in a decline in fuelwood demand in the household sector by $40 \%$, or in absolute terms, by $61000 \mathrm{t}$. On the other hand, demand in the commercial and religious/ social sectors showed a sharp three/fourfold increase. The total consumption of fuelwood in the city therefore declined by about $4 \%$, although the population of the city increased by $50 \%$ during 1981-1994. The consumption of charcoal, sawdust and other biofuels was in total about $1 \%$. One of the main reasons for the reduction in the use of coal by the commercial sector was the decline in the quality of coal.

Table I C. 2 Energy mix in the household and establishment sectors in the city of Hyderabad in 1994

\begin{tabular}{lc}
\hline Energy form & Percentage contribution \\
\hline Fuelwood & 11 \\
Charcoal & 1 \\
Electricity & 26 \\
Kerosene & 34 \\
LPG & 28 \\
\hline Total & 100 \\
\hline
\end{tabular}

Though the energy mix scenario of 1994 was not exactly comparable with that of 1981 because electricity was not included in 1981 survey, the changes were still very significant. Almost all households were electrified in 1994, whereas in the 1981 survey only about $50 \%$ of houses were officially listed as electrified. 


\section{Energy Transition}

The factors that influenced the transition from fuelwood were the greater availability of kerosene and LPG and the relative price of those fuels vis-à-vis fuelwood. Since the government controlled the prices of kerosene and LPG, their prices did not increase so much due to subsidy, but in the case of fuelwood, market forces determined the cost, especially in urban areas. During this period the price of fuelwood increased threefold whereas prices of kerosene and LPG just doubled. The policy of economic liberalisation in India since the 1990s opened up the LPG market to private retailers and has helped improve the supply of imported LPG and thus the availability, especially to middle and high-income consumers.

\section{Sources and Supply of Fuelwood}

To study the change due to fuelwood collection in the forest resource in the areas adjoining Hyderabad within a radius of $100 \mathrm{~km}$, a separate study was simultaneously undertaken by Indian Resource and Management Technology Ltd., Hyderabad. Landsat imageries of two periods, January to December 1986 and May 1993 to May 1994, were compared (Unni 1995). The wooded areas were divided into dense and open forests and scrub. Ground measurements were taken to estimate the biomass in the broad categories of wooded areas and agricultural lands by laying out sample plots. It was found that in the 8-year period, the area of wooded land declined by $4 \%$ and was transformed to agricultural land. The net loss of woody biomass was about 0.4 million $t$ or an average of $50000 \mathrm{t}$ per year. This showed that the woody resources around Hyderabad were under stress.

\section{Comments}

Classification of forests and wooded areas using satellite data has its own limitations. The variability of biomass content within intradensity classes of forests could be quite high. For example, the range of crown density for the dense forest being wide ( $40 \%$ to $100 \%$ ), the biomass content at the highest end may be more than twice that of the lowest end. Biomass content based on classification of satellite data is likely to be either underestimated or overestimated. Further, it is not possible to discern tree cover in non-forest areas through satellite data if the trees are scattered or in groves with a small area due to limitations of resolution and interpretation. It is possible that a sizeable volume of growing stock standing in such trees would have been missed. 
ISBN 979-8764-92-7

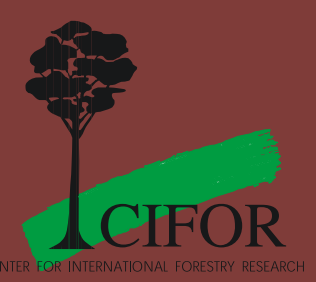

" Sida 


\section{C.4 Fuelwood Collection and Trade in Northwest Bengal}

Source: Bhattacharya, P. and Joshi, B. 2000. (draft) A case Study on Forest and Displaced People: Fuelwood Collection and Trade as a First Step Survival Strategy. Indian Institute of Forest Management, Bhopal and RWEDP, FAO Regional Office for Asia and the Pacific Bangkok.

The study was undertaken as a research project sponsored by the Regional Wood Energy Development Project (RWEDP)/FAO, Regional Office Bangkok, to understand the peculiarities of woodfuel flow in three selected districts of northwest Bengal, India. These districts (Cooch Bihar, Darjeeling and Jalpauguri) are prone to the influx of people who migrate from adjoining states of India and neighbouring countries (Bangladesh and Nepal) due to economic distress. Employment opportunities are limited due to the absence of any major industries in the region. Fuelwood collection and trade acts as a first step survival strategy. The study was conducted in $1998 / 9$.

\section{Sampling Design and Methodology for Consumption}

A combination of methods was adopted for data gathering, which included a questionnaire survey, interviews with key informants and participatory rural appraisal. A purposive sampling approach was followed. Firstly, 18 Forest Ranges were selected based on secondary information. These ranges had a regular influx of migrant population, fuelwood collection and trade and the presence of government beneficiary programmes. A similar approach was followed to select 55 villages from these ranges and 218 households as the final stage unit. In addition, a survey in 15 rural and six urban markets was carried out to understand the composition of buyers (households and institutions). In limited cases, physical measurements were taken to quantify the fuelwood collected, sold and consumed. Members of the villages' forest protection committees, officials of the forest department, and officials of villages, blocks, and districts, fuelwood collectors, sellers and consumers formed the key informants. Focus group discussions were used as the most effective participatory rural appraisal tool to understand the fuelwood dynamics in the area.

\section{Energy Consumption}

Based on the field observation, it was assumed that all the fuelwood used by households in rural areas was collected free of cost (non-monetised) from forests or elsewhere, whereas by those living in urban areas, including institutions and establishments, it was purchased (monetised) from fuelwood collectors/traders. The average per capita consumption of fuelwood in the rural areas of the three districts was estimated at $796 \mathrm{~kg}$. In urban areas, it was almost half the rural per capita figure due to substitution of other sources of fuel. The total consumption of monetised fuelwood was estimated at 3.26 million $t$, and of non-monetised fuelwood, 3.23 million $t$ by multiplying by the existing population.

\section{Fuelwood Trade}

The study estimated that about $10 \%$ of the total rural population $(0.73$ million) was engaged in fuelwood trade, $36 \%$ of which were migrants. More than $50 \%$ of fuelwood collecting/trading migrants were from Bangladesh. These were mostly landless and marginal farmers who took up the fuelwood trade as an income-generating activity. Using the average quantity of fuelwood collected by male and female headloads per week and, multiplying by their numbers, the total fuelwood collected and traded annually was estimated to be 3.7 million $t$. The fuelwood was traded in primary (small local) markets, which were held weekly. Most of the sellers in these markets were women, from whom middlemen made bulk purchases to be taken to the secondary 
markets. The secondary markets, which were larger in size and permanent, were held daily. These markets mostly catered for the fuelwood needs of urban households and institutions.

\section{Sources and Supply of Fuelwood}

Of the three districts, Darjeeling and Jalpaiguri had forest cover of $45 \%$ and $25 \%$ respectively, whereas Cooch Bihar was poor in forest resources with 1\% forest cover. The study found that $69 \%$ of the total respondents collected fuelwood from forests, $10 \%$ from homegardens and $11 \%$ from mixed sources. Ten percent of the respondents did not collect fuelwood at all. In terms of quantity, $80 \%$ of the total fuelwood collected by the rural folk for self-use and trading was from forests, $11 \%$ from homegardens and farmlands and $9 \%$ from villages, commons, etc. Thus the estimated annual removal of 5.5 million t of fuelwood was from about 280000 ha of accessible forests of these districts, which means removal of $20 \mathrm{t}$ per ha per year.

Nearly half of the collectors collected fuelwood 2-3 times per week. Fuelwood collection was unorganised and unregulated, leading to degradation of all the accessible forests.

\section{Comments}

The study focused on fuelwood collection and trade by the migrant population. Alternative sources of traditional and commercial energy used in the households have been given only passing reference. The total supply has been estimated, using partly demand and partly removal from the forests, which is not appropriate. The estimate of per capita fuelwood consumption $(783 \mathrm{~kg})$ is very much on the high side-as is the annual removal of fuelwood estimated from the forest areas-and compares with the cold/hilly regions of the country. Annual removal of $20 \mathrm{t}$ per ha would lead to the disappearance of the forest resource from these districts very rapidly. 


\section{C.5 Energy Consumption in Rural Households of Two Districts of Orissa}

Source: Mahapatra, A.K. and Michell, C.P. 1999. Biofuel consumption, deforestation, and farm level tree growing in rural India. Biomass and Bioenergy 17: 291-303.

The study was conducted as a part of research work in two districts of Orissa to identify the use of a range of biomass fuels by villagers in forested and non-forested areas of the state, and the relation between the socio-economic status of rural households and biofuel consumption. The fieldwork was accomplished between October 1994 and April 1995.

\section{Sampling Design and Methodology for Consumption}

The selected districts were Cuttack and Sambalpur, which had forest cover of about $14 \%$ and $47 \%$ respectively. Twelve villages were randomly selected from each district. The land holdings of the households of the selected villages were classified into marginal (0.2-1.0 ha); small (1-2 ha); medium (2-4 ha) and large ( $>4 \mathrm{ha}$ ) size farmers, and $20 \%$ of the households were selected from each category, making it 428 households in all. The questionnaire-based survey was supplemented by discussion with farmer groups and key informants. The weight of the fuelwood, crop residue, dung cake and leaf litter was estimated to ascertain the exact weight.

\section{Energy Consumption}

The average per capita consumption of fuelwood in the study area was found to be $460 \mathrm{~kg}$. Per capita consumption increased with the increase of landholding size. Farmers with marginal land consumed $2.62 \mathrm{t}$ of fuelwood whereas the consumption of large farmers was $4.1 \mathrm{t}$ per household. The per capita fuelwood consumption in Cuttack was slightly higher than in Sambalpur, because the greater proportion of tribals in Sambalpur cooked fewer meals a day than non-tribal farmers. The quality of fuelwood used by the villagers of Sambalpur was also better than that used in Cuttack, thus a smaller quantity was required for cooking the food. In Cuttack, other farms of biofuel (dung cake, leaf fuel and crop residue) constituted quite a significant (42\%) portion of the total household energy, whereas in Sambalpur it was only about $28 \%$.

\section{Sources and Supply of Fuelwood}

The study found that forests were the major source of fuelwood for rural households. In the forest-rich district of Sambalpur, more villagers (57\%) collected fuelwood from forests than in Cuttack (44\%). The supply of fuelwood from village wood lots was $14 \%$ in Cuttack and only $5 \%$ in Sambalpur. About $14 \%$ of households met most of their fuelwood demand by purchasing it from the government depot or from headloaders. In Sambalpur, a higher proportion of respondents travelled longer distances (5-8 km and more) to collect fuelwood for self-use and selling in the market. 


\section{Appendix II. Coal Replacement Ratios}

\begin{tabular}{lcc}
\hline Item & Unit & Coal Replacement per unit \\
\hline Coal & $\mathrm{kg}$ & 1.00 \\
Soft coke & $\mathrm{kg}$ & 1.50 \\
Kerosene (pressure stove) & litre & 6.98 \\
Kerosene (wicked stove) & litre & 5.20 \\
Kerosene (lamp) & litre & 2.10 \\
Electricity & $\mathrm{kWh}$ & 0.70 \\
Charcoal & $\mathrm{kg}$ & 1.81 \\
Fuelwood (closed stove) & $\mathrm{kg}$ & 0.95 \\
Fuelwood (open stove) & $\mathrm{kg}$ & 0.70 \\
Crop residue (closed stove) & $\mathrm{kg}$ & 0.61 \\
Crop residue (open stove) & $\mathrm{kg}$ & 0.45 \\
Dung cake (closed stove) & $\mathrm{kg}$ & 0.40 \\
Dung cake ( open stove) & $\mathrm{kg}$ & 0.30 \\
Liquefied Petroleum Gas (LPG) & $\mathrm{kg}$ & 10.25 \\
Biogas & cubic metre & 3.50 \\
\hline
\end{tabular}


ISBN 979-8764-92-7
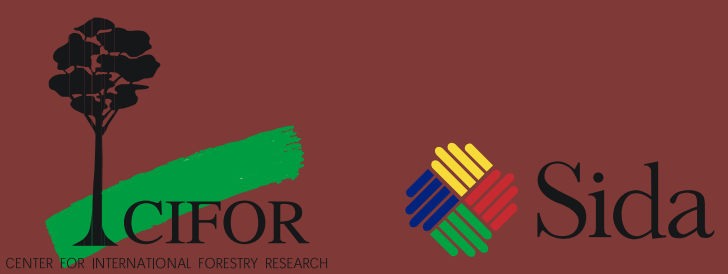